\title{
La situación de
}

las Personas

Mayores en la isla

\section{de Tenerife}

Análisis de fuentes secundarias y estudio de recursos sociales 
Fecha de ejecución

Octubre - diciembre 2020

\section{Equipo que elabora el proyecto}

Centro de Estudios de Desigualdad y Gobernanza

Universidad de La Laguna

Asociación de Investigación Acción Social Siendo

Este informe ha sido elaborado en el marco del encargo realizado por el Cabildo Insular de Tenerife para la realización de la fase 1 del Diagnóstico sobre las personas mayores de la isla de Tenerife.

DOI: https://doi.org/10.25145/r.MayoresTenerife.2021 
Coordinación del proyecto

Guacimara Rodríguez Suárez

\author{
Grupo de trabajo \\ Miriam Álvarez Lorenzo \\ Leopoldo Cabrera Rodríguez \\ Celsa Cáceres Rodríguez \\ Marta García Ruiz \\ Dácil Yurena González González \\ María Candelaria Luque Linares \\ Gustavo Marrero Díaz \\ Javier Mendoza Jiménez \\ Estrella Monterrey Viña \\ Rosa Elena Rapp Luz \\ Benjamín Vega Peñate
}

Colaboradoras (Asociación de Investigación Acción Social Siendo) María Noemí López Pérez Rosa Elvira Pereyra Acosta 
El equipo de trabajo muestra un sincero agradecimiento a las/os representantes de los Servicios Sociales Municipales y de las Residencias de Mayores por su participación desinteresada en este estudio, especialmente en unos meses tan difíciles debido a la pandemia de COVID-19.

Nuestro reconocimiento a las personas que, desde la atención social y sanitaria formal e informal, han trabajado en la protección, cuidado y bienestar de las personas mayores durante este año 2020. 



\section{ÍNDICE}

1. Justificación 9

2. Organización del documento 13

3. Un perfil de las Personas Mayores de la Isla de Tenerife 17

3.1. Características socio-demográficas de la población mayor $\quad 19$

3.1.1. La población de Tenerife 19

3.1.2. Evolución de la población mayor durante este siglo 19

3.1.3. Evolución de la población mayor en función del sexo 21

3.1.4. Proporción de personas de 65 y más años en las Islas Canarias 23

3.1.5. Tasas de vejez en los municipios de la isla de Tenerife 24

3.1.6. El sobre-envejecimiento en las Islas Canarias 26

3.1.7. El sobre-envejecimiento en los municipios de la isla de Tenerife 27

3.1.8. La población mayor extranjera residente en Tenerife 29

3.2. Tipología de hogares $\quad 31$

3.3. El nivel de estudios de la población mayor 33

3.4. Características económicas de la población mayor 35

3.4.1. Renta media por persona 35

3.4.2. Los ingresos por unidad de consumo de los mayores en Tenerife 36

3.4.3. Importe de las pensiones y evolución 41

4. Recursos sociales municipales dirigidos a las Personas Mayores 43

4.1. Introducción $\quad 45$

4.2. Metodología 46

4.3. Servicios Sociales municipales dirigidos a Personas Mayores $\quad 47$

4.3.1. Organización municipal $\quad 47$

4.3.2. El Servicio de Teleasistencia 49

4.3.3. El servicio de ayuda a domicilio 52

4.3.4. Centros de día/estancia diurna 56

4.3.5. Viviendas para mayores $\quad 57$

4.4. Asociacionismo $\quad 58$

4.5. Proyectos Socio Educativos para Personas Mayores 60

5. Centros residenciales para Personas Mayores 65 
5.1. Metodología

5.2. Datos obtenidos a partir de los directorios publicados

5.3. Datos proporcionados por las residencias de personas mayores 69

6. Conclusiones y orientaciones para el desarrollo de políticas públicas

Anexo 1. Programas, proyectos o actividades socioeducativas dirigidas a Personas Mayores en los ayuntamientos de la isla de Tenerife

Anexo 2. Ficha sobre Servicios Sociales y Proyectos socioeducativos en los municipios de Tenerife 113 


\section{RELACIÓN DE FIGURAS Y TABLAS}

Figura 3.1. Evolución de la población tinerfeña de 65 y más años entre 2000 y 2019

Figura 3.2. Evolución de la población tinerfeña de 65 y más años en función del sexo entre 2000 y 2019

Figura 3.3. Porcentaje de mujeres y varones de 65 y más años en Tenerife en 2019

Figura 3.4. Porcentaje de mujeres y varones de 85 y más años en Tenerife en 2019

Figura 3.5. Personas que viven solas según sexo y edad. Año 2019. Porcentaje33 Figura 3.6. Distribución de la renta (€) por persona en la isla de Tenerife en 2017

Figura 3.7. Distribución municipal de la población (\%) con ingresos por unidad de consumo por debajo del $40 \%$ de la mediana donde la persona principal tiene 65 o más años

Figura 4.1. Porcentaje de municipios que cuentan con Consejo de Mayores 60

Figura 5.1. Comarcas en las que se divide la isla de Tenerife

Tabla 3.1. Tasas de vejez, población de 65 y más años y población total, por sexos, por islas y en Canarias en 2019

Tabla 3.2. Tasas de vejez, población 65 años y más y población total, por sexos y por municipios de Tenerife en 2019

Tabla 3.3. Tasas de sobre-envejecimiento, población de 65 años y más y población total, por sexos, por islas y en Canarias en 2019

Tabla 3.4. Tasas de sobre-envejecimiento, población de 85 años y más y población de 65 años y más, por sexos y por municipios de Tenerife en 201928 Tabla 3.5. Número y porcentaje de población mayor extranjera en Tenerife por municipios en 2019

Tabla 3.6. Total de hogares, hogares unipersonales y hogares unipersonales de personas mayores de 65 años, en España y Canarias, desagregado por sexo, en 2019 y 2015

Tabla 3.7. Niveles de estudios de la población mayor de 65 años en España, por Comunidades Autónomas y para la provincia de Santa Cruz de Tenerife en 2019

Tabla 3.8. Niveles de estudios de la población (n y \%) mayor de 65 años en Canarias y Tenerife en 2011 
Tabla 3.9. Porcentaje de personas de 64 años y más, por sexo, con ingresos menores de $10.000 €$ por unidad de consumo

Tabla 3.10. Distribución municipal de la población con ingresos por unidad de consumo por debajo del $40 \%$ de la mediana donde la persona principal tiene 65 o más años

Tabla 3.11. Distribución municipal de la población con ingresos por unidad de consumo por encima del $200 \%$ de la mediana donde la persona principal tiene 65 o más años

Tabla 3.12. Evolución de la pensión media 2005 - 2019

Tabla 4.1. Servicio de teleasistencia en los municipios de Tenerife

Tabla 4.2. Servicio de ayuda a domicilio en los municipios de Tenerife

Tabla 4.3. Profesionales adscritos al SAD en los municipios de Tenerife

Tabla 4.4. Centros de día / estancia diurna en los municipios de Tenerife

Tabla 4.5. Asociaciones y Hogares / Clubs de mayores en los municipios de Tenerife

Tabla 5.1. Número de residencias de mayores y plazas, distribuidas en las comarcas de Tenerife, según la información publicada en los directorios web69 Tabla 5.2. Plazas totales y ocupadas por hombres y mujeres de las residencias de mayores participantes en este estudio distribuidas en las comarcas de Tenerife

Tabla 5.3. Plazas totales y ocupadas por hombres y mujeres de las residencias de mayores participantes en este estudio correspondientes a la Comarca de Acentejo

Tabla 5.4. Plazas totales y ocupadas por hombres y mujeres de las residencias de mayores participantes en este estudio correspondientes a la Comarca de La Orotava

Tabla 5.5. Plazas totales y ocupadas por hombres y mujeres de las residencias de mayores participantes en este estudio correspondientes a la Comarca lcodDaute

Tabla 5.6. Plazas totales y ocupadas por hombres y mujeres de las residencias de mayores participantes en este estudio correspondientes a la Comarca Metropolitana

Tabla 5.7. Plazas totales y ocupadas por hombres y mujeres de las residencias de mayores participantes en este estudio correspondientes a la Comarca Valle de Güímar 
1.Justificación 
La proporción de personas mayores está aumentando en la mayoría de las regiones de nuestro planeta, particularmente en los países europeos y de forma muy notoria en España, país con una esperanza de vida de las más altas del mundo. Tal y como señala la Organización Mundial de la Salud, el envejecimiento de la población -fundamentando en el aumento de la esperanza de vida y la disminución de la tasa de fecundidad- debe entenderse como un logro derivado de los avances sanitarios y políticas de salud pública, así como del desarrollo socioeconómico. Sin embargo, trae consigo una serie de retos para la sociedad, ya que debemos adaptarnos para proporcionar a las personas mayores las mejores condiciones sociosanitarias, de participación social y de seguridad.

Tenerife no es ajena a este envejecimiento global de la población. Si bien Canarias es una de las Comunidades Autónomas menos envejecidas del territorio español, la población mayor ha aumentado de manera acusada en las últimas décadas y se espera que continúe haciéndolo en los próximos años. Esta transformación poblacional sin precedentes supone un gran reto a afrontar a través, entre otros, de una cuidada planificación de las políticas sociales y de la política social gerontológica en particular. Así, los servicios sociosanitarios, la organización de los entornos urbanos, la participación social y cultural, las relaciones intergeneracionales o el uso del tiempo libre, entre otros aspectos, deben adecuarse a una población que, cada vez en mayor medida, será más longeva.

Esta respuesta a la transformación demográfica debe tener en consideración que la población mayor no es de ningún modo un grupo homogéneo. Por el contrario, se compone de personas cuyas edades abarcan tres o más décadas de la vida, con condiciones de salud, socioeconómicas, de autonomía e independencia distantes; así como también con intereses y problemas de diferente índole. De hecho, en contra del estereotipo comúnmente establecido, la mayoría de las personas mayores son independientes y autónomas, aunque los problemas de salud y las situaciones de dependencia aumentan a medida que se avanza en las edades que conforman esta última etapa de la vida. Por tanto, los planes de acción dirigidos a las personas mayores, así como los recursos sociosanitarios, deben ajustarse a esta 
realidad heterogénea y además cambiante, ya que con el transcurso de los años se incorporan a esta etapa de la vida cohortes generacionales cuya trayectoria vital tiene características diferenciales ${ }^{1}$ a las anteriores.

Todo ello nos lleva a considerar la relevancia de realizar un análisis sobre las características de las personas mayores que residen en nuestro territorio, así como de los recursos sociosanitarios y socioeducativos que conforman la atención que se les presta. Este acercamiento a las características de la población y a la situación de los recursos existentes en la actualidad, podrá facilitar la articulación de planes de acción ajustados, en la medida de lo posible, a la realidad social, asumiendo que es dinámica y cambiante.

Sumado a ello, será necesario atender en una siguiente etapa el principio de participación social en la elaboración de toda actuación dirigida a las personas mayores. Esto es, escuchar a grupos que representan el complejo y heterogéneo entramado que conforman las personas que transitan en esta etapa de la vida, así como a las personas que trabajan (de manera formal e informal) en la atención a los adultos mayores. Solo así podrán diseñarse acciones que acojan las demandas establecidas por la propia población a la que van dirigidas.

El presente informe trata de dar respuesta al encargo realizado por el Cabildo Insular de Tenerife respecto a la realización de un estudio sobre la situación de las personas mayores. Este trabajo está basado, por una parte, en el análisis de datos objetivos obtenidos a partir de fuentes secundarias, que hacen referencia a características socio-demográficas, convivenciales, educativas y económicas de las personas mayores en Tenerife. Por otro lado, se recoge la recopilación de información sobre la atención y los servicios que desde el ámbito municipal se presta a las personas mayores.

No tiene por tanto la pretensión de analizar de manera pormenorizada la complejidad que caracteriza a este sector de la población, pero sirva como un acercamiento para conocer, grosso modo, algunas de las características de las personas mayores que residen en Tenerife y cuál es la situación de la atención social que se les presta.

\footnotetext{
1 Características económicas, nivel educativo, culturales, estilos de vida, entre otras.
} 
2.Organización del
documento 

El presente informe se compone de tres grandes apartados, cada uno de los cuales responde a unos objetivos específicos y utiliza un acercamiento metodológico diferente para dar respuesta a la realización del análisis preliminar sobre la situación de las personas mayores residentes en el territorio insular.

El primer apartado se centra en el establecimiento de un perfil sobre las personas mayores de Tenerife, el cual recoge cuatro subapartados que hacen referencia a los siguientes contenidos. En primer lugar, la descripción de características socio-demográficas de la población mayor, en la que se incluye la evolución de la población mayor en los últimos años, las tasas de envejecimiento y sobre-envejecimiento que se observan a nivel insular y municipal, la distribución de la población mayor en función del sexo y la proporción de la población mayor extranjera. En segundo lugar, las características de convivencia, y en concreto, la descripción de la población mayor que reside en hogares unipersonales. Un tercer subapartado describe el nivel de estudios alcanzado por las personas mayores. Por último, en el cuarto subapartado se aportan datos sobre las características económicas de la población mayor tinerfeña.

La información que conforma este primer bloque del informe ha sido obtenida a partir del análisis de datos secundarios, procedentes del Instituto Canario de Estadística -ISTAC-, el Instituto Nacional de Estadística -INE- y el Instituto Nacional de la Seguridad Social -INSS-.

El segundo apartado del informe hace referencia a los recursos municipales que se ofrecen a las personas mayores, englobando tres subapartados. En primer lugar, se realiza la descripción de los servicios sociales dirigidos a personas mayores desde el ámbito municipal, como son el servicio de ayuda a domicilio, la teleasistencia o los centros de día, entre otros. A continuación, las asociaciones de mayores existentes en los diferentes municipios. En tercer lugar, se exponen cuáles son los proyectos socioeducativos que actualmente se están llevando a cabo con personas mayores desde este mismo ámbito. Para obtener esta información ha sido necesario realizar un trabajo de campo, cuya metodología se expondrá en este segundo apartado de contenidos.

El tercer apartado pretende establecer un directorio actualizado de los centros residenciales dirigidos a personas mayores en el territorio insular. En este caso también ha sido necesario un trabajo de campo. Debe indicarse que es 
un directorio en construcción, el cual deberá complementarse con los datos de los centros residenciales que no han aportado la información durante el periodo de ejecución de este proyecto.

Para finalizar, se establecen las conclusiones que se extraen de la realización de este trabajo y se proporcionan una serie de recomendaciones generales orientadas al desarrollo de políticas públicas con personas mayores. 


\section{Un perfil de las}

Personas Mayores

de la Isla de

$$
\text { Tenerife }
$$





\subsection{Características socio-demográficas de la población mayor}

\subsubsection{La población de Tenerife}

Canarias tenía a 1 de enero de 2019 una población de 2.153.389 habitantes, según los datos del padrón municipal publicados por el ISTAC. De esta población, 917.841 personas residen en Tenerife, lo cual supone el $42,6 \%$ del total de población residente en Canarias. Por sexos, de la población tinerfeña, 466.973 son mujeres y 450.868 varones.

La población tinerfeña ha crecido de manera ininterrumpida desde el año 2016, observándose en cambio, entre los años 2012 y 2015, descensos en el tamaño de la población. Con anterioridad al 2012, y remontándonos hasta el 2000, el crecimiento interanual también sucedió de forma ininterrumpida.

\section{1.2. Evolución de la población mayor durante este siglo}

Nos referimos a la población mayor como las personas que han cumplido los 65 años, edad que se considera el umbral de vejez.

De las 2.153.389 personas que residen en nuestro archipiélago a 1 de enero de $2019,340.679$ son personas mayores. De ellas, 148.632 residen en la isla de Tenerife, según los datos del padrón municipal publicados por el ISTAC. Como se muestra en la Figura 3.1., ha habido un crecimiento continuado de este grupo de población en la isla de Tenerife desde el año 2000, con la única excepción del año 2014 en el que la población mayor sufrió un descenso, teniendo que llegar al año 2016 para que se superaran las cifras absolutas del 2013. Este crecimiento resulta muy acusado, observándose que entre los años 2000 y 2019, se ha registrado un aumento de la población mayor desde 87.113 personas hasta 148.632 personas. 
Figura 3.1. Evolución de la población tinerfeña de 65 y más años entre 2000 y 2019

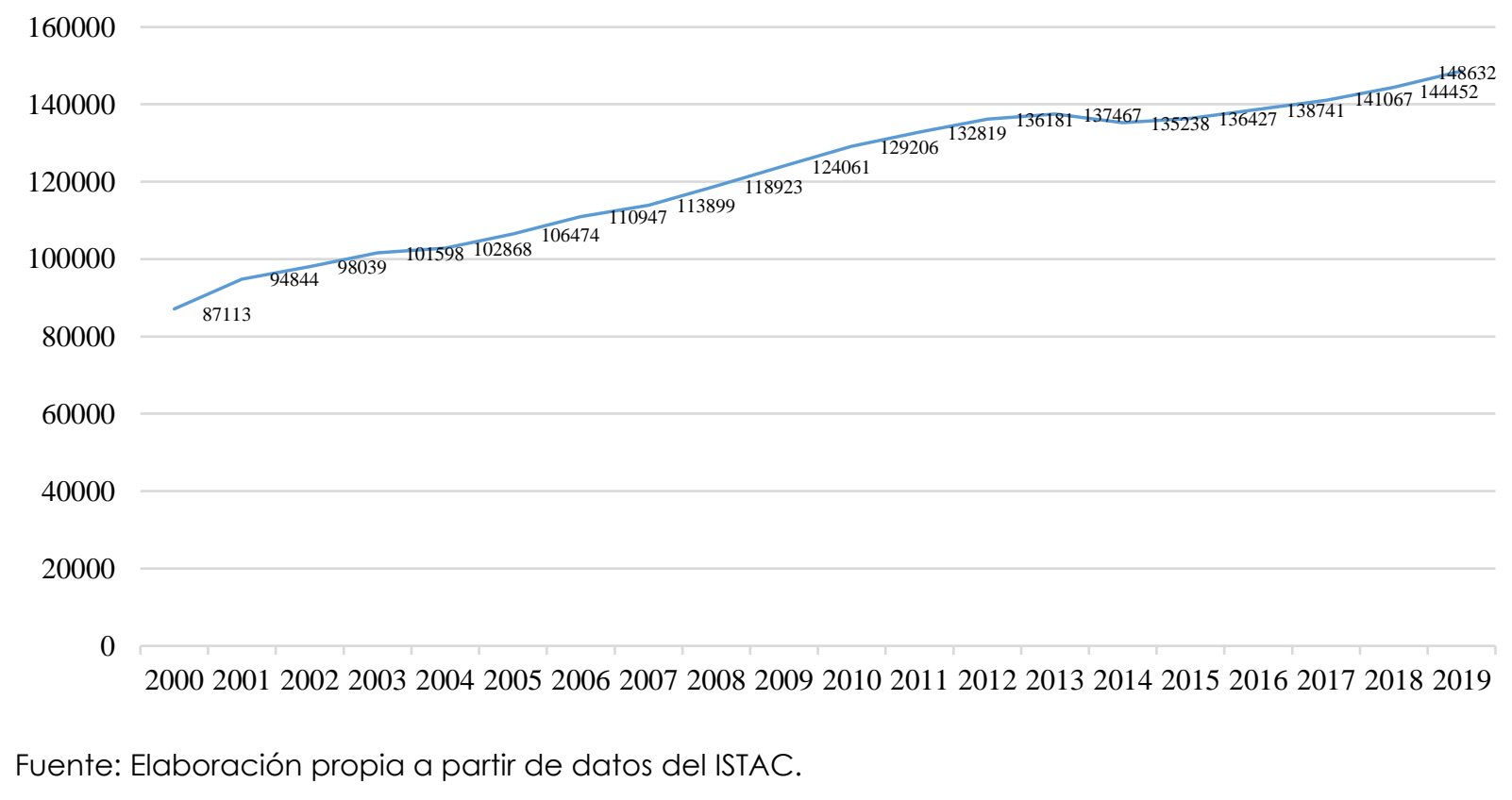

Estos datos constatan el rápido envejecimiento de la estructura de la población que está experimentando nuestro territorio. Así, en 1975 la proporción de personas mayores de 65 años respecto al total de la población en nuestra Comunidad Autónoma era del 7,29\%; en 2000, del 11,52\%; y en 2019 alcanzó el 15,82\%.

Pese a ello, Canarias es una de las Comunidades Autónomas menos envejecidas del territorio español, únicamente las Ciudades Autónomas de Ceuta y Melilla, Baleares y Murcia presentan proporciones inferiores de personas mayores, según los datos publicados por el INE. De hecho, a nivel nacional el promedio de la proporción de la población mayor respecto al total poblacional representa el 19,3\%, dos puntos y medio por encima del promedio registrado en Canarias (15,82\%).

Sin embargo, las proyecciones de población establecidas por el Instituto Nacional de Estadística indican que la proporción de personas mayores continuará creciendo en nuestro archipiélago en los próximos años, alcanzando en 2025 el 18,85\% y en 2.035 el 25,04\% de la población. Es decir, se estima que, en 15 años, una de cada cuatro personas residentes en Canarias será mayor de 65 años. 


\section{1.3. Evolución de la población mayor en función del sexo}

Como es sabido, dentro del grupo de las personas mayores predominan las mujeres. Así, si se realiza el análisis de la evolución de la población mayor en la isla de Tenerife en función del sexo, se observa, como muestra la Figura 3.2., que, de manera constante, es mayor la población de mujeres mayores de 65 años, en comparación con la de varones en este mismo rango de edad.

Ello se corresponde con la mayor esperanza de vida que presentan las mujeres. En concreto, según el INE, en Canarias en 2019 la esperanza de vida al nacer para las mujeres es de 85,27 años, mientras que para los hombres es de 80,38 años. Y la esperanza de vida a los 65 años en las islas Canarias es de 22,69 años para las mujeres y 19,36 años para los hombres. Es decir, en términos promedios, las mujeres viven más años que los hombres, por lo que el número de mujeres en la etapa de la vejez es mayor. Es lo que se conoce como la feminización del envejecimiento.

Figura 3.2. Evolución de la población tinerfeña de 65 y más años en función del sexo entre 2000 y 2019

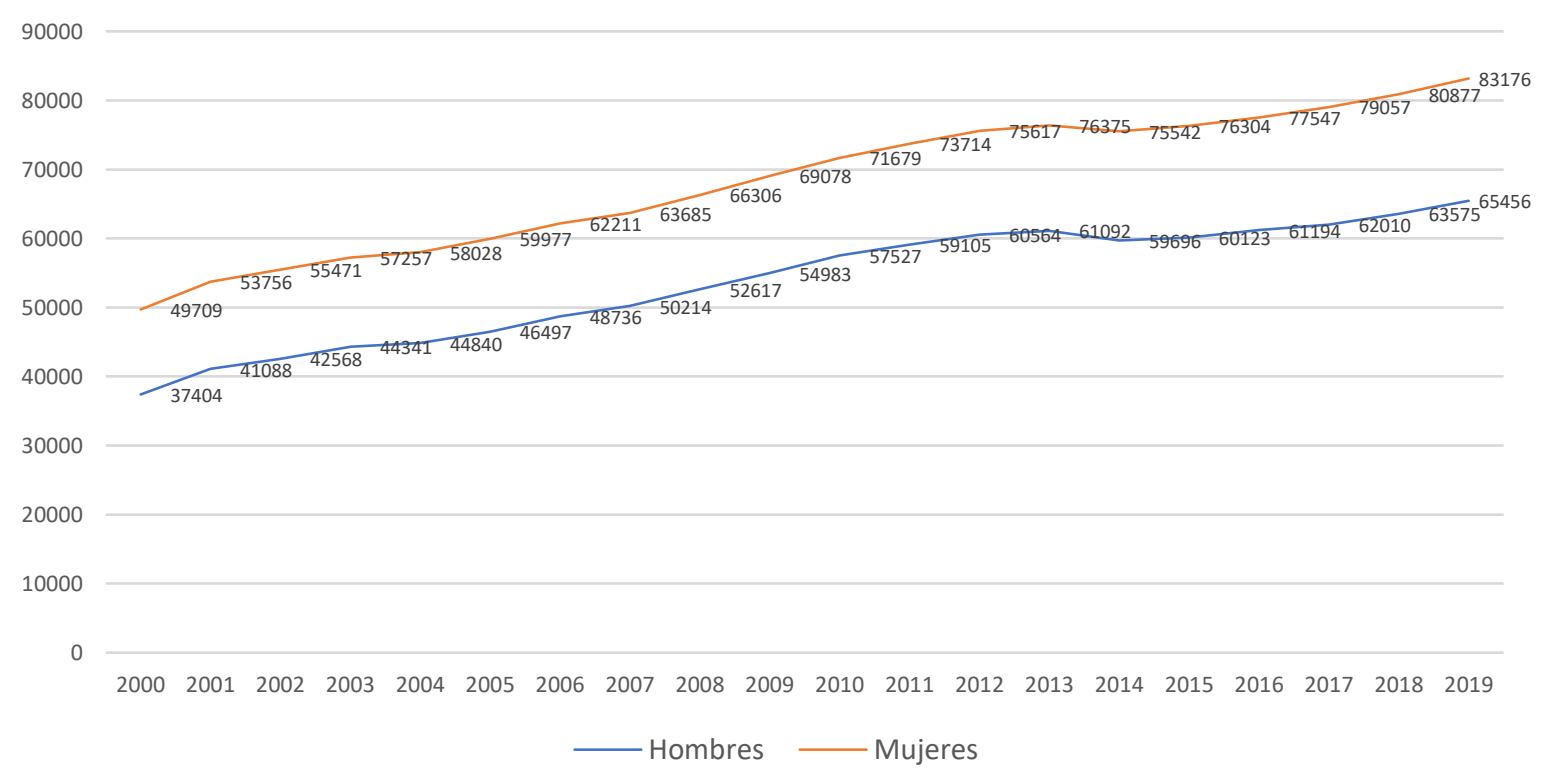

Fuente: Elaboración propia a partir de datos del ISTAC.

Esta feminización del envejecimiento se observa también en la Figura 3.3., que indica que la proporción de mujeres de 65 y más años en la isla de Tenerife es del $55,96 \%$, mientras que los varones en ese rango de edad representan el $44,04 \%$. 
Figura 3.3. Porcentaje de mujeres y varones de 65 y más años en Tenerife en 2019

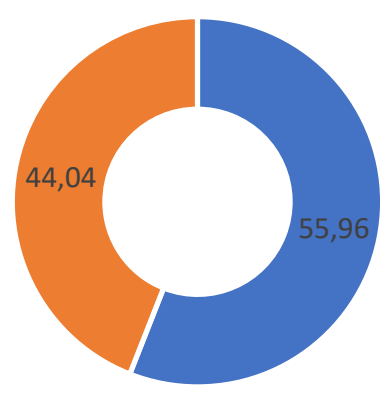

- Mujeres - Varones

Fuente: Elaboración propia a partir de datos del ISTAC.

Al prestar atención de manera específica a las personas mayores de 85 años, esta diferencia entre la proporción de mujeres y varones resulta más pronunciada. Así, como se observa en la Figura 3.4., las mujeres representan el $67 \%$ de la población de 85 y más años.

Figura 3.4. Porcentaje de mujeres y varones de 85 y más años en Tenerife en 2019

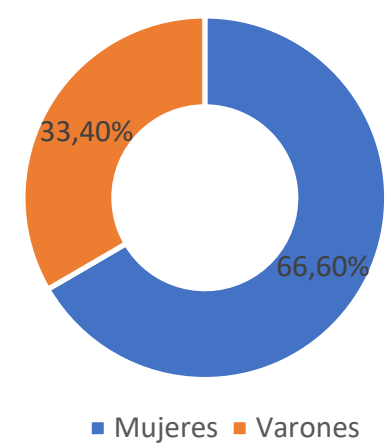

Fuente: Elaboración propia a partir de datos del ISTAC.

Esta diferenciación de la población mayor en función del sexo deberá tenerse en consideración a la hora de planificar las políticas sociales. Así, entre otros factores en los que repercute, implica que hay un mayor número de mujeres 
que se han enfrentado al fallecimiento de su pareja y, por tanto, que con mayor probabilidad residen solas en esta última etapa de su vida. Estos datos sobre la composición de los hogares se presentarán de forma detallada en ulterior apartado.

\section{1.4. Proporción de personas de 65 y más años en las Islas Canarias}

Como se ha comentado, el número de personas mayores se ha incrementado en las últimas décadas, de forma que las personas en esta etapa de la vida constituyen de forma progresiva una mayor proporción de la población total. Sin embargo, las islas presentan una distribución desigual en cuanto a la magnitud de su población mayor, como se observa en la Tabla 3.1.

Tabla 3.1. Tasas de vejez, población de 65 y más años y población total, por sexos, por islas y en Canarias en 2019

\begin{tabular}{|c|c|c|c|c|c|c|c|c|c|}
\hline & Tasa vejez & $\begin{array}{l}\text { Población } \\
\geq 65 \text { años }\end{array}$ & $\begin{array}{c}\text { Población } \\
\text { total }\end{array}$ & Tasa vejez & $\begin{array}{l}\text { Población } \\
\geq 65 \text { años }\end{array}$ & $\begin{array}{c}\text { Población } \\
\text { total }\end{array}$ & Tasa vejez & $\begin{array}{l}\text { Población } \\
\geq 65 \text { años }\end{array}$ & $\begin{array}{c}\text { Población } \\
\text { total }\end{array}$ \\
\hline Islas & Total & Total & Total & Hombres & Hombres & Hombres & Mujeres & Mujeres & Mujeres \\
\hline TENERIFE & 16,19 & 148.632 & 917.841 & 14,52 & 65.456 & 450.868 & 17,84 & 83.176 & 466.176 \\
\hline La Gomera & 21,57 & 4.638 & 21.503 & 20,05 & 2.189 & 10.917 & 23,13 & 2.449 & 10.586 \\
\hline La Palma & 20,77 & 17.168 & 82.671 & 18,64 & 7.620 & 40.864 & 22,84 & 9.548 & 41.807 \\
\hline El Hierro & 22,56 & 2.474 & 10.968 & 21,23 & 1.178 & 5.548 & 23,27 & 1.296 & 5.420 \\
\hline Lanzarote & 11,64 & 17.726 & 152.289 & 10,74 & 8.273 & 77.028 & 12,56 & 9.453 & 75.261 \\
\hline Fuerteventura & 10,10 & 11.802 & 116.886 & 9,88 & 5.952 & 60.250 & 10,33 & 5.850 & 56.636 \\
\hline Gran Canaria & 16,24 & 138.239 & 851.231 & 14,62 & 61.463 & 420.496 & 17,82 & 76.776 & 430.735 \\
\hline Canarias & 15,82 & 340.679 & 2.153 .389 & 14,27 & 152.131 & 1.065 .971 & 17,34 & 188.548 & 1.087 .418 \\
\hline
\end{tabular}

Fuente: Elaboración propia a partir de datos del ISTAC.

Nota: Tasa de vejez es el porcentaje de la población de 65 años y más entre el total de la población.

Así, tenemos islas con una proporción baja de personas mayores respecto al total de su población, como son Fuerteventura $(10,10 \%)$ y Lanzarote $(11,64 \%)$; mientras que otras islas presentan proporciones muy altas de población mayor, situándose por encima del promedio nacional (19,3\%). Es el caso de El Hierro (22,56\%), La Gomera $(21,57 \%)$ y La Palma $(20,77 \%)$. Por su parte, Tenerife se sitúa en una posición intermedia entre las islas más y menos envejecidas, con un 16,19\% de población mayor, presentando cifras similares a las de Gran Canaria (16,24\%).

Si se analiza la proporción de personas mayores en función del sexo, se observa que en todas las islas es mayor la proporción de mujeres mayores, en comparación con la de varones. Esta diferencia es especialmente notable en el caso de La Palma, donde se observan cuatro puntos de diferencia, mientras 
que es muy reducida en la isla de Fuerteventura, donde no se supera ni el medio punto. En el caso de Tenerife, las mujeres de 65 y más años representan el 17,84\% del total de la población femenina, mientras que la proporción de varones para el mismo grupo de edad es de $14,52 \%$.

\section{1.5. Tasas de vejez en los municipios de la isla de Tenerife}

Al realizar un análisis más detenido sobre la proporción de personas mayores en los 31 municipios de la isla de Tenerife, presentados en la Tabla 3.2., se observa, al igual que lo descrito para las diferentes islas, que a nivel intrainsular existen también importantes diferencias entre los municipios tinerfeños

Tabla 3.2. Tasas de vejez, población 65 años y más y población total, por sexos y por municipios de Tenerife en 2019

\begin{tabular}{|c|c|c|c|c|c|c|c|c|c|}
\hline & $\begin{array}{l}\text { Tasa } \\
\text { vejez }\end{array}$ & $\begin{array}{l}\text { Población } \\
\geq 65 \text { años }\end{array}$ & $\begin{array}{c}\text { Población } \\
\text { total }\end{array}$ & $\begin{array}{l}\text { Tasa } \\
\text { vejez }\end{array}$ & $\begin{array}{c}\text { Población } \geq \\
65 \text { años }\end{array}$ & $\begin{array}{c}\text { Población } \\
\text { total }\end{array}$ & $\begin{array}{l}\text { Tasa } \\
\text { vejez }\end{array}$ & $\begin{array}{l}\text { Población } \\
\geq 65 \text { años }\end{array}$ & $\begin{array}{c}\text { Población } \\
\text { total }\end{array}$ \\
\hline & Total & Total & Total & Hombres & Hombres & Hombres & Mujeres & Mujeres & Mujeres \\
\hline TENERIFE & 16,19 & 148.632 & 917.841 & 14,52 & 65.456 & 450.868 & 17,84 & 83.176 & 466.176 \\
\hline Adeje & 10,12 & 4.844 & 47.869 & 9,83 & 2.369 & 24.110 & 10,42 & 2.475 & 23.759 \\
\hline Arafo & 18,00 & 999 & 5.551 & 16,44 & 449 & 2.731 & 19,50 & 550 & 2.820 \\
\hline Arico & 17,49 & 1.397 & 7.988 & 16,02 & 665 & 4.151 & 19,08 & 732 & 3.837 \\
\hline Arona & 11,62 & 9.434 & 81.216 & 11,06 & 4.566 & 41.283 & 12,19 & 4.868 & 39.933 \\
\hline Buenavista Norte & 23,50 & 1.123 & 4.778 & 21,46 & 516 & 2.405 & 25,58 & 607 & 2.373 \\
\hline Candelaria & 15,55 & 4.353 & 27.985 & 14,28 & 1.945 & 13.619 & 16,76 & 2.408 & 14.366 \\
\hline Fasnia & 23,55 & 656 & 2.786 & 19,62 & 286 & 1.458 & 27,86 & 370 & 1.328 \\
\hline Garachico & 23,55 & 1.147 & 4.874 & 21,54 & 526 & 2.442 & 25,57 & 621 & 2.429 \\
\hline Granadilla Abona & 10,30 & 5.164 & 50.146 & 9,27 & 2.325 & 25.076 & 11,32 & 2.839 & 25.070 \\
\hline Guancha (La) & 21,39 & 1.181 & 5.520 & 19,61 & 527 & 2.687 & 23,09 & 654 & 2.833 \\
\hline Guía de Isora & 14,84 & 3.172 & 21.368 & 14,09 & 1.501 & 10.653 & 15,59 & 1.671 & 10.715 \\
\hline Güímar & 17,17 & 3.466 & 20.190 & 15,19 & 1.521 & 10.010 & 16,16 & 1.645 & 10.180 \\
\hline Icod de Los Vinos & 20,36 & 4.734 & 23.254 & 18,47 & 2.110 & 11.427 & 22,19 & 2.624 & 11.827 \\
\hline Laguna (La) & 16,06 & 25.290 & 157.503 & 14,32 & 10.913 & 76.211 & 17,69 & 14.377 & 81.292 \\
\hline Matanza Acentejo & 14,65 & 1.327 & 9.061 & 13,44 & 616 & 4.585 & 15,88 & 711 & 4.476 \\
\hline Orotava (La) & 16,79 & 7.055 & 42.029 & 15,07 & 3.098 & 20.564 & 18,43 & 3.957 & 21.465 \\
\hline Puerto de La Cruz & 24,45 & 7.450 & 30.468 & 22,63 & 3.370 & 14.889 & 26,19 & 4.080 & 15.579 \\
\hline Realejos (Los) & 16,95 & 6.170 & 36.402 & 15,36 & 2.744 & 17.862 & 18,48 & 3.426 & 18.540 \\
\hline Rosario (EI) & 13,77 & 2.391 & 17.370 & 13,34 & 1.173 & 8.792 & 14,20 & 1.218 & 8.578 \\
\hline San Juan Rambla & 20,03 & 967 & 4.828 & 17,41 & 417 & 2.395 & 22,61 & 550 & 2.433 \\
\hline San Miguel & 10,65 & 2.225 & 20.886 & 10,45 & 1.104 & 10.563 & 10,86 & 1.121 & 10.323 \\
\hline $\mathrm{S} / \mathrm{C}$ de Tenerife & 18,85 & 39.074 & 207.312 & 15,96 & 15.798 & 98.991 & 21,49 & 23.276 & 108.321 \\
\hline Santa Úrsula & 14,48 & 2.125 & 14.679 & 13,23 & 968 & 7.319 & 15,72 & 1.157 & 7.360 \\
\hline Santiago del Teide & 18,77 & 2.085 & 11.111 & 18,94 & 1.049 & 5.538 & 18,59 & 1.036 & 5.573 \\
\hline Sauzal (EI) & 15,82 & 1.413 & 8.934 & 18,94 & 649 & 4.409 & 16,88 & 764 & 4.525 \\
\hline Silos (Los) & 24,68 & 1.158 & 4.693 & 22,06 & 518 & 2.348 & 27,29 & 640 & 2.345 \\
\hline Tacoronte & 16,03 & 3.869 & 24.134 & 14,63 & 1.754 & 11.990 & 17,42 & 2.115 & 12.144 \\
\hline Tanque (EI) & 19,87 & 549 & 2.763 & 18,09 & 242 & 1.338 & 21,54 & 307 & 1.425 \\
\hline Tegueste & 16,65 & 1.881 & 11.294 & 15,21 & 846 & 5.561 & 18,05 & 1.035 & 5.733 \\
\hline Victoria Acentejo & 16,98 & 1.560 & 9.185 & 15,42 & 710 & 4.604 & 18,55 & 850 & 4.581 \\
\hline Vilaflor & 22,38 & 373 & 1.667 & 21,12 & 181 & 857 & 23,70 & 192 & 810 \\
\hline
\end{tabular}

Fuente: Elaboración propia a partir de datos del ISTAC.

Nota: Tasa de vejez es el porcentaje de la población de 65 años y más entre el total de la población. 
Los datos reflejan un rango en la proporción de personas mayores de 65 y más años, que oscila entre el 10,12\% del municipio de Adeje y el 24,68\% del municipio de Los Silos. Es decir, una cuarta parte de los habitantes que residen en este municipio son ya personas que han cumplido los 65 años.

Se constata que los municipios que tienen mayor proporción de población mayor se corresponden, de manera general, con localidades de ámbito rural, que se sitúan en todos los casos (con la excepción de Fasnia y Vilaflor) en la zona norte de la isla. Se trata del ya mencionado municipio de Los Silos, además del Puerto de la Cruz (como única excepción en esta categoría de municipios de carácter rural), Fasnia, Garachico, Buenavista del Norte, Vilaflor, La Guancha, Icod de los Vinos o San Juan de la Rambla. En todos estos casos, la población de 65 y más años representa más del $20 \%$ de la población total del municipio. En cambio, los municipios que presentan menores tasas de población mayor corresponden a territorios del sur de la isla, cuya economía se sustenta de forma mayoritaria en el turismo, como son Adeje, Granadilla de Abona, San Miguel o Arona. En ninguna de estas localidades la tasa de personas mayores supera el $12 \%$.

Tal y como se describió para los indicadores promedios de la isla y de la Comunidad Autónoma, en todos los municipios -con la única excepción de El Sauzal- la proporción de mujeres de 65 y más años es mayor, en comparación con la que presentan los varones. Llaman especialmente la atención los municipios de Fasnia, Los Silos, Puerto de la Cruz y Garachico, en los cuales las mujeres mayores de 65 años representan más del $25 \%$ del total de mujeres que residen en el municipio, alcanzando en los dos primeros municipios el $27,86 \%$ y $27,29 \%$ respectivamente. En cambio, en ninguno de los municipios de la isla la población masculina mayor supera el $25 \%$ del total de varones residentes, siendo el municipio de Puerto de la Cruz el que destaca, con una proporción de varones de 65 y más años que alcanza el 22,63\% de la población masculina total del municipio.

En el polo opuesto se encuentran los municipios de Adeje y Granadilla de Abona, cuya proporción de hombres de 65 y más años no alcanza el $10 \%$ (9,83\% y 9,27\% respectivamente). En el caso de las mujeres, son los municipios de Adeje y San Miguel los que presentan proporciones más reducidas, superando apenas el $10 \%(10,42 \%$ y $10,86 \%$ respectivamente). 
Por su parte, el eje formado por la capital Santa Cruz de Tenerife y La Laguna, en los que se concentran los mayores núcleos de población (207.312 y 157.503 habitantes respectivamente) presenta proporciones de personas de 65 y más años, que se sitúan alrededor de la media insular en el caso de La Laguna $(16,06 \%)$, y dos puntos por encima en el caso de Santa Cruz de Tenerife (18,85\%). Es notable el arco de 6 puntos de diferencia entre la proporción de hombres y mujeres de 65 años y más en la capital insular $15,96 \%$ frente a $21,49 \%)$, diferencia en esta distribución por sexos sólo superada por el municipio de Fasnia.

\section{1.6. El sobre-envejecimiento en las Islas Canarias}

La tasa de sobre-envejecimiento hace referencia a la población de 85 años y más entre el total de la población de 65 años en adelante. Permite conocer en qué medida la población mayor en un determinado contexto alcanza las etapas más longevas de la vida, en las que los niveles de dependencia y por tanto la demanda de servicios sociosanitarios se incrementa, con respecto a las etapas anteriores.

Tabla 3.3. Tasas de sobre-envejecimiento, población de 65 años y más y población total, por sexos, por islas y en Canarias en 2019

\begin{tabular}{lrrrrrrrrr}
\hline & $\begin{array}{l}\text { Tasa de } \\
\text { S-vejez }\end{array}$ & $\begin{array}{r}\text { Población } \\
\geq 85 \text { años }\end{array}$ & $\begin{array}{l}\text { Población } \\
\geq 65 \text { años }\end{array}$ & $\begin{array}{l}\text { Tasa de } \\
\text { S-vejez }\end{array}$ & $\begin{array}{r}\text { Población } \\
\geq 85 \text { años }\end{array}$ & $\begin{array}{l}\text { Población } \\
\geq 65 \text { años }\end{array}$ & $\begin{array}{r}\text { Tasa de } \\
\text { S-vejez }\end{array}$ & $\begin{array}{r}\text { Población } \\
\geq 85 \text { años }\end{array}$ & $\begin{array}{l}\text { Población } \\
\geq 65 \text { años }\end{array}$ \\
\hline \multicolumn{1}{c}{ Islas } & Total & Total & Total & Hombres & Hombres & Hombres & Mujeres & Mujeres & Mujeres \\
\hline TENERIFE & 12,56 & 18.666 & 148.632 & 9,53 & 6.236 & 65.456 & 14,94 & 12.430 & 83.176 \\
\hline La Gomera & 16,65 & 772 & 4.638 & 13,52 & 296 & 2.189 & 19,44 & 476 & 2.449 \\
\hline La Palma & 16,46 & 2.825 & 17.168 & 12,32 & 939 & 7.620 & 19,75 & 1.886 & 9.548 \\
\hline El Hierro & 19,12 & 473 & 2.474 & 16,47 & 194 & 1.178 & 21,53 & 279 & 1.296 \\
\hline Lanzarote & 9,50 & 1.683 & 17.726 & 7,00 & 579 & 8.273 & 11,68 & 1.104 & 9.453 \\
\hline Fuerteventura & 9,29 & 1.096 & 11.802 & 7,01 & 421 & 5.952 & 11,54 & 675 & 5.850 \\
\hline Gran Canaria & 12,67 & 17.511 & 138.239 & 9,78 & 6.009 & 61.463 & 14,98 & 11.502 & 76.776 \\
\hline Canarias & 12,63 & 43.026 & 340.679 & 9,65 & 14.674 & 152.131 & 15,04 & 28.352 & 188.548 \\
\hline
\end{tabular}

Fuente: Elaboración propia a partir de datos del ISTAC.

Nota: La tasa de sobre-envejecimiento es el porcentaje de la población de 85 años y más entre el total de la población de 65 años y más.

Como puede observarse en la Tabla 3.3., las islas más sobre-envejecidas son El Hierro, La Gomera y La Palma, en las que la proporción de personas mayores de 85 años respecto al total de la población mayor es considerable, ya que alcanza el 19,12\%, 16,65\% y 16,46\% respectivamente. En cambio, ni en Fuerteventura ni en Lanzarote la proporción de personas mayores de 85 años alcanza el $10 \%$ del total de la población mayor $19,29 \%$ y $9,50 \%$ respectivamente). Por su parte, Tenerife muestra porcentajes similares a Gran 
Canaria, ocupando posiciones intermedias entre las islas anteriormente mencionadas. Así, el 12,56\% de las personas mayores de la isla de Tenerife han cumplido ya los 85 años (12,67\% en el caso de Gran Canaria).

Se observa, por tanto, que las islas con mayor proporción de población de 65 y más años, son también las que muestran mayor proporción de personas con edades de 85 y más años.

Si prestamos atención a las tasas de sobre-envejecimiento en función del sexo, se observa que en todas las islas es mayor la proporción de mujeres de 85 y más años, respecto a los varones. Como se ha comentado, esto obedece a la mayor esperanza de vida alcanzada por las mujeres, lo cual explica que la diferencia se incrementa en los últimos años de la vida. Este contraste es especialmente notable en el caso de La Palma, donde se observan siete puntos de diferencia entre la tasa de sobre-envejecimiento de las mujeres $(19,75 \%)$ frente a la de los hombres (12,32\%). La Gomera alcanza cifras parecidas (19,44\% frente a 13,52\%), mientras que, en El Hierro, la isla más sobreenvejecida del archipiélago, las mujeres mayores de 85 años suponen más de la quinta parte $(21,53 \%)$ del total de mujeres mayores, frente al $16,47 \%$ de los hombres. En cuanto a la isla de Tenerife, las mujeres mayores de 85 años suponen el $14,94 \%$ del total de mujeres mayores, mientras que los hombres representan el 9,53\%. Son estas personas quienes, en mayor medida, requerirán de los servicios destinados a personas mayores, ya que las situaciones de dependencia se incrementan a estas edades. Asimismo, son las mujeres mayores, y en especial las más longevas, quienes con mayor frecuencia se enfrentan a situaciones de soledad no deseada.

\section{1.7. El sobre-envejecimiento en los municipios de la isla de Tenerife}

Al realizar un análisis de las tasas de sobre-envejecimiento en los diferentes municipios de Tenerife, se observa, tal y como se comentó en el apartado dedicado a la proporción de personas de 65 y más años, que los municipios presentan características muy heterogéneas respecto al volumen de su población mayor. En cierta manera, se reproducen en la isla datos tan dispares como los observados a nivel interinsular. 
Tabla 3.4. Tasas de sobre-envejecimiento, población de 85 años y más y población de 65 años y más, por sexos y por municipios de Tenerife en 2019

\begin{tabular}{|c|c|c|c|c|c|c|c|c|c|}
\hline & $\begin{array}{l}\text { Tasa de } \\
\text { S-vejez }\end{array}$ & $\begin{array}{l}\text { Población } \\
\geq 85 \text { años }\end{array}$ & $\begin{array}{l}\text { Población } \\
\geq 65 \text { años }\end{array}$ & $\begin{array}{l}\text { Tasa de } \\
\text { S-vejez }\end{array}$ & $\begin{array}{l}\text { Población } \\
\geq 85 \text { años }\end{array}$ & $\begin{array}{l}\text { Población } \\
\geq 65 \text { años }\end{array}$ & $\begin{array}{l}\text { Tasa de } \\
\text { S-vejez }\end{array}$ & $\begin{array}{l}\text { Población } \\
\geq 85 \text { años }\end{array}$ & $\begin{array}{l}\text { Población } \\
\geq 65 \text { años }\end{array}$ \\
\hline & Total & Total & Total & Hombres & Hombres & Hombres & Mujeres & Mujeres & Mujeres \\
\hline TENERIFE & 12,56 & 18.666 & 148.632 & 9,53 & 6.236 & 65.456 & 14,94 & 12.430 & 83.176 \\
\hline Adeje & 6,79 & 329 & 4.844 & 5,70 & 135 & 2.369 & 7,84 & 194 & 2.475 \\
\hline Arafo & 17,62 & 176 & 999 & 14,92 & 67 & 449 & 19,82 & 109 & 550 \\
\hline Arico & 11,67 & 163 & 1.397 & 9,47 & 63 & 665 & 13,66 & 100 & 732 \\
\hline Arona & 7,83 & 739 & 9.434 & 6,40 & 292 & 4.566 & 9,18 & 447 & 4.868 \\
\hline Buenavista Norte & 15,58 & 175 & 1.123 & 11,43 & 59 & 516 & 19,11 & 116 & 607 \\
\hline Candelaria & 11,60 & 505 & 4.353 & 9,82 & 191 & 1.945 & 13,04 & 314 & 2.408 \\
\hline Fasnia & 16,62 & 109 & 656 & 8,74 & 25 & 286 & 22,70 & 84 & 370 \\
\hline Garachico & 16,39 & 188 & 1.147 & 11,98 & 63 & 526 & 20,13 & 125 & 621 \\
\hline Granadilla Abona & 10,15 & 524 & 5.164 & 7,70 & 179 & 2.325 & 12,15 & 345 & 2.839 \\
\hline Guancha (La) & 15,41 & 182 & 1.181 & 10,06 & 53 & 527 & 19,72 & 129 & 654 \\
\hline Guía de Isora & 10,34 & 328 & 3.172 & 8,59 & 129 & 1.501 & 11,91 & 199 & 1.671 \\
\hline Güímar & 14,66 & 508 & 3.466 & 10,39 & 158 & 1.521 & 21,28 & 350 & 1.645 \\
\hline Icod de Los Vinos & 13,98 & 662 & 4.734 & 9,81 & 207 & 2.110 & 17,34 & 455 & 2.624 \\
\hline Laguna (La) & 13,30 & 3.364 & 25.290 & 10,17 & 1.110 & 10.913 & 15,68 & 2.254 & 14.377 \\
\hline Matanza Acentejo & 12,13 & 161 & 1.327 & 10,71 & 66 & 616 & 13,36 & 95 & 711 \\
\hline Orotava (La) & 11,92 & 841 & 7.055 & 9,17 & 284 & 3.098 & 14,08 & 557 & 3.957 \\
\hline Puerto de La Cruz & 11,61 & 865 & 7.450 & 9,53 & 321 & 3.370 & 13,33 & 544 & 4.080 \\
\hline Realejos (Los) & 12,59 & 777 & 6.170 & 10,06 & 276 & 2.744 & 14,62 & 501 & 3.426 \\
\hline Rosario (EI) & 10,16 & 243 & 2.391 & 7,84 & 92 & 1.173 & 12,40 & 151 & 1.218 \\
\hline San Juan Rambla & 15,31 & 148 & 967 & 9,59 & 40 & 417 & 19,64 & 108 & 550 \\
\hline San Miguel & 8,22 & 183 & 2.225 & 5,80 & 64 & 1.104 & 10,62 & 119 & 1.121 \\
\hline S/C Tenerife & 14,66 & 5.727 & 39.074 & 11,21 & 1.771 & 15.798 & 17,00 & 3.956 & 23.276 \\
\hline Santa Úrsula & 11,01 & 234 & 2.125 & 7,95 & 77 & 968 & 13,57 & 157 & 1.157 \\
\hline Santiago del Teide & 7,67 & 160 & 2.085 & 5,82 & 61 & 1.049 & 8,59 & 89 & 1.036 \\
\hline Sauzal (EI) & 11,04 & 156 & 1.413 & 7,09 & 46 & 649 & 14,40 & 110 & 764 \\
\hline Silos (Los) & 17,10 & 198 & 1.158 & 13,13 & 68 & 518 & 20,31 & 130 & 640 \\
\hline Tacoronte & 11,50 & 445 & 3.869 & 8,04 & 141 & 1.754 & 14,37 & 304 & 2.115 \\
\hline Tanque (EI) & 12,57 & 69 & 549 & 7,44 & 18 & 242 & 16,61 & 51 & 307 \\
\hline Tegueste & 13,18 & 248 & 1.881 & 8,87 & 75 & 846 & 16,71 & 173 & 1.035 \\
\hline Victoria Acentejo & 13,01 & 203 & 1.560 & 10,00 & 71 & 710 & 15,53 & 132 & 850 \\
\hline Vilaflor & 15,01 & 56 & 373 & 13,26 & 24 & 181 & 16,67 & 32 & 192 \\
\hline
\end{tabular}

Fuente: Elaboración propia a partir de datos del ISTAC.

Nota: Tasa de sobre-envejecimiento es el porcentaje de la población de 85 años y más entre el total de la población de 65 años y más.

Los municipios de Tenerife con mayor proporción de personas mayores de 85 años son Arafo, Los Silos, Fasnia, Garachico, Buenavista del Norte, La Guancha y Vilaflor. En todos estos casos la población mayor de 85 años supone más del 15\% de la población mayor de 65 años. En el polo opuesto, los municipios con menor proporción de población más longeva son Adeje, Santiago del Teide, Arona y San Miguel. En ninguno de estos municipios la población mayor de 85 años alcanza el 9\% de la población mayor de 65. Resulta también llamativo el caso de Santiago del Teide, municipio en el que si bien la proporción de personas mayores de 65 años es bastante alta $(18,77 \%)$, en cambio las personas mayores de 85 años representan un porcentaje bajo dentro de este 
grupo $(7,67 \%)$. Por su parte, los municipios metropolitanos presentan en ambos casos cifras de sobre-envejecimiento superiores a la media insular: $14,66 \%$ en el caso de Santa Cruz de Tenerife y $13,30 \%$ en el caso de La Laguna.

Respecto al análisis por sexos, y de manera similar a lo ya comentado en el caso de las islas, en todos los municipios es mayor la proporción de mujeres mayores de 85 que la de varones. Por su parte, si bien en términos generales los municipios con mayores tasas de sobre-envejecimiento femenino corresponden a municipios con altas tasas tanto de envejecimiento como de sobre-envejecimiento, no son necesariamente las mismas localidades en todos los casos. Así, son los municipios de Fasnia, Güímar, Los Silos y Garachico los que presentan una mayor proporción de mujeres en estos últimos años de la vida, en todos los casos mayor del $20 \%$ (22,70\%, $21,28 \%, 20,31 \%$ y $20,13 \%$ respectivamente). En estos municipios, una o más de cada cinco mujeres mayores han cumplido los 85 años. La diferencia respecto a los varones es especialmente notable en el caso de Fasnia, donde los hombres mayores de 85 años suponen el $8,74 \%$ del total de varones mayores, observándose por tanto una brecha de 14 puntos entre hombres y mujeres. También Güímar presenta diferencias llamativas entre el sobre-envejecimiento femenino y el masculino, con 11 puntos de diferencia. En el polo contrario se encuentran los ya mencionados Adeje, Arona y Santiago del Teide, donde en ningún caso las mujeres mayores de 85 años alcanzan el 10\% del total de mujeres mayores. En este caso, tanto Adeje como Arona son municipios con baja proporción de personas mayores de 65 años, no así Santiago del Teide, que alcanza una tasa de envejecimiento superior a la media insular.

\section{1.8. La población mayor extranjera residente en Tenerife}

Tenerife cuenta con una importante población extranjera que reside de manera estable en la isla. Entre esta población, es relevante el grupo de personas mayores de otras nacionalidades, aunque estas personas no se distribuyen de la misma manera entre los diferentes municipios de la isla. 
Tabla 3.5. Número y porcentaje de población mayor extranjera en Tenerife por municipios en 2019

\begin{tabular}{|c|c|c|c|}
\hline & $\begin{array}{l}\text { Población extranjera } \\
\qquad 65 \text { años }\end{array}$ & $\begin{array}{c}\text { Población } \geq \\
65 \text { años }\end{array}$ & $\begin{array}{l}\text { Tasa población } \\
\text { mayor extranjera }\end{array}$ \\
\hline TENERIFE & 15.692 & 148.632 & 10,56 \\
\hline Adeje & 2.305 & 4.844 & 47,58 \\
\hline Arafo & 23 & 999 & 2,30 \\
\hline Arico & 181 & 1.397 & 12,96 \\
\hline Arona & 3.379 & 9.434 & 35,82 \\
\hline Buenavista del Norte & 52 & 1.123 & 4,63 \\
\hline Candelaria & 226 & 4.353 & 5,19 \\
\hline Fasnia & 22 & 656 & 3,35 \\
\hline Garachico & 65 & 1.147 & 5,67 \\
\hline Granadilla de Abona & 959 & 5.164 & 18,57 \\
\hline Guancha (La) & 39 & 1.181 & 3,30 \\
\hline Guía de Isora & 778 & 3.172 & 24,53 \\
\hline Güímar & 99 & 3.466 & 2,86 \\
\hline Icod de Los Vinos & 322 & 4.734 & 6,80 \\
\hline Laguna (La) & 673 & 25.290 & 2,66 \\
\hline Matanza Acentejo & 90 & 1.327 & 6,78 \\
\hline Orotava (La) & 252 & 7.055 & 3,57 \\
\hline Puerto de La Cruz & 1.581 & 7.450 & 21,22 \\
\hline Realejos (Los) & 413 & 6.170 & 6,69 \\
\hline Rosario (EI) & 142 & 2.391 & 5,94 \\
\hline San Juan de La Rambla & 24 & 967 & 2,48 \\
\hline San Miguel & 991 & 2.225 & 44,54 \\
\hline Santa Cruz de Tenerife & 1.082 & 39.074 & 2,77 \\
\hline Santa Úrsula & 218 & 2.125 & 10,26 \\
\hline Santiago del Teide & 1.141 & 2.085 & 54,72 \\
\hline Sauzal (EI) & 197 & 1.413 & 13,94 \\
\hline Silos (Los) & 118 & 1.158 & 10,19 \\
\hline Tacoronte & 168 & 3.869 & 4,34 \\
\hline Tanque (EI) & 25 & 549 & 4,55 \\
\hline Tegueste & 23 & 1.881 & 1,22 \\
\hline Victoria Acentejo & 74 & 1.560 & 4,74 \\
\hline Vilaflor & 30 & 373 & 8,04 \\
\hline
\end{tabular}

Fuente: Elaboración propia a partir de datos del ISTAC.

Así, como se muestra en la Tabla 3.5., la población mayor extranjera que reside en la isla supone el $10,56 \%$ del total de la población que ha cumplido los 65 años. Sin embargo, hay un gran número de municipios en los que este grupo es muy reducido, mientras que, en una minoría de municipios, suponen un importante volumen de la población mayor. Entre los primeros estarían los municipios en los que la población mayor extranjera no llega o apenas supera el $5 \%$ de la población mayor. Es el caso de las localidades que conforman la comarca metropolitana, además de Tacoronte (Tegueste: 1,22\%; La Laguna: 2,66\%; Santa Cruz de Tenerife: 2,77\%; Tacoronte: 4,34\%; Candelaria: 5,19\%; El Rosario: 5,94\%). También se encuentran en este grupo la mayoría de los municipios situados en la cara norte de la isla, así como en la zona este, hasta el municipio de Fasnia. Como excepción a este patrón de distribución 
poblacional, se encuentran los municipios de Los Silos (10,19\%), Santa Úrsula $(10,26 \%)$, El Sauzal $(13,94 \%)$ y el Puerto de la Cruz, cuya tasa de población extranjera supone el 21,22\% del total de la población mayor. Estos municipios, a excepción de Los Silos, han sido tradicionalmente receptores de población mayor extranjera, sobre todo en la costa. Cabe recordar que Los Silos y el Puerto de la Cruz son los dos municipios con las proporciones más altas de personas de 65 y más años de la isla, y en el caso de Los Silos, con la segunda proporción más alta de personas de 85 y más años de la isla.

Por el contrario, son un pequeño grupo de municipios situados al sur y suroeste de la isla los que concentran a la mayor proporción de la población extranjera mayor (con la excepción del ya mencionado municipio de Puerto de la Cruz), con un rango que va desde una cuarta parte hasta situarse por encima de la mitad de la población en este rango de edad. Es el caso de los municipios de Guía de Isora (24,53\%), Arona (35,82\%), San Miguel (44,54\%), Adeje $(47,58 \%$ ) y Santiago del Teide $(54,72 \%)$, estos municipios, a excepción de Santiago del Teide presentan proporciones de personas mayores de 65 y más años de las más bajas de la isla.

\subsection{Tipología de hogares}

Si bien el análisis de las características sociodemográficas de la población mayor a nivel unipersonal es necesario, para orientar una estrategia dirigida a esta población es también fundamental el conocimiento de las tipologías de los hogares de la población mayor de la isla, destacando en concreto la caracterización de los hogares unipersonales compuestos por una persona de 65 y más años.

En España hay un $10,79 \%$ de hogares unipersonales compuestos por una persona de 65 y más años (de 2.009.100 total de hogares). El 72,3\% de estos hogares unipersonales de personas con 65 y más años, están ocupados por mujeres, tal y como se observa en la Tabla 3.6.

En Canarias los hogares unipersonales de personas con 65 y más años son proporcionalmente menos que en España, representando un $7,81 \%$ del total de hogares en Canarias. También en Canarias, están ocupados mayoritariamente por mujeres $(62,1 \%)$, aunque en menor medida que en España. 
En los últimos años, se ha producido un aumento considerable de este tipo de hogares. Desde el año 2015 hasta el año 2019 los hogares unipersonales de las personas con 65 y más años, aumentan en casi 150.000 en toda España. Este aumento también se observa con claridad para este periodo en Canarias, con 4.800 hogares más de personas mayores que viven solas en 2019 , alcanzado los 66.300 hogares.

Aunque no contamos con datos a nivel municipal sobre el número de hogares unipersonales de personas mayores de 65 y más años, el porcentaje referencial disponible para el conjunto de Canarias en 2019 muestra proporciones próximas al 8\%, es decir, 1 de cada 12 hogares en Canarias corresponde a una persona mayor que vive sola. Aplicando este como referente al ámbito municipal, 1 de cada 12 hogares de los municipios de nuestra isla estaría ocupado por una persona de 65 y más años que vive sola, dato que podría ser superior en los municipios con mayor proporción de personas de 65 y más años y en los municipios con mayores tasas de sobreenvejecimiento.

Tabla 3.6. Total de hogares, hogares unipersonales y hogares unipersonales de personas de 65 años y más años, en España y Canarias, desagregado por sexo, en 2019 y 2015

\begin{tabular}{|c|c|c|c|c|c|c|c|c|}
\hline AÑO & \multirow[t]{2}{*}{$\begin{array}{l}\text { Ámbito } \\
\text { geográfico }\end{array}$} & \multirow[t]{2}{*}{$\begin{array}{l}\text { Hogares } \\
\text { total }\end{array}$} & \multicolumn{2}{|c|}{$\begin{array}{c}\text { Hogares } \\
\text { unipersonales }\end{array}$} & \multicolumn{2}{|c|}{$\begin{array}{c}\text { Hogares } \\
\text { Unipersonales } \geq 65 \text { años }\end{array}$} & \multicolumn{2}{|c|}{$\begin{array}{l}\% \text { Hogares } \\
\text { Unipersonales } \geq 65 \text { años } \\
\text { respecto a total de } \\
\text { hogares }\end{array}$} \\
\hline \multirow{6}{*}{2019} & & & \multicolumn{2}{|c|}{4.793 .700} & \multicolumn{2}{|c|}{2.009 .100} & \multicolumn{2}{|c|}{$10,79 \%$} \\
\hline & \multirow[t]{2}{*}{ España } & \multirow[t]{2}{*}{18.625 .700} & Hombres & Mujeres & Hombres & Mujeres & Hombres & Mujeres \\
\hline & & & 2.204 .000 & 2.589 .700 & 556.800 & 1.452 .300 & $27,7 \%$ & $72,3 \%$ \\
\hline & \multirow{3}{*}{ Canarias } & \multirow{3}{*}{848.600} & \multicolumn{2}{|c|}{202.900} & \multicolumn{2}{|c|}{66.300} & \multicolumn{2}{|c|}{$7,81 \%$} \\
\hline & & & Hombres & Mujeres & Hombres & Mujeres & Hombres & Mujeres \\
\hline & & & 112.900 & 90.000 & 25.100 & 41.200 & $37,9 \%$ & $62,1 \%$ \\
\hline \multirow{2}{*}{2015} & España & 18.346 .200 & \multicolumn{2}{|c|}{4.584 .200} & \multicolumn{2}{|c|}{1.859 .800} & \multicolumn{2}{|c|}{$10,14 \%$} \\
\hline & Canarias & 817.700 & \multicolumn{2}{|c|}{193.300} & \multicolumn{2}{|c|}{61.500} & \multicolumn{2}{|c|}{$7,52 \%$} \\
\hline
\end{tabular}

Por su parte, la Figura 3.5. muestra la proporción de personas que viven solas en España según el sexo y los diferentes grupos de edad en el año 2019. Se observa con claridad que la proporción de mujeres que viven solas aumenta considerablemente a partir de los 65 años, prácticamente duplicando a la proporción de hombres a partir de los 74 años. Este dato está estrechamente relacionado con la mayor esperanza de vida de las mujeres. En 2019 la 
esperanza de vida al nacimiento de las mujeres era de 86,2 años en España y 85,3 años en Canarias, mientras que la esperanza de vida al nacimiento de los hombres en 2019 estaba 5 puntos por debajo; 80,9 años en España y 80,4 años en Canarias. No obstante, debe señalarse que, aunque por término medio las mujeres viven más años que los hombres, su salud percibida y su esperanza de vida saludable es menor que la de los varones.

Figura 3.5. Personas que viven solas según sexo y edad. Año 2019. Porcentaje

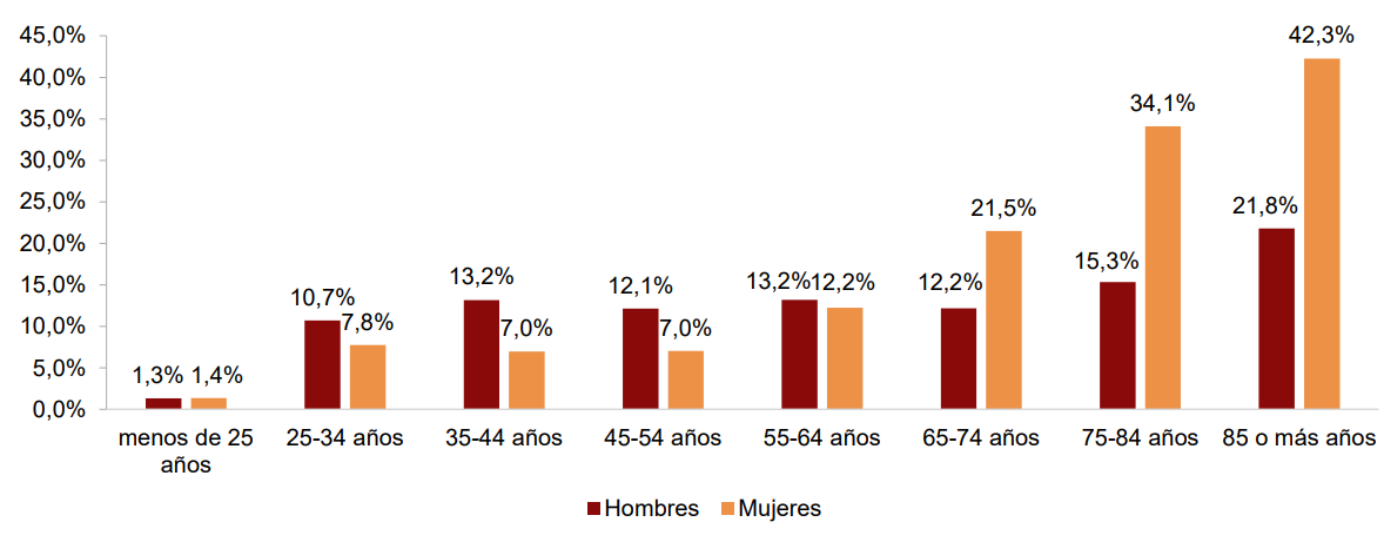

Fuente: INE (2020). Nota de Prensa. Encuesta Continua de Hogares 2019. https://www.ine.es/prensa/ech 2019.pdf

\subsection{El nivel de estudios de la población mayor}

La Encuesta Continua de Hogares 2019 del Instituto Nacional de Estadística ofrece los últimos datos registrados sobre el nivel de estudios de la población española. Estos datos muestran que el nivel de estudios de las personas de 65 y más años se distribuye de forma asimétrica. Tal y como se observa en la Tabla 3.7., en la provincia de Santa Cruz de Tenerife, aproximadamente un 10\% de las personas de 65 y más años cuenta con estudios universitarios, un 10,6\% ha cursado estudios secundarios postobligatorios, un 27,8\% estudios obligatorios básicos de secundaria y más de la mitad de las personas mayores $(51,8 \%)$ han cursado estudios primarios o menos. Estos porcentajes son similares en la Comunidad Autónoma de Canarias y en España para este grupo de edad, por lo que pueden tomarse como referencia aplicable a los municipios de Tenerife para la programación de actividades y políticas educativas dirigidas a personas mayores. 
Tabla 3.7. Niveles de estudios de la población mayor de 65 años en España, por Comunidades Autónomas y para la provincia de Santa Cruz de Tenerife en 2019

\begin{tabular}{|c|c|c|c|c|c|}
\hline $\begin{array}{c}\text { CCAA y Provincia de } S / C \text { de } \\
\text { Tenerife }\end{array}$ & $\begin{array}{l}\text { Primarios o } \\
\text { menos }\end{array}$ & $\begin{array}{c}\text { Secundarios } \\
\text { obligatorios } \\
\text { (ESO) }\end{array}$ & $\begin{array}{c}\text { Secundarios de } \\
\text { Bachillerato y } \\
\text { Formación } \\
\text { Profesional }\end{array}$ & Universitarios & Total \\
\hline Andalucía & $56,4 \%$ & $26,8 \%$ & $7,9 \%$ & $8,9 \%$ & $100,0 \%$ \\
\hline Aragón & $40,8 \%$ & $39,6 \%$ & $10,5 \%$ & $9,2 \%$ & $100,0 \%$ \\
\hline Canarias $(n=2.029)$ & $50,4 \%$ & $27,5 \%$ & $11,5 \%$ & $10,6 \%$ & $100,0 \%$ \\
\hline Santa Cruz de Tenerife $(n=953)$ & $51,8 \%$ & $27,8 \%$ & $10,6 \%$ & $9,8 \%$ & $100,0 \%$ \\
\hline Cantabria & $33,0 \%$ & $44,8 \%$ & $12,9 \%$ & $9,3 \%$ & $100,0 \%$ \\
\hline Castilla y León & $42,7 \%$ & $36,4 \%$ & $10,0 \%$ & $10,9 \%$ & $100,0 \%$ \\
\hline Galicia & $55,7 \%$ & $30,0 \%$ & $7,2 \%$ & $7,1 \%$ & $100,0 \%$ \\
\hline Madrid, Comunidad de & $35,8 \%$ & $31,3 \%$ & $14,9 \%$ & $18,0 \%$ & $100,0 \%$ \\
\hline Murcia, Región de & $51,9 \%$ & $27,2 \%$ & $9,7 \%$ & $11,2 \%$ & $100,0 \%$ \\
\hline Navarra, Comunidad Foral de & $36,5 \%$ & $39,7 \%$ & $14,0 \%$ & $9,8 \%$ & $100,0 \%$ \\
\hline País Vasco & $34,8 \%$ & $37,6 \%$ & $17,5 \%$ & $10,0 \%$ & $100,0 \%$ \\
\hline Rioja, La & $42,4 \%$ & $39,2 \%$ & $10,3 \%$ & $8,1 \%$ & $100,0 \%$ \\
\hline Ceuta & $52,9 \%$ & $30,8 \%$ & $9,2 \%$ & $7,1 \%$ & $100,0 \%$ \\
\hline Melilla & $41,5 \%$ & $32,5 \%$ & $17,9 \%$ & $8,1 \%$ & $100,0 \%$ \\
\hline España $(n=52.553)$ & $45,1 \%$ & $33,6 \%$ & $11,1 \%$ & $10,1 \%$ & $100,0 \%$ \\
\hline
\end{tabular}

La Tabla 3.8. muestra el nivel de estudios de la población de 65 y más años en Canarias y en la Isla Tenerife, a partir de datos extraídos del ISTAC procedentes de los Censos de Población y Vivienda 2011. Al comparar estos datos con los procedentes de la Encuesta Continua de Hogares 2019 (Tabla 3.7.), se observa que tanto para Canarias, como para la Isla de Tenerife los porcentajes para los diferentes niveles de estudio de la población de personas mayores son similares en los estudios postobligatorios. Sin embargo, se observan diferencias en los estudios primarios y secundarios obligatorios. En concreto, en el año 2019 disminuye la proporción de personas de 65 y más años con estudios primarios en Canarias al $50.4 \%$ y en Santa Cruz de Tenerife al 51,8\% $163,7 \%$ y $63,0 \%$, respectivamente, en 2011 ) y asciende la proporción de personas mayores de 65 y más años con estudios secundarios obligatorios del 17\% (2011) al $28 \%$ (2019) para Canarias. 
Tabla 3.8. Niveles de estudios de la población (n y \%) mayor de 65 años en Canarias y Tenerife en 2011

\begin{tabular}{lrrrr}
\hline \multicolumn{1}{c}{ CENSO 2011 ISTAC } & \multicolumn{2}{c}{ CANARIAS } & \multicolumn{2}{c}{ TENERIFE } \\
\hline Población de 65 años y más años/Estudios & 286.275 & 100,0 & 128.124 & 100,0 \\
\hline Estudios primarios o menos & 182.484 & 63,7 & 80.744 & 63,0 \\
\hline Secundarios obligatorios (ESO/EGB/Bachillerato Elemental) & 50.525 & 17,6 & 23.287 & 18,2 \\
\hline Secundarios postobligatorios & 28.711 & 10,0 & 12.496 & 9,8 \\
\hline Universitarios & 24.555 & 8,5 & 11.597 & 9,0 \\
\hline
\end{tabular}

Fuente: Elaboración propia con datos del ISTAC (2011). Censos de Población y Viviendas.

http://www.gobiernodecanarias.org/istac/estadisticas/demografia/poblacion/cifrascensales/E30.243A.h

$\underline{\mathrm{tml}}$

\subsection{Características \\ económicas \\ de \\ la población mayor}

Para ofrecer una visión aproximada de las características económicas de las personas mayores de la isla de Tenerife en este apartado se presentan, en primer lugar, los datos sobre la renta media por persona y los ingresos por unidad de consumo de los mayores de Tenerife, extraídos del Atlas de distribución de la renta de los hogares (ADRH) que publica el INE. Esta primera fuente permite mostrar los datos desagregados hasta el nivel de distritos e incluso secciones, organizadas según código postal, dentro de la isla. Al tratarse de un primer estudio, el nivel se centrará en la escala municipal. En segundo lugar, se presenta un breve resumen de datos sobre el importe y evolución de las pensiones extraídos de los datos de pensiones publicados por el Instituto Nacional de la Seguridad Social -INSS-.

\subsubsection{Renta media por persona}

La renta media por persona se calcula con los datos suministrados por la Agencia Estatal de Administración Tributaria -AEAT- sobre los ingresos individuales, por hogar y unidad de consumo (ver metodología detallada aquí). A través de una serie de cálculos es posible detallar cuál es el valor medio en cada unidad territorial considerada, en este caso, el municipio. En Tenerife, la renta media por persona ascendía en 2017 a $9.230 €$ por persona y año, lo que supone un aumento del $7,71 \%$ con respecto a 2015 , año que alcanzaba los $8.569 €$. Tomando los datos por hogar, esa renta media alcanzaba en 2017 los $25.471 €$, con un aumento del 7,22\% respecto a 2015 .

Comparando los datos de Tenerife con el conjunto de España, la renta media por persona es un $23,57 \%$ menor que el promedio nacional $(11.211,28 €)$ y en 
cuanto al total por hogar la diferencia es menos acentuada, un 9,93\% menos, frente a la media de 28.281,93 €. La distribución de la renta tanto media como por hogar no es homogénea dentro de la isla. Como puede verse en la Figura 3.6., los municipios con mayor renta se concentran en la zona noreste de la isla, destacando El Rosario, Santa Cruz de Tenerife y Candelaria. Los municipios con menor renta media por persona son El Tanque, Santiago del Teide y la Victoria de Acentejo, cuya renta por persona no alcanza los $8.000 €$ de media.

Figura 3.6. Distribución de la renta $(€)$ por persona en la isla de Tenerife en 2017

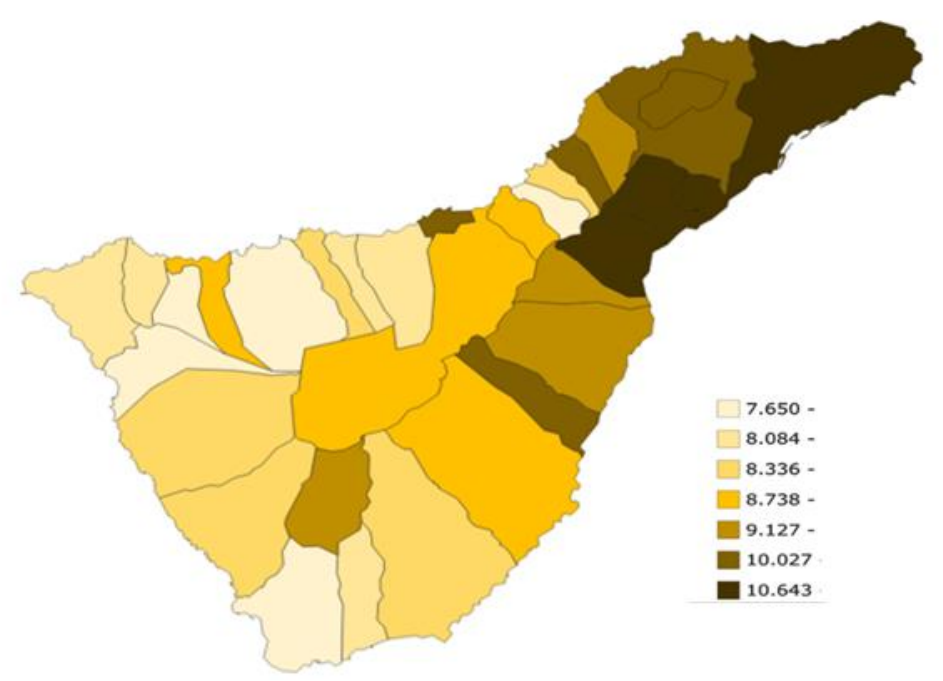

Fuente: Atlas de distribución de la Renta de los hogares (INE)

Nota: En la leyenda se indica el límite mínimo del intervalo.

En la Figura 3.6. destaca la situación de municipios donde se genera una gran parte de la riqueza fruto de la concentración turística como son Arona y Adeje, y que paradójicamente no muestran rentas medias por persona de las más altas de la isla. Ello podría señalar la presencia de un fuerte componente de economía sumergida que no recogen las estadísticas oficiales.

\subsubsection{Los ingresos por unidad de consumo de los mayores en Tenerife}

El ADRH que publica el INE permite acceder a datos por unidad de consumo², incluso desagregando por sexo y grupo de edad. A continuación, se analiza

\footnotetext{
2 En la metodología del INE se ha adaptado el tamaño de los hogares a unidades de consumo mediante la llamada escala de la OCDE modificada. En esta escala se asigna un peso de 1 al primer adulto de cada hogar, 0,5 a los demás adultos y un peso de 0,3 a los menores de 14 años. Por lo tanto, un hogar con dos adultos y dos niños menores
} 
la distribución de los ingresos en aquellos hogares donde la persona principal tiene 64 años o más, tanto en términos absolutos como en relación con la media general.

\subsubsection{1lngresos en términos absolutos}

La Tabla 3.9. presenta un resumen de datos disponibles en el INE sobre el nivel de ingresos por unidad de consumo de las personas de 64 y más años de la isla de Tenerife en función del sexo y con el umbral de $10.000 €$. Puesto que no todos los datos están disponibles para todos los municipios, se aportan datos para la isla, pero existe la posibilidad de que los datos por sexo se desvíen de la media, ya que es en la desagregación por sexo donde la falta de disponibilidad de registros es mayor.

Tabla 3.9. Porcentaje de personas de 64 años y más, por sexo, con ingresos menores de $10.000 €$ por unidad de consumo

\begin{tabular}{lccc}
\hline Ingresos por unidad de consumo & Mujeres & Hombres & Total \\
\hline Menos de $5.000 €$ & $7,4 \%$ & $7,3 \%$ & $7,0 \%$ \\
\hline Entre 5.000 y $7.500 €$ & $11,8 \%$ & $10.4 \%$ & $11,7 \%$ \\
\hline Entre 7.500 y $10.000 €$ & $18,6 \%$ & $14,4 \%$ & $18,4 \%$ \\
\hline Menos de $10.000 €$ & $37,8 \%$ & $32,1 \%$ & $37,1 \%$ \\
\hline
\end{tabular}

Fuente: Elaboración propia con datos del Atlas de Distribución de la Renta de los Hogares (INE).

Más de un tercio de las unidades de consumo con personas de 65 y más años tienen ingresos inferiores a $10.000 €$ anuales. Esta situación se agrava en los municipios de El Tanque $(50,8 \%)$, la Victoria de Acentejo $(49,1 \%)$, lcod de los Vinos $(45,7 \%)$ y Santiago del Teide $(45,4 \%)$. El Rosario $(25,7 \%)$, Tegueste $(26,5 \%)$, Santa Cruz de Tenerife $(28,3 \%)$ y San Juan de la Rambla $(28,6 \%)$ son los únicos municipios donde las unidades de consumo con ingresos inferiores a $10.000 €$ son inferiores al $30 \%$.

Por su parte, parece claro que la situación de bajos ingresos es mayor entre las mujeres en todos los intervalos considerados, con una diferencia mayor tomando como referencia la categoría total de menos de $10.000 €$.

\subsubsection{Ingresos en términos relativos}

A continuación, se muestra una segunda caracterización sobre los ingresos de la población de personas de 65 y más años de los municipios de la isla de Tenerife, en base a la mediana de ingresos de la isla. Para ello, entre las

de 14 años equivaldrían a 2,1 unidades de consumo y los ingresos totales del hogar se dividirán entre este cociente para obtener los ingresos por unidad de consumo. 
categorías que ofrece el ADRH del INE, se han considerado las dos categorías extremas: población con ingresos de consumo por debajo del $40 \%$ de la mediana y población con ingresos de consumo por encima del $200 \%$ de la mediana.

En el grupo de población por debajo del $40 \%$ de la mediana de ingresos de la isla, los resultados de la Tabla 3.10. destacan que, en el caso de unidades de consumo donde la persona principal tiene 65 y más años, ocupan las primeras posiciones municipios con gran impacto del turismo como Santiago del Teide, Adeje y Arona. Por su parte, Tegueste, los Silos y La Guancha son los tres únicos municipios cuyo porcentaje de población de 65 y más años que no alcanza el $40 \%$ de la mediana de ingresos se encuentra por debajo del $7 \%$.

Tabla 3.10. Distribución municipal de la población con ingresos por unidad de consumo por debajo del $40 \%$ de la mediana donde la persona principal tiene 65 o más años

\begin{tabular}{lc}
\hline & $\begin{array}{c}\text { Población con ingresos por unidad de } \\
\text { consumo por debajo 40\% de la mediana }\end{array}$ \\
\hline Santiago del Teide & 18,4 \\
\hline Adeje & 17,5 \\
\hline El Tanque & 16,9 \\
\hline San Miguel de Abona & 16,8 \\
\hline Arona & 15,4 \\
\hline Arico & 12,8 \\
\hline Icod de los Vinos & 12,2 \\
\hline Guía de Isora & 12,1 \\
\hline Granadilla de Abona & 12,0 \\
\hline Santa Úrsula & 12,0 \\
\hline Garachico & 11,4 \\
\hline Puerto de la Cruz & 10,8 \\
\hline Victoria de Acentejo, La & 9,6 \\
\hline Matanza de Acentejo, La & 9,2 \\
\hline Buenavista del Norte & 9,0 \\
\hline Güímar & 8,8 \\
\hline Rosario, El & 8,5 \\
\hline Candelaria & 8,4 \\
\hline Tacoronte & 8,2 \\
\hline Los Realejos & 8,1 \\
\hline Arafo & 7,9 \\
\hline Fasnia & 7,8 \\
\hline Santa Cruz de Tenerife & 7,8 \\
\hline La Laguna & 7,7 \\
\hline Orotava, La & 7,5 \\
\hline San Juan de la Rambla & 7,2 \\
\hline Sauzal, El & 7,1 \\
\hline Guancha, La & 6,8 \\
\hline Silos, Los & 6,2 \\
\hline Tegueste & 5,2 \\
\hline Fuente: Atlas de Distribución de la Renta de los Hogares (INE) \\
\hline
\end{tabular}


La Figura 3.7. muestra datos similares a los de la tabla 3.10. pero asignando colores en función del porcentaje de unidades de consumo con ingresos por debajo del $40 \%$ de la mediana donde la persona principal tiene 65 o más años. Aquellos municipios donde el porcentaje es mayor tienen un color más oscuro.

Figura 3.7. Distribución municipal de la población (\%) con ingresos por unidad de consumo por debajo del $40 \%$ de la mediana donde la persona principal tiene 65 o más años

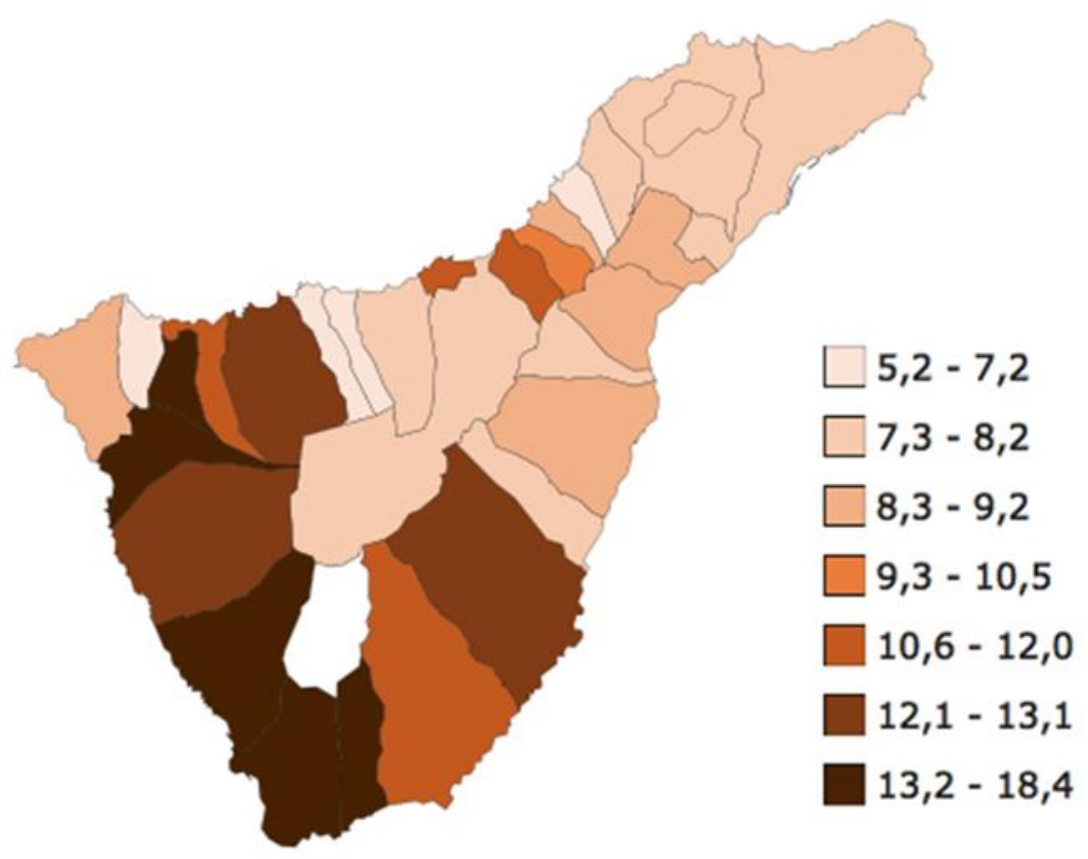

Fuente: Atlas de Distribución de la Renta de los Hogares (INE).

Por su parte, para la categoría superior, ingresos por unidad de consumo superior al $200 \%$ de la mediana, como se observa en la Tabla 3.11., son los municipios del área metropolitana más Puerto de la Cruz los que tienen un mayor porcentaje de población en el escalón alto de la renta. Por lo tanto, se repite el esquema que para el total poblacional se relataba al inicio de este epígrafe. 
Tabla 3.11. Distribución municipal de la población con ingresos por unidad de consumo por encima del $200 \%$ de la mediana donde la persona principal tiene 65 o más años.

\begin{tabular}{lr} 
& $\begin{array}{c}\text { Población con ingresos por unidad de consumo por } \\
\text { encima del 200\% de la mediana }\end{array}$ \\
\hline Santa Cruz de Tenerife & 16,5 \\
\hline Rosario, El & 14,7 \\
\hline Tegueste & 13,7 \\
\hline Puerto de la Cruz & 12,0 \\
\hline La Laguna & 11,5 \\
\hline Candelaria & 10,9 \\
\hline Sauzal, El & 10,2 \\
\hline Tacoronte & 10,0 \\
\hline Arafo & 9,7 \\
\hline Adeje & 9,0 \\
\hline Arona & 8,9 \\
\hline San Juan de la Rambla & 8,5 \\
\hline Santa Úrsula & 8,2 \\
\hline Fasnia & 7,8 \\
\hline Güímar & 7,5 \\
\hline Orotava, La & 7,5 \\
\hline San Miguel de Abona & 7,0 \\
\hline Granadilla de Abona & 6,7 \\
\hline Matanza de Acentejo, La & 6,1 \\
\hline Icod de los Vinos & 6,0 \\
\hline Garachico & 5,7 \\
\hline Santiago del Teide & 5,6 \\
\hline Guía de Isora & 5,2 \\
\hline Silos, Los & 4,8 \\
\hline Arico & 4,7 \\
\hline Realejos, Los & 4,2 \\
\hline Guancha, La & 3,9 \\
\hline Buenavista del Norte & 3,6 \\
\hline Victoria de Acentejo, La & 3,6 \\
\hline Tanque, El & 1,9 \\
\hline Fuente: Atlas de Distribución de la Renta de los hogares (INE) & \\
\hline & \\
\hline
\end{tabular}

Por su parte, los municipios de la isla baja más Arico y la Victoria concentran aquellos casos donde el porcentaje de población de 65 y más años en esta categoría no alcanza el 5\%.

Atendiendo a los datos analizados, en la distribución de la renta en el grupo de población de mayor edad parece existir una división este-oeste, con el primer eje concentrando la mayor riqueza en la isla. La división en función del sexo también muestra que sigue apreciándose una brecha desfavorable para las mujeres, que puede tener su origen en una menor cotización laboral que haga que las pensiones recibidas sean de menor importe. 


\subsubsection{Importe de las pensiones y evolución}

A continuación, se hará un breve repaso del importe y evolución de las pensiones, aportando datos para la isla de Tenerife, ya que los datos no han podido ser desagregados a nivel municipal.

Según datos del Instituto Nacional de la Seguridad Social en la provincia de Santa Cruz de Tenerife, a fecha de 1 de septiembre de 2020 había un total de 90.211 beneficiarios de pensiones de jubilación con un importe medio de $1.070,41 €$. Este total de beneficiarios supone un $57 \%$ del total de beneficiarios de pensiones y la cifra media es un $16,81 \%$ mayor del importe medio del total de pensiones del sistema.

Si extrapolamos el número de beneficiarios a la isla de Tenerife usando el porcentaje de personas mayores que viven en la isla sobre el total de la provincia $(85,96 \%)$ podría estimarse que hay un total de 77.545 personas que cobran una pensión de jubilación.

Si atendemos a la evolución del importe de las pensiones de jubilación en los últimos 15 años que puede verse en la Tabla 3.12., se aprecia una revalorización de un $61,41 \%$ en el total del período y una subida en términos monetarios de $398,59 €$.

Tabla 3.12. Evolución de la pensión media 2005 - 2019

\begin{tabular}{ccc}
\hline & & Jubilación \\
\cline { 2 - 3 } & Pensión media & Variación anual (\%) \\
\hline 2005 & 649,09 & 6,20 \\
\hline 2006 & 687,53 & 5,92 \\
\hline 2008 & 724,45 & 5,37 \\
\hline 2009 & 776,25 & 7,15 \\
\hline 2010 & 813,28 & 4,77 \\
\hline 2011 & 841,01 & 3,41 \\
\hline 2012 & 869,03 & 3,33 \\
\hline 2013 & 896,33 & 3,14 \\
\hline 2014 & 925,32 & 3,23 \\
\hline 2015 & 941,40 & 1,74 \\
\hline 2016 & 956,25 & 1,58 \\
\hline 2017 & 970,68 & 1,51 \\
\hline 2018 & 985,57 & 1,53 \\
\hline 2019 & $1.006,10$ & 2,08 \\
\hline Variación total & $1.047,68$ & 4,13 \\
\hline Fuente: Elaboración propia a partir de datos del Instituto Nacional de la Seguridad Social.
\end{tabular}

Se trata de una subida bastante por encima del aumento del IPC en el período considerado, lo que ha permitido ganar poder adquisitivo al grupo de 
pensionistas. Sin embargo, a pesar de la evolución favorable, el nivel de las pensiones en Canarias se encuentra por debajo del nivel medio estatal, que según datos nacionales se sitúa en los 1.139,83€. 
4.Recursos sociales municipales dirigidos a las

Personas Mayores 



\subsection{Introducción}

Este apartado del estudio tiene como finalidad describir las características de los principales recursos sociales que, desde el ámbito municipal, se prestan a las personas mayores. Se ha organizado en tres: subapartados: Servicios sociales municipales, Asociacionismo y Proyectos socioeducativos para personas mayores.

El trabajo correspondiente al primer subapartado ha estado guiado por la consecución de diferentes objetivos específicos, como son, en primer lugar, conocer cómo es la organización de las áreas o unidades municipales con competencias en los servicios sociales dirigidos a personas mayores, identificar con qué recursos humanos cuentan y conocer cuáles son los planes municipales dirigidos a las personas mayores. En segundo lugar, el objetivo ha sido recabar información sobre dos de los servicios de atención primaria que se gestionan desde el ámbito municipal, el servicio de teleasistencia y el servicio de ayuda a domicilio (SAD), los cuales, si bien no están destinados de manera exclusiva a la población mayor, es patente que gran parte de las personas usuarias son mayores. De forma específica, los objetivos han sido conocer si la prestación está externalizada, el número de personas usuarias de 65 y más años y su desagregación por sexos, así como la constitución de los equipos de trabajo en el caso del SAD. En tercer lugar, conocer los servicios sociales de atención especializada dirigidos a personas mayores, en concreto, los centros de día / estancia diurna y las viviendas tuteladas con las que cuenta el municipio.

El segundo subapartado, se dedica a explorar el alcance del tejido asociativo conformado por las personas mayores y, así mismo, conocer en qué medida esta participación de las personas mayores se refleja en una formalización institucional, a través de la constitución de Consejos de Mayores Municipales.

El tercer subapartado se ha dirigido a conocer el número y las principales características de los programas, proyectos y actividades socioeducativas que desde el ámbito municipal se dirigen a las personas mayores. Para ello, se han recabado datos como su nombre, descripción 
general, características sociodemográficas de las personas participantes y organización temporal, entre otros. De esta manera se ha pretendido establecer una fotografía general de las acciones que actualmente se están realizando a nivel municipal dirigidas a promover aspectos como la participación social, la salud, el desarrollo personal, la educación o el ocio entre las personas mayores. Por cuestiones de organización del documento, las fichas con la información detallada de las acciones socioeducativas, aportadas desde los municipios participantes, se incluyen en el Anexo 1.

\subsection{Metodología}

En este estudio han participado un total de 24 municipios de los 31 que conforman la isla de Tenerife. De forma mayoritaria, las y los profesionales que han aportado la información han sido trabajadoras sociales o concejalas del área competente en la intervención con personas mayores. En concreto, se ha contado con la participación de los municipios de Candelaria, San Juan de la Rambla, Arona, La Victoria de Acentejo, Guía de Isora, El Rosario, La Laguna, Tegueste, La Guancha, La Orotava, Icod de los Vinos, El Tanque, El Sauzal, Arafo, Los Silos, Garachico, Santa Úrsula, Vilaflor de Chasna, Santa Cruz de Tenerife, Tacoronte, Santiago del Teide, La Matanza, Fasnia y Los Realejos.

Respecto al instrumento utilizado, se ha elaborado un cuestionario ad hoc (ver Anexo 2) conformado por un primer apartado que recoge los datos del/a profesional de referencia en la intervención con personas mayores, seguido de dos grandes apartados destinados a recoger información sobre los servicios sociales municipales dirigidos a personas mayores y sobre los proyectos socioeducativos implementados desde este ámbito.

En cuanto al procedimiento llevado a cabo para realizar la recogida de datos, en una primera fase se recopiló la información a incluir en el estudio; a continuación, se elaboró el instrumento y se preparó una carta de presentación; en tercer lugar, se remitió esta carta a las direcciones de correo electrónico de las Concejalías competentes en cada uno de los municipios y, posteriormente, se contactó con las/os concejalas/es y/o 
las y los profesionales (mayoritariamente trabajadoras/es sociales) para solicitar la cumplimentación del cuestionario, el cual se remitió tanto en formato online (Google formulario) como en formato editable. En los casos necesarios, se realizó un seguimiento a través del correo electrónico y de manera telefónica. Este seguimiento se llevó a cabo en repetidas ocasiones, hasta la fecha establecida para cerrar la recogida de datos y dar cumplimiento a los plazos establecidos. Una vez finalizado el trabajo de campo, se procedió a organizar y analizar la información obtenida, lo cual llevó al establecimiento de los resultados de carácter descriptivo, que a continuación se presentan.

\subsection{Servicios Sociales municipales dirigidos a Personas Mayores}

\subsubsection{Organización municipal}

De los 24 municipios que han participado en este estudio, es ligeramente mayor el número de ellos que cuenta con una unidad o área específica dedicada a la intervención con personas mayores $(54,2 \%)$, con respecto a los que no cuentan con esta área específica $(45,8 \%)$. En concreto, los municipios que cuentan con esta unidad son Candelaria, Arona, Guía de Isora, La Laguna, Tegueste, La Guancha, La Orotava, El Tanque, Los Silos, Vilaflor, Santa Cruz de Tenerife, Santiago del Teide y La Matanza. En cambio, aquellos que no disponen de área específica de intervención con personas mayores son San Juan de la Rambla, La Victoria de Acentejo, El Rosario, Icod de los Vinos, El Sauzal, Arafo, Garachico, Santa Úrsula, Tacoronte, Fasnia y Los Realejos.

Respecto a la composición de los equipos profesionales de la unidad o área específica de mayores, en todos los casos está presente la figura del/a trabajador/a social, contando los municipios de mayor población, así como otros más pequeños, con más de un/a técnico de este perfil profesional (Santa Cruz de Tenerife, La Laguna, La Orotava, Candelaria, Guía de Isora). Otras figuras profesionales presentes en algunos de los municipios son las de fisioterapeuta, logopeda, animador/a sociocultural, 
educador/a social, psicólogo/a, auxiliar administrativo o monitor/a deportivo.

Atendiendo a la planificación sectorial y específica de servicios sociales en el área de mayores, se observa una variedad en la denominación de los instrumentos propios de la planificación. Algunos de los municipios cuentan o han contado en los últimos años con Planes municipales dirigidos a las personas mayores. Es el caso del I Plan Estratégico Municipal para Personas Mayores de Santa Cruz de Tenerife (2011-2014) y el II Plan Municipal para Personas Mayores de Santa Cruz de Tenerife (2017-2021). También se menciona el Plan de Intervención con Mayores, con temporalidad de un año, en La Orotava.

Otros municipios hacen referencia a programas o proyectos específicos dirigidos a la intervención en situaciones de soledad no deseada, como el Programa de acompañamiento a personas mayores en situación de soledad no voluntaria, con temporalidad de dos años (Arona); el Programa de acompañamiento en la soledad (Tegueste); o el Proyecto de acompañamiento a las personas mayores en soledad, durante el 2018 (Guía de Isora). En el ayuntamiento de Los Realejos están trabajando en un proyecto sobre Mayores en soledad.

Por otro lado, también se mencionan programas y proyectos centrados en el envejecimiento activo y la promoción de la salud, como el Programa Movimiento y Salud (Arafo); Programa de Envejecimiento Activo y Programa de Estimulación Cognitiva (Santa Úrsula); Proyecto Guata de intervención profesional en Trabajo Social, Fisioterapia o voluntariado (Santa Úrsula).

Otro grupo de programas y proyectos hacen referencia al ocio, como el Programa de ocio y tiempo libre dirigido a mayores (Guía de Isora); Proyecto "La Laguna cuida", farma-escuela, huerto comunitario (La Laguna).

Por su parte, se advierte la mención de Programas consistentes en ayudas económicas, como el Programa de ayudas económicas para mayores, con convocatoria anual (La Laguna); Programa de subvenciones para asociaciones de mayores (La Laguna), Programa de subvenciones a cuatro centros residenciales de personas mayores (La Laguna); 
Subvenciones para el folklore dirigido a las asociaciones de personas mayores (La Guancha), Ayudas individuales dirigidas a personas mayores (La Guancha), o Apoyo a los Club de mayores (Santa Úrsula).

Tras la organización de los datos hemos advertido, también, que desde el ámbito municipal se han llevado a cabo proyectos específicos, como el Programa candidatura con diagnóstico y plan de acción de "La Laguna, ciudad amigable con las personas mayores" (La Laguna). Y, en el caso de Vilaflor, se hace referencia a los planes y programas propios de la Concejalía de Tercera Edad, como participación social, intervenciones profesionales o actividades de ocio y tiempo libre.

Se hace necesario señalar respecto a este apartado de planificación de los recursos municipales que, el hecho de que un ayuntamiento no los haya mencionado (p.e. programas de subvenciones económicas) no necesariamente significa que no dispongan de los mismos.

\subsubsection{El Servicio de Teleasistencia}

El servicio de teleasistencia facilita que la persona mayor continúe residiendo en su propio hogar, proporcionando condiciones de mayor seguridad y tranquilidad para la propia persona, ya que permite asegurar una atención profesional especializada ante situaciones de emergencia, así como ante situaciones en las que se perciba inseguridad, soledad $u$ otros sentimientos de malestar emocional. Consiste en un dispositivo (pulsera, colgador) conectado a la línea telefónica, el cual la persona puede pulsar si se encuentra en una de las situaciones mencionadas. Ello hará posible la atención profesional necesaria y la movilización de los recursos específicos para atender la demanda.

En términos generales, está dirigido a la población mayor que pueda encontrarse en situación de riesgo (también a personas que por razón de discapacidad u otra circunstancia se encuentren en esta situación), que vivan solas o convivan con personas con similares características, que no padezcan enfermedad o trastorno que pueda dificultar la respuesta requerida ante situaciones de crisis, que dispongan de línea telefónica y que cuenten con personas de su círculo de relación con teléfono y llave de la vivienda. 
Según el informe Servicios Sociales dirigidos a las personas mayores en España en 20183, realizado por el Imserso, en la Comunidad Autónoma de Canarias el servicio de teleasistencia atendió, en el año 2018, a 6.420 personas, lo cual supone un índice de cobertura de 1,89 respecto al total de la población mayor residente en las islas. Representa el segundo índice más bajo de todo el territorio español, solo por delante de Extremadura. El índice de cobertura nacional se encuentra, en el año 2018, en el 10,4. Siguiendo el citado informe, en la Comunidad Autónoma de Canarias el $75 \%$ de las personas usuarias mayores tenían entre 65 y 79 años, mientras que el $25 \%$ restante eran personas con 80 y más años. Este dato resulta llamativo al compararlo con el resto de las Comunidades Autónomas, en las que la distribución por grupos de edad prácticamente se invierte, atendiendo a una mayor proporción de usuarios mayores de 80 años (salvo en Cataluña y Valencia, donde la distribución es prácticamente equitativa). En ambos grupos de edad, es mayoritario el número de mujeres usuarias ( $73 \%$ en el primer grupo de edad y $80 \%$ en el segundo grupo), como corresponde a la mayor esperanza de vida de las mujeres respecto a la de los hombres.

Siguiendo el citado estudio, el precio del servicio en Canarias, al contrario de lo observado respecto al índice de cobertura, es el más alto de España (260 euros al año por usuario/a), si bien la aportación promedio del usuario/a respecto al precio total del servicio es la séptima más baja, con un promedio del $8,3 \%(21,72 €)$ respecto al total del costo (en las seis primeras CCAA, la aportación es del 0\%).

En cuanto a los datos recabados en este trabajo respecto al servicio de teleasistencia prestado en los diferentes municipios de Tenerife, de los 24 municipios participantes, dos de ellos no cuentan o no han proporcionado información sobre este servicio (San Juan de la Rambla y El Tanque). De los 22 restantes, sólo en siete es gestionado de forma directa por el Ayuntamiento (Candelaria, La Victoria de Acentejo, Guía de Isora, Garachico, Santa Úrsula, Tacoronte y La Matanza); en 14 municipios es gestionado por una ONG (Arona, El Rosario, Tegueste, La Guancha, lcod de los Vinos, El Sauzal, La Orotava, Arafo, Los Silos, Vilaflor,

\footnotetext{
3 IMSERSO (2018). Servicios Sociales dirigidos a las Personas Mayores en España. Ministerio de Sanidad, Consumo y Bienestar Social.
} 
Santa Cruz de Tenerife, Santiago del Teide, Fasnia y Los Realejos). En todas estas localidades la ONG que presta el servicio es Cruz Roja Española. Por último, solo en el caso del Ayuntamiento de La Laguna el servicio es gestionado por una empresa (Grupo CLECE, S.A.).

A continuación, se muestran en la Tabla 4.1., datos sobre el número de personas mayores usuarias de la teleasistencia, a partir de la información proporcionada desde los respectivos ayuntamientos. Asimismo, se proporciona un dato orientativo del índice de cobertura que presenta este servicio en cada municipio.

Tabla 4.1. Servicio de teleasistencia en los municipios de Tenerife

\begin{tabular}{|c|c|c|c|c|}
\hline Municipios & $\begin{array}{c}\text { Personas usuarias } \\
\geq 65 \text { años }\end{array}$ & Usuarias mujeres & Usuarios varones & $\begin{array}{c}\text { Índice de } \\
\text { cobertura* }\end{array}$ \\
\hline \multicolumn{5}{|l|}{ Adeje } \\
\hline Arafo & 10 & 9 & 1 & 1,00 \\
\hline \multicolumn{5}{|l|}{ Arico } \\
\hline Arona & 60 & 49 & 11 & 0,64 \\
\hline \multicolumn{5}{|l|}{ Buenavista del Norte } \\
\hline Candelaria** & - & - & - & - \\
\hline Fasnia & 9 & 8 & 1 & 1,37 \\
\hline Garachico & 22 & 15 & 7 & 1,92 \\
\hline \multicolumn{5}{|l|}{ Granadilla de Abona } \\
\hline Guancha (La)** & - & - & - & - \\
\hline Guía de Isora & 26 & 23 & 3 & 0,82 \\
\hline \multicolumn{5}{|l|}{ Güímar } \\
\hline Icod de Los Vinos & 54 & 49 & 5 & 1,14 \\
\hline Laguna (La) & 338 & 296 & 59 & 1,34 \\
\hline Matanza Acentejo (La)** & - & - & - & - \\
\hline Orotava (La) & 56 & 48 & 8 & 0,79 \\
\hline \multicolumn{5}{|l|}{ Puerto de La Cruz } \\
\hline Realejos (Los)** & - & - & - & - \\
\hline Rosario (EI) & 8 & 8 & 0 & 0,33 \\
\hline San Juan de La Rambla** & - & - & - & - \\
\hline \multicolumn{5}{|l|}{ San Miguel } \\
\hline Santa Cruz de Tenerife & 286 & 250 & 36 & 0,73 \\
\hline Santa Úrsula & 28 & 26 & 2 & 1,32 \\
\hline Santiago del Teide & 8 & - & - & 0,38 \\
\hline Sauzal (El) & 5 & 5 & 0 & 0,35 \\
\hline Silos (Los) & 5 & 3 & 2 & 0,43 \\
\hline Tacoronte & 26 & - & - & 0,67 \\
\hline Tanque $(E I) * *$ & - & - & - & - \\
\hline Tegueste & 15 & 11 & 4 & 0,80 \\
\hline Victoria Acentejo (La) & 10 & 7 & 3 & 0,64 \\
\hline Vilaflor & 12 & 8 & 4 & 3,22 \\
\hline \multicolumn{5}{|c|}{$\begin{array}{l}\text { Fuente: Elaboración propia, con datos proporcionados por las responsables de los Servicios Sociales Municipales. } \\
\text { Nota: *Índice de cobertura: Personas usuarias / Población } \geq 65 \text { años * } 100 \text { (total de la población } \geq 65 \text { años a } 1 \text { de enero de } 2019 \text {, } \\
\text { a partir de datos del ISTAC). El dato de personas usuarias es el proporcionado por los municipios. Este índice de cobertura es } \\
\text { aproximado, ya que la diferencia temporal entre ambos datos puede modificar sensiblemente el resultado obtenido y en algunos } \\
\text { casos los municipios pueden haber proporcionado datos de usuarios totales. } \\
\text { **Municipios que han participado en el estudio, pero no han proporcionado datos sobre el servicio de teleasistencia, bien } \\
\text { porque no disponían de esta información o bien porque no ofrecen este servicio. }\end{array}$} \\
\hline
\end{tabular}


Como se observa en la Tabla 4.1., los municipios que tienen un mayor número de usuarios de la teleasistencia municipal son La Laguna, en primer lugar, y a continuación Santa Cruz de Tenerife. En este sentido, se puede observar que la relación entre ambos datos (población mayor y población usuaria) no es en todos los casos proporcional. Así, el índice de cobertura aproximado más alto se sitúa en el municipio de Vilaflor, seguido de Garachico y, a continuación, La Laguna, Fasnia y Santa Úrsula; mientras que el más bajo está en el municipio de El Rosario, seguido de El Sauzal, Santiago del Teide y Los Silos. En todos los municipios es mayor el número de usuarias mujeres, en comparación con el de varones.

\subsubsection{El servicio de ayuda a domicilio}

Según el artículo 23 de la Ley 39/2006, el servicio de ayuda a domicilio lo constituye el conjunto de actuaciones llevadas a cabo en el domicilio de las personas en situación de dependencia con el fin de atender sus necesidades de la vida diaria, prestadas por entidades o empresas, acreditadas para esta función. Responde a la lógica de poder cubrir las necesidades de las personas en sus entornos naturales. Se prestan dos tipos de servicios:

a) Servicios relacionados con la atención de las necesidades domésticas o del hogar: limpieza, lavado, cocina u otros.

b) Servicios relacionados con la atención personal en la realización de las actividades de la vida diaria. En este apartado encontramos, entre otros, el apoyo en el aseo personal, en el control de la medicación, y en el acompañamiento dentro y fuera del hogar.

Además, se puede proporcionar atención de carácter socioeducativo, centrada en la promoción de habilidades y hábitos de vida saludable.

Siguiendo el informe ya citado Servicios Sociales dirigidos a las personas mayores en España (Imserso, 2018), el servicio de ayuda a domicilio atendió en Canarias a 14.061 personas, lo cual supone un índice de cobertura del 4,13, respecto al total de la población mayor de 65 años. Las islas se sitúan de nuevo, respecto a este servicio, por debajo del índice de cobertura nacional (4,99), aunque en este caso Canarias, es la décima Comunidad Autónoma con mayor índice de cobertura. También 
respecto a este servicio, en nuestro archipiélago es mayoritaria la población beneficiaria entre los 65 y 79 años $170 \%$, frente al $30 \%$ de usuarios/as de 80 y más años) y, en ambos grupos de edad, predominan las usuarias mujeres $(77 \%$ y $83 \%$ respectivamente). Nuevamente es destacable como esta proporción de personas usuarias entre los 65 y 79 años en nuestra Comunidad Autónoma sea la mayor de todo el territorio nacional, ya que en la mayoría de las comunidades autónomas predominan las/os usuarias/os mayores de 80 años.

En relación con la intensidad horaria de prestación del servicio, Canarias es la cuarta comunidad autónoma (junto con la ciudad autónoma de Melilla) en la que más horas se presta este servicio al mes (media ponderada de 24 horas mensuales por persona usuaria). Sin embargo, atendiendo a la distribución de las tareas (y señalando que no se cuenta con los datos de tres comunidades autónomas), nuestra comunidad autónoma es en la que más tiempo se dedica a las tareas domésticas, con un $60 \%$ del total del tiempo, frente a un $30 \%$ dedicado a los cuidados y un $10 \%$ a otras tareas.

Respecto al precio del servicio, Canarias es la quinta con un precio público más bajo de hora por persona usuaria (13€). No se presentan datos de la aportación promedio del usuario/a.

En cuanto a los resultados obtenidos en la elaboración de este estudio, todos los municipios de la isla de Tenerife participantes (24) prestan el servicio de ayuda a domicilio. En la mayoría de los casos - 19 municipiosel servicio es gestionado de forma directa por el ayuntamiento (San Juan de la Rambla, Arona, La Victoria, El Rosario, La Guancha, El Tanque, El Sauzal, Los Silos, Garachico, Santa Úrsula, Vilaflor, Santiago del Teide, La Matanza y Fasnia), si bien en cinco de ellos hay un apoyo complementario de una empresa, que no supone la externalización (Candelaria, Guía de Isora, La Laguna, La Orotava y Los Realejos). En los dos primeros casos se trata de una empresa de inserción municipal; y de las empresas privadas ServiSar, Clece y Lirecan en los tres últimos. En los otros cinco municipios (Arafo, Tegueste, Icod de los Vinos, Santa Cruz de Tenerife y Tacoronte), el servicio es gestionado por una empresa privada (Formas Nivaria en los dos primeros casos; Sadaliar, Clece y Eulen en los tres restantes respectivamente). 
Tabla 4.2. Servicio de ayuda a domicilio en los municipios de Tenerife

\begin{tabular}{|c|c|c|c|c|}
\hline Municipios & $\begin{array}{c}\text { Personas usuarias } \\
\geq 65 \text { años }\end{array}$ & Usuarias mujeres & Usuarios varones & $\begin{array}{c}\text { Índice de } \\
\text { cobertura* }\end{array}$ \\
\hline \multicolumn{5}{|l|}{ Adeje } \\
\hline Arafo & 63 & 51 & 12 & 6,31 \\
\hline \multicolumn{5}{|l|}{ Arico } \\
\hline Arona & 115 & 68 & 47 & 1,22 \\
\hline \multicolumn{5}{|l|}{ Buenavista del Norte } \\
\hline Candelaria & 98 & 77 & 21 & 2,25 \\
\hline Fasnia & 11 & 6 & 5 & 1,68 \\
\hline Garachico & 39 & 21 & 16 & 3,40 \\
\hline \multicolumn{5}{|l|}{ Granadilla de Abona } \\
\hline Guancha (La) & 34 & 23 & 11 & 2,88 \\
\hline Guía de Isora & 75 & 43 & 32 & 2,36 \\
\hline \multicolumn{5}{|l|}{ Güímar } \\
\hline Icod de Los Vinos & 55 & 39 & 16 & 1,16 \\
\hline Laguna (La)** & 1.058 & 928 & 247 & 4,18 \\
\hline Matanza Acentejo (La) & - & - & - & - \\
\hline Orotava (La) & 155 & 106 & 49 & 2,20 \\
\hline \multicolumn{5}{|l|}{ Puerto de La Cruz } \\
\hline Realejos (Los) & - & - & - & - \\
\hline Rosario (EI) & 30 & 22 & 8 & 1,25 \\
\hline San Juan de La Rambla & 23 & 15 & 8 & 2,38 \\
\hline \multicolumn{5}{|l|}{ San Miguel } \\
\hline Santa Cruz de Tenerife & 1.438 & 1.176 & 262 & 3,68 \\
\hline Santa Úrsula & 70 & 47 & 23 & 3,29 \\
\hline Santiago del Teide & 43 & 29 & 14 & 2,06 \\
\hline Sauzal (EI) & 50 & 38 & 12 & 3,54 \\
\hline Silos (Los) $* * *$ & 25 & 15 & 10 & 2,16 \\
\hline Tacoronte & 92 & 59 & 33 & 2,38 \\
\hline Tanque (EI) & 17 & 14 & 3 & 3,10 \\
\hline Tegueste & 35 & 22 & 13 & 1,86 \\
\hline Victoria Acentejo (La) & 72 & 42 & 30 & 4,62 \\
\hline Vilaflor & 30 & 22 & 8 & 8,04 \\
\hline \multicolumn{5}{|c|}{$\begin{array}{l}\text { Fuente: Elaboración propia, con datos proporcionados por las responsables de los Servicios Sociales Municipales. } \\
\text { Nota: } * \text { Índice de cobertura: Personas usuarias / Población } \geq 65 \text { años * } 100 \text { (total de la población } \geq 65 \text { años a } 1 \text { de enero de } 2019 \text {, } \\
\text { a partir de datos del ISTAC. El dato de personas usuarias es el proporcionado por los municipios. Este índice de cobertura es } \\
\text { aproximado, ya que la diferencia temporal entre ambos datos puede modificar sensiblemente el resultado obtenido y en algunos } \\
\text { casos los municipios pueden haber proporcionado datos de usuarios totales o aproximados. }\end{array}$} \\
\hline
\end{tabular}

Como se muestra en la Tabla 4.2., en este caso es el municipio de Santa Cruz de Tenerife el que tiene un mayor número de personas usuarias, seguido de La Laguna. Los índices aproximados de cobertura son, en todos los casos, mayores que los obtenidos respecto al servicio de teleasistencia. El más alto vuelve a situarse en el municipio de Vilaflor, seguido de Arafo. También en este caso es mayor en todos los municipios el número de usuarias mujeres respecto al de varones, aunque en algunas localidades la diferencia es reducida, como en el municipio de Garachico o Los Silos. 
En cuanto al perfil de las trabajadoras/es que conforman el SAD en los diferentes municipios, en la Tabla 4.3., se aportan datos sobre el número de auxiliares mujeres y varones, así como el perfil profesional del resto del equipo de trabajo asignado al SAD.

Tabla 4.3. Profesionales adscritos al SAD en los municipios de Tenerife

\begin{tabular}{|c|c|c|c|}
\hline Municipios & $\begin{array}{c}\text { № auxiliares } \\
\text { mujeres }\end{array}$ & $\begin{array}{c}\text { № auxiliares } \\
\text { varones }\end{array}$ & Otras/os profesionales \\
\hline \multicolumn{4}{|l|}{ Adeje } \\
\hline Arafo & 5 & 1 & - \\
\hline \multicolumn{4}{|l|}{ Arico } \\
\hline Arona & 17 & 1 & - \\
\hline \multicolumn{4}{|l|}{ Buenavista del Norte } \\
\hline Candelaria & 23 & 0 & Coordinadora, Trabajador/a social y administrativo \\
\hline Fasnia & 2 & - & - \\
\hline Garachico & - & 5 & Trabajadora social \\
\hline \multicolumn{4}{|l|}{ Granadilla de Abona } \\
\hline Guancha (La) & 7 & 0 & Trabajadora social \\
\hline Guía de Isora & 8 & 0 & Trabajadoras sociales \\
\hline \multicolumn{4}{|l|}{ Güímar } \\
\hline Icod de Los Vinos & 7 & 1 & - \\
\hline Laguna $(\text { La) })^{* *}$ & 183 & 14 & Educadora social y aux. administrativo \\
\hline \multicolumn{4}{|l|}{ Matanza Acentejo (La) } \\
\hline Orotava (La) & 18 & 0 & Trabajadora social \\
\hline \multicolumn{4}{|l|}{ Puerto de La Cruz } \\
\hline Realejos (Los)* & - & - & - \\
\hline Rosario (El) & 6 & 0 & Trabajadora social \\
\hline San Juan de La Rambla & 5 & 1 & - \\
\hline \multicolumn{4}{|l|}{ San Miguel } \\
\hline Santa Cruz de Tenerife & 285 & 8 & 9 trabajadoras sociales \\
\hline Santa Úrsula & 9 & 0 & Trabajadora social \\
\hline Santiago del Teide & 8 & 0 & - \\
\hline Sauzal (EI) & 10 & 0 & Trabajadora social \\
\hline Silos (Los) & 3 & 0 & - \\
\hline Tacoronte & 14 & 0 & Trabajadora social y coordinadora \\
\hline Tanque (EI) & 2 & 0 & - \\
\hline Tegueste & 7 & 2 & Trabajadora social \\
\hline Victoria Acentejo (La) & 7 & 0 & - \\
\hline Vilaflor & 4 & 0 & 2 trabajadoras sociales \\
\hline
\end{tabular}

Tal y como se observa en la Tabla 4.3., la asistencia en la ayuda a domicilio es una profesión altamente feminizada, tal y como en general se observa en los trabajos (remunerados o no) relacionados con el cuidado de otras personas. En todos los municipios participantes (excepto en Garachico) es mayor el número de mujeres auxiliares que el de varones. En los municipios en los que el volumen en que se presta este servicio es mayor, como Santa Cruz de Tenerife y La Laguna, esta diferencia entre las mujeres y varones auxiliares resulta especialmente 
llamativa. Por su parte, en cuanto a otras profesiones incluidas en este servicio, destaca de manera mayoritaria la de Trabajo Social (también altamente feminizada), desde la que se realizan tareas como la gestión del servicio, selección de usuarios/as, planificación del tipo de intervención y seguimiento.

\subsubsection{Centros de día/estancia diurna}

Atendiendo al informe Servicios Sociales dirigidos a las personas mayores en España (Imserso, 2018) los centros de mayores ofrecen servicios diurnos no residenciales dirigidos a la integración social, a través de la realización de actividades que fomentan la participación social y la integración de las personas mayores en su entorno social. Por su parte, los centros de día son centros no residenciales que ofrecen una atención integral de carácter psicosocial a personas mayores, con el fin de mejorar su nivel de autonomía, de manera que se prolongue en lo posible la permanencia de las personas en su entorno habitual de residencia. Favorecen además el apoyo a los familiares que prestan cuidados a estas personas mayores.

En cambio, desde nuestra Comunidad Autónoma (información publicada en su web) se definen los centros de día como aquellos que prestan servicios de promoción e inserción social, actuando desde el ámbito de los servicios comunitarios y dirigidos al fomento de la participación personal y de grupo. Por su parte, se entiende por centros de estancia diurna aquellos en los que se presta atención integral durante el día a las personas mayores que presenten carencias, tanto en la situación psicofísica como social, con el fin de mantener o mejorar su nivel de autonomía mientras continúan residiendo en su entorno habitual.

Para el desarrollo del presente trabajo se ha abordado la recogida de información sobre los centros de día y de estancia diurna de manera conjunta, preguntando por el número y la titularidad de los existentes en el municipio. No se han contabilizado las plazas de estancia diurna que ofertan las residencias. 
Tabla 4.4. Centros de día / estancia diurna en los municipios de Tenerife

\begin{tabular}{|c|c|c|}
\hline Municipios & $\begin{array}{c}\text { Centros día / } \\
\text { Estancia diurna }\end{array}$ & Titularidad \\
\hline \multicolumn{3}{|l|}{ Adeje } \\
\hline \multicolumn{3}{|l|}{ Arico } \\
\hline Arona & 1 & Pública \\
\hline Fasnia & 2 & Infraestructura pública, gestión ONG / privada \\
\hline Garachico & 1 & Pública \\
\hline \multicolumn{3}{|l|}{ Granadilla de Abona } \\
\hline Guancha (La) & 0 & - \\
\hline Laguna (La) & 1 & Infraestructura pública, gestión privada \\
\hline Matanza de Acentejo (La) & 1 & Privada \\
\hline Orotava (La) & 1 & Privada \\
\hline \multicolumn{3}{|l|}{ Puerto de La Cruz } \\
\hline Realejos (Los) & 1 & Privada \\
\hline Rosario (EI) & 1 & Infraestructura pública, gestión ONG (personas con demencia) \\
\hline San Juan de La Rambla & 1 & Privada \\
\hline \multicolumn{3}{|l|}{ San Miguel } \\
\hline Santa Cruz de Tenerife* & 10 & Pública (2), ONG (6), privada (2) \\
\hline Tegueste & 1 & Pública \\
\hline Victoria de Acentejo (La) & 1 & Pública \\
\hline Vilaflor & 0 & - \\
\hline
\end{tabular}

Como se observa en la Tabla 4.4. Santa Cruz de Tenerife es el municipio que cuenta con un mayor número de centros de día / estancia diurna, con un total de 10. El resto de los municipios oscilan entre los tres centros y no contar con ninguno. Por su parte, es mayoritaria la gestión pública, seguida de las ONG y, en tercer lugar, la gestión privada.

\subsubsection{Viviendas para mayores}

Las viviendas tuteladas 0 , denominación por la que nos decantamos, viviendas para mayores, son servicios de atención residencial que se caracterizan por dar cobertura a pocos usuarios y estar dirigidas a personas mayores con alto grado de autonomía. Ofrecen una alternativa a las residencias con un alto número de plazas, permitiendo a las 
personas mayores continuar residiendo en su entorno habitual disfrutando de una alta independencia. Se prestan a través de los servicios sociales, bien sea mediante la gestión pública o privada.

La implantación de este tipo de viviendas, tanto en el ámbito nacional como en nuestra Comunidad Autónoma, es escasa. Según el informe Servicios Sociales dirigidos a las personas mayores en España (Imserso, 2018), había en Canarias 4 viviendas para mayores que ofrecían 27 plazas, lo cual supone un índice de cobertura del $0,01 \%$ de las personas de 65 y más años. La media del índice de cobertura nacional se encuentra en 0,11 . En este caso, cabe destacar que hay comunidades autónomas que no disponen de ninguna vivienda para mayores. Por el contrario, destacan comunidades autónomas como Navarra o País Vasco, que son las que ostentan un mayor índice de cobertura $(0,70$ y 0,57 respectivamente).

Volviendo a nuestra Comunidad Autónoma, según el citado informe, el promedio de plazas por vivienda es de 6,8 personas, por debajo de la media nacional, que se sitúa en 13,2 plazas. Las cuatro viviendas se distribuyen de manera equitativa entre la titularidad pública y privada. No se da a conocer dónde se ubican estas viviendas.

Los datos recogidos en este trabajo han permitido conocer la existencia de dos viviendas para mayores, en los municipios de El Sauzal y de Guía de Isora, esta última con dos plazas.

\subsection{Asociacionismo}

A continuación, se presentan los resultados sobre las características del tejido asociativo entre las personas mayores en los diferentes municipios. En concreto, se ha consultado el número de asociaciones de personas mayores y el número de hogares o clubs de la tercera edad, los cuales generalmente presentan un funcionamiento gestionado de manera más directa por las propias asociaciones. Los resultados se muestran en la Tabla 4.5. Se debe mencionar que en algunos municipios se ha replicado el dato respecto a asociaciones y a hogares o clubs de mayores, por lo que es posible que se esté haciendo referencia a las mismas entidades. 
Tabla 4.5. Asociaciones y Hogares / Clubs de mayores en los municipios de Tenerife

\begin{tabular}{|c|c|c|}
\hline Municipios & $\begin{array}{l}\text { Asociaciones de } \\
\text { personas mayores }\end{array}$ & $\begin{array}{l}\text { Hogares / Clubs de } \\
\text { personas mayores }\end{array}$ \\
\hline \multicolumn{3}{|l|}{ Adeje } \\
\hline Arafo & 1 & - \\
\hline \multicolumn{3}{|l|}{ Arico } \\
\hline Arona & 11 & 11 \\
\hline \multicolumn{3}{|l|}{ Buenavista del Norte } \\
\hline Candelaria & 1 & 1 \\
\hline Fasnia & 1 & 1 \\
\hline Garachico & 2 & 2 \\
\hline \multicolumn{3}{|l|}{ Granadilla de Abona } \\
\hline Guancha (La) & 3 & - \\
\hline Guía de Isora & 5 & 1 \\
\hline \multicolumn{3}{|l|}{ Güímar } \\
\hline Icod de Los Vinos & 3 & 1 \\
\hline Laguna (La)* & 35 & 1 \\
\hline Matanza de Acentejo (La) & - & - \\
\hline Orotava (La) & 13 & 13 \\
\hline \multicolumn{3}{|l|}{ Puerto de La Cruz } \\
\hline Realejos (Los) & 10 & 1 \\
\hline Rosario (EI) & 0 & 1 \\
\hline San Juan de La Rambla & - & - \\
\hline \multicolumn{3}{|l|}{ San Miguel } \\
\hline Santa Cruz de Tenerife** & 45 & 2 \\
\hline Santa Úrsula & - & 3 \\
\hline Santiago del Teide & 5 & 5 \\
\hline Sauzal (El) & 2 & - \\
\hline Silos (Los) & 2 & - \\
\hline Tacoronte & - & - \\
\hline Tanque (EI) & 1 & 1 \\
\hline Tegueste & 1 & 1 \\
\hline Victoria de Acentejo (La) & 1 & - \\
\hline Vilaflor & 2 & - \\
\hline \multicolumn{3}{|c|}{$\begin{array}{l}\text { Fuente: Elaboración propia, con datos proporcionados por las responsables de los Servicios } \\
\text { Sociales Municipales. }\end{array}$} \\
\hline
\end{tabular}

Como se observa en la Tabla 4.5., Santa Cruz de Tenerife y La Laguna son los municipios que cuentan con un mayor número de asociaciones de mayores (45 y 35, respectivamente), muy por encima del resto de municipios. En cambio, hay localidades que no reportan ninguna asociación, como San Juan de la Rambla, Tacoronte y Santa Úrsula (que sí cuenta con tres hogares / clubs de mayores).

Respecto a la formalización institucional de la participación de las personas mayores en los aspectos que les afectan dentro de su localidad de residencia, se ha consultado el número de municipios que cuentan 
con un Consejo Municipal de Mayores. Los resultados se recogen en la Figura 4.1.

Figura 4.1. Porcentaje de municipios que cuentan con Consejo de Mayores

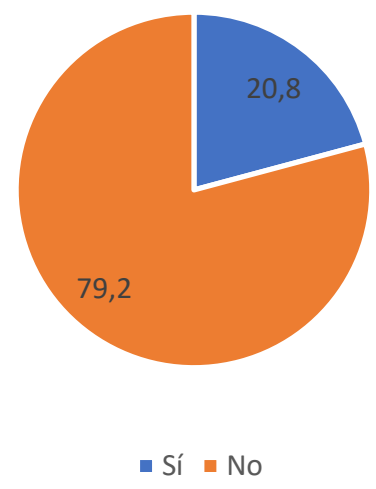

Fuente: Elaboración propia, con datos proporcionados por las responsables de los Servicios Sociales Municipales.

De los 24 municipios participantes, sólo cinco cuentan con un Consejo Municipal de Mayores (Guía de Isora, La Laguna, Tegueste, La Orotava y Santa Cruz de Tenerife). Destaca, por tanto, que a nivel institucional la participación de las personas mayores es escasa en la mayoría de los municipios de la isla.

\subsection{Proyectos Socio Educativos para Personas Mayores}

Esta parte del trabajo se ha dirigido a conocer los programas, proyectos y actividades de carácter socioeducativo que desde los ayuntamientos se dirigen las personas mayores desde el ámbito municipal.

Como se observa en la Tabla 4.6., de los 24 ayuntamientos participantes en el trabajo, seis no indican o no tienen programas o proyectos socioeducativos. El resto de los ayuntamientos señalan los proyectos de los que disponen, si bien unos completan la información de las fichas (29 acciones) y otros no (17 acciones sobre las que se da el título, pero no se proporciona más información). 
Tabla 4.6. Programas / proyectos / actividades socioeducativas por municipios de Tenerife

\begin{tabular}{|c|c|}
\hline Municipio & Programa / Proyecto / Actividad \\
\hline Adeje & -Sin respuesta. \\
\hline Arafo & -Programa Movimiento y Salud. \\
\hline Arico & -Sin respuesta. \\
\hline Arona & -Programa de acompañamiento a personas mayores en situación de soledad no voluntaria. \\
\hline Buenavista del Norte & -Sin respuesta. \\
\hline Candelaria & $\begin{array}{l}\text {-Sonrisas Mayores (Proyecto de acompañamiento a personas mayores de la Fundación } \\
\text { Candelaria Solidaria). } \\
\text {-CERI (Centro especial de recuperación integral). } \\
\text {-Proyecto de Acompañamiento. } \\
\text {-Mayores conectados. }\end{array}$ \\
\hline El Rosario & $\begin{array}{l}\text {-Gimnasia de mantenimiento para personas mayores. } \\
\text {-Los Mayores de El Rosario van a la playa. } \\
\text {-Actividad fin de verano. }\end{array}$ \\
\hline El Sauzal & -Talleres por los barrios. \\
\hline El Tanque & $\begin{array}{l}\text {-Manejo de las redes sociales. } \\
\text {-Semana del mayor. }\end{array}$ \\
\hline Fasnia & $\begin{array}{l}\text {-Envejecimiento activo. } \\
\text {-Ocio saludable. }\end{array}$ \\
\hline Garachico & -No indica. \\
\hline Granadilla de Abona & -Sin respuesta. \\
\hline Güímar & -Sin respuesta. \\
\hline Guía de Isora & $\begin{array}{l}\text {-Proyecto de acompañamiento a personas mayores en soledad. } \\
\text {-Proyecto de apoyo al Área de mayores en materia de intervención psicológica y fisioterapia por } \\
\text { situación de alerta sanitaria. } \\
\text {-Programa de ocio y tiempo libre dirigido a mayores con actividades especializadas dirigidas a } \\
\text { mayores de la escuela municipal de ocio y tiempo libre. } \\
\text {-Programa de colaboración en materia de ocio y tiempo libre entre la Caixa y la Concejalía de } \\
\text { mayores. } \\
\text {-Jornadas de celebración del Día del Mayor. } \\
\text {-Actividades de verano en la playa y otras actividades de ocio. } \\
\text {-Formación específica en materia de asociacionismo para mayores, informática y otros. }\end{array}$ \\
\hline Icod de los Vinos & -No indica. \\
\hline La Guancha & $\begin{array}{l}\text {-Turismo social. } \\
\text {-Respiro familiar. } \\
\text {-Subvenciones para el folklore dirigidos a las asociaciones de mayores: La Guacha Casco, XXV de } \\
\text { Noviembre y Renacer Costero. }\end{array}$ \\
\hline La Matanza de Acentejo & -No indica. \\
\hline La Orotava & $\begin{array}{l}\text {-Salud y bienestar. } \\
\text {-Programa de ocio. } \\
\text {-Proyecto de mejora y actualización informática } 3.0 . \\
\text {-Promoción del voluntariado en personas mayores. } \\
\text {-Programa cuidado de la persona cuidadora. }\end{array}$ \\
\hline La Victoria de Acentejo & -Apoyo a la unidad convivencial con mayores. \\
\hline Los Realejos & -Proyecto de mayores en soledad. \\
\hline Los Silos & -No indica. \\
\hline Puerto de la Cruz & -Sin respuesta. \\
\hline La Laguna & -Programa de dinamización de mayores. \\
\hline San Juan de la Rambla & -No indica. \\
\hline San Miguel de Abona & -Sin respuesta. \\
\hline Santa Cruz de Tenerife & $\begin{array}{l}\text {-Personas mayores en situación de vulnerabilidad. } \\
\text {-Envejecimiento activo y saludable. } \\
\text {-Proyecto de bienestar integral. } \\
\text {-Dinamización de las asociaciones de mayores para un ocio y tiempo libre saludable y positivo y } \\
\text { potenciación de las redes comunitarias. }\end{array}$ \\
\hline Santa Úrsula & $\begin{array}{l}\text {-Programa de envejecimiento activo (animación sociocultural con mayores: canto, } \\
\text { acompañamiento en domicilio, alfabetización, etc). }\end{array}$ \\
\hline
\end{tabular}




\begin{tabular}{ll}
\hline & -Programa de estimulación cognitiva. \\
& -Actividades deportivas varias: verano en la playa, piscina municipal, ...). \\
& -Apoyo al club de mayores. \\
\hline Santiago del Teide & -Mantenimiento físico para mayores. \\
\hline Tacoronte & -No indica. \\
\hline Tegueste & -Programa de Acompañamiento en la Soledad (temporal por subvención). \\
\hline Vilaflor & -Planificación y programación de la Concejalía de la Tercera Edad: Viajes culturales, fomento de \\
& la participación social, manualidades, informática para mayores, ejercicio en la playa, etc. \\
\hline
\end{tabular}

En el Anexo 2 se incluye la información detallada sobre cada uno de los proyectos que han descrito los municipios participantes. En concreto, se ha preguntado por el año de inicio, el área o Concejalía responsable, la descripción de la actividad, el número de plazas ofertadas, el perfil de las personas participantes (en función del sexo), la edad mínima para participar, la accesibilidad desde el punto de vista de la movilidad, el coste para las personas participantes, la planificación temporal, el horario, lugar y desplazamiento de las personas participantes. Si bien no todas las iniciativas descritas son estrictamente de carácter socioeducativo, se han incluido en este informe, con la excepción de las referidas a la información y orientación general, y a las prestaciones económicas de asistencia social.

El análisis de la información recogida respecto a las acciones sobre las que se aportan datos completos permite establecer que, en cuanto a las temáticas o contenidos de las iniciativas, hay una amplia diversidad. Algunas propuestas se centran en un tópico, como el ocio y el tiempo libre (4), el uso de las TICs y las redes sociales (3), la actividad física (2) o la atención cognitiva y psicológica (1). Otras iniciativas se centran a nivel general en el envejecimiento activo, la salud y la autonomía (3) o el acompañamiento (2). También encontramos propuestas de contenido mixto, que centran sus objetivos en dos ámbitos, como el desarrollo físico y cognitivo (3). Otras propuestas recogen acciones más variadas relacionadas con varios objetivos como el ocio, las Tics, la estimulación cognitiva y el senderismo (2). Dos propuestas están centradas en las situaciones de vulnerabilidad social, soledad y aislamiento. Por último, otras iniciativas están dirigidas a las asociaciones de personas mayores (1), a la promoción del voluntariado entre las personas mayores (1) y a las personas cuidadoras (1).

Algunos municipios tienen una variedad de propuestas en las que se abarcan diferentes objetivos como el ocio, las TICs o la atención 
cognitiva (ej. Candelaria). Otros se centran de forma exclusiva en un área como las TICs (ej. El Tanque) o el desarrollo físico (ej. Santiago del Teide).

Respecto al año de inicio, gran parte de las iniciativas comenzaron en el año 2019 y 2020 (10). El proyecto más longevo data del año 1992.

En 6 proyectos tiene responsabilidad las áreas o concejalías específicas de mayores. Un total de tres proyectos tienen como entidad responsable a ONG asociaciones o empresas, otros diecisiete son responsabilidad de ayuntamientos $\bigcirc$ Institutos municipales $\bigcirc$ fundaciones públicas municipales. En cinco la responsabilidad es compartida entre ayuntamiento y otras entidades.

Respecto a las plazas ofertadas, de las 20 iniciativas que aportan este dato, cinco tienen plazas ilimitadas, cuatro tienen entre 100 y 200 plazas, otros cuatro tienen entre 50 y 70 plazas y cinto tienen entre 6 y 45 plazas.

En diecinueve iniciativas participan mayoritariamente las mujeres (sobre las veintitrés que aportan este dato), solo en una, relacionada con las Tics, participan más los hombres. En otras dos hay una participación mixta.

De las once iniciativas que aportan datos sobre la edad mínima para participar, más de la mitad establecen como referencia los 60 años, mientras que otras tres indican 55, y dos lo marcan en 50 años.

Solo una iniciativa no es accesible desde el punto de vista de la movilidad.

Todas las iniciativas que informan sobre los costes de la actividad para la persona beneficiaria (23), informan que se tratan de iniciativas gratuitas.

La mayor parte de las iniciativas tienen una planificación anual (16), mientras que otras cinco son mensuales, dos son permanentes, una es trimestral, otra es cuatrimestral y otra tiene una duración de nueve meses. Las acciones se suelen desarrollar en horario de mañana y tarde (11) o en horario de mañana (10), mientras que solo cuatro se desarrollan en horario exclusivo de tarde.

En cuanto al lugar donde se desarrollan las actividades, gran parte se llevan a cabo de manera conjunta en dependencias municipales y otros espacios como aire libre, asociaciones de mayores, asociaciones de 
vecinos, locales culturales (12); otras se desarrollan en dos espacios, como asociaciones de vecinos y aire libre, locales culturales y asociaciones de vecinos (5); dos se desarrollan de formar exclusiva en el domicilio y otras cuatro se llevan a cabo tanto en el domicilio como en otros lugares (ej. dependencias municipales, entorno, locales culturales); solo dos se desarrollan de forma exclusiva en otros espacios como aire libre (1) y asociaciones de vecinos (1).

En cuanto al traslado, la mayor parte de iniciativas requieren transporte por cuenta propia (13), mientras que otras también facilitan transporte (11).

Respecto a las iniciativas sobre las que se proporciona el título, pero no se aporta la información detallada, se puede inferir que se centran en temáticas como el acompañamiento en situaciones de soledad no deseada (4), el ocio y el tiempo libre (4), el apoyo al asociacionismo (2), las actividades por el día o la semana del mayor (2), las actividades deportivas (1), el folklore (1), la estimulación cognitiva (1), la intervención en Psicología y Fisioterapia por la alerta sanitaria (1), y el respiro familiar (1). 


\section{Centros residenciales para Personas Mayores}





\subsection{Metodología}

El presente apartado del estudio ha tenido como objetivo recabar información actualizada sobre los recursos residenciales para mayores con los que cuenta la isla de Tenerife.

Para ello, se ha elaborado un cuestionario compuesto por cinco preguntas sobre el estado y funcionamiento de las residencias de mayores. En concreto, se han recogido los siguientes aspectos: número total de plazas; plazas totales ocupadas y en función del sexo de sus residentes; tipo de plazas (bajo, medio y alto requerimiento); servicios que se ofrecen (fisioterapia, terapia ocupacional, actividades de ocio, acompañamiento en salidas, enfermería del centro).

La población objeto de estudio son los centros residenciales para personas mayores, extraídos a partir de los datos publicados tanto por webs oficiales como por otras de información sociosanitaria para personas mayores.

Para crear el directorio inicial, durante el mes de octubre se realizó una búsqueda intensiva de los centros para personas mayores existentes en la isla. Para ello, se acudió a diferentes fuentes de información, tanto oficiales (p.e. web del Instituto Insular de Atención Social y Sociosanitaria), como páginas web de información sociosanitaria para personas mayores.

Una vez creado el directorio inicial de residencias de mayores se procedió a comprobar y actualizar la información, a través de contacto telefónico y vía correo electrónico con las propias residencias. La recogida de datos se realizó entre el 1 de noviembre y el 14 de diciembre. La información se obtuvo del personal técnico como trabajadoras sociales, pedagogas, psicólogas, o de las propias directoras de los centros.

Para la clasificación de la información obtenida se ha decidido usar la división de la isla de Tenerife en diferentes comarcas, a partir de la clasificación presentada desde las áreas sociales del Cabildo (como el área de juventud), en las que se utiliza la ordenación territorial de comarcas que tiene en cuenta los límites municipales. 
En concreto, los municipios que componen las comarcas que utilizamos para la clasificación de los datos obtenidos son los siguientes:

Comarca metropolitana: Santa Cruz de Tenerife, La Laguna, Tegueste, El Rosario, Candelaria.

Comarca de Acentejo: Tacoronte, El Sauzal, La Matanza de Acentejo, La Victoria de Acentejo, Santa Úrsula.

Comarca de la Orotava: Puerto de la Cruz, La Orotava, Los Realejos.

Comarca Icod-Daute: San Juan de la Rambla, La Guancha, Icod de los Vinos, Garachico, el Tanque, Los Silos, Buenavista del Norte.

Comarca Suroeste: Santiago del Teide, Guia de Isora, Adeje.

Comarca de Arona: Vilaflor, Arona, San Miguel de Abona, Granadilla de Abona, Arico.

Comarca del Valle Güímar: Fasnia, Güímar, Arafo.

Figura 5.1. Comarcas en las que se divide la isla de Tenerife

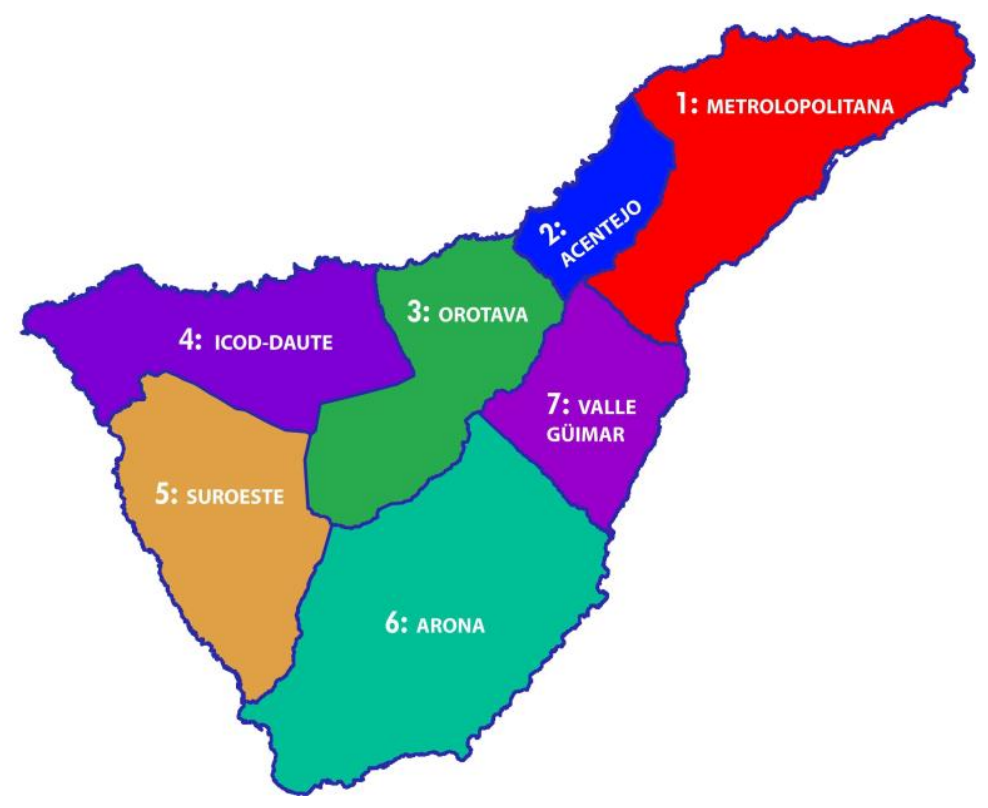

Fuente: Tenerife Joven. Recuperado de https://tenerifejovenyeduca.com

Este trabajo de campo ha permitido contar con una muestra final de 27 residencias para la isla de Tenerife, distribuidas entre las 7 comarcas. Ello nos permite ofrecer solamente una imagen preliminar, que necesita ser 
complementada, de los recursos residenciales existentes en Tenerife en la actualidad.

\subsection{Datos obtenidos a partir de los directorios publicados}

Según los datos obtenidos en Internet, a través de la página del IASS y de la búsqueda realizada en diferentes residencias de mayores en la isla de Tenerife, aparecen reseñas de un total de 60 residencias de mayores, donde se incluyen las públicas y las privadas. Tal y como se recoge en la Tabla 5.1., de estas 60 residencias, 32 pertenecen a la comarca Metropolitana, que engloba Santa Cruz, La Laguna, Tegueste, el Rosario y Candelaria. El resto de las residencias están distribuidas entre la comarca de Arona (1), la Comarca de Acentejo (4), la Comarca de la Orotava (11), la comarca Icod-Daute (8), la Comarca Suroeste (1) y la Comarca Valle Güímar (3). El mayor número de plazas se concentran en la Comarca Metropolitana (1.656), mientras que la zona con menos plazas es la Comarca Suroeste (8).

Tabla 5.1. Número de residencias de mayores y plazas, distribuidas en las comarcas de Tenerife, según la información publicada en los directorios web

\begin{tabular}{lcc}
\hline & $\begin{array}{c}\text { Residencias de } \\
\text { Mayores }\end{array}$ & Plazas \\
\hline Comarca Metropolitana & 32 & 1.656 \\
\hline Comarca de Acentejo & 4 & 256 \\
\hline Comarca de la Orotava & 11 & 924 \\
\hline Comarca Icod-Daute & 8 & 384 \\
\hline Comarca Suroeste & 1 & 8 \\
\hline Comarca Arona & 1 & 30 \\
\hline Comarca Valle Güímar & 3 & 136 \\
\hline TOTAL & 60 & 3.394 \\
\hline
\end{tabular}

\subsection{Datos proporcionados por residencias de personas mayores}

las

Durante la realización del presente trabajo se han obtenido datos de 27 residencias de mayores de la isla de Tenerife, distribuidas de la siguiente manera: Comarca de Arona (1), Comarca de Acentejo (3), Comarca de 
la Orotava (4), Comarca Icod-Daute (5), Comarca Metropolitana (12), Comarca Valle Güímar (2).

En general, según la información recabada, todos los centros cuentan con servicios residenciales y sanitarios básicos. Aquellos que no tienen un servicio médico y de enfermería propio, tienen una conexión cercana con centros de salud, por lo que solo se expondrán aquellos servicios que sean de alguna manera diferenciadores.

En la Tabla 5.2. se presentan los datos sobre plazas totales y ocupadas por hombres y mujeres, a partir de la información proporcionada desde las propias residencias participantes.

Tabla 5.2. Plazas totales y ocupadas por hombres y mujeres de las residencias de mayores participantes en este estudio distribuidas en las comarcas de Tenerife

\begin{tabular}{lccccc}
\hline & Plazas Totales & $\begin{array}{c}\text { Plazas } \\
\text { Ocupadas }\end{array}$ & Hombres & Mujeres & No se sabe \\
\hline Comarca Metropolitana & 512 & 480 & 157 & 323 & 0 \\
\hline Comarca de Acentejo & 190 & 175 & 36 & 99 & 40 \\
\hline Comarca de la Orotava & 130 & 126 & 27 & 99 & 0 \\
\hline Comarca Icod-Daute & 323 & 295 & 110 & 185 & 0 \\
\hline Comarca Suroeste & - & - & - & - & - \\
\hline Comarca Arona & 60 & 60 & - & - & 60 \\
\hline Comarca Valle Güímar & 184 & 182 & 10 & 22 & 150 \\
\hline TOTAL & 1.399 & 1.318 & 340 & 728 & 250 \\
\hline
\end{tabular}

Como se muestra en la Tabla 5.2., la ocupación se acerca a la totalidad de las plazas disponibles. En todas las comarcas destacan las usuarias mujeres, en comparación con los varones. La Comarca Metropolitana es la que mayor número de plazas concentra, seguida de la Comarca lcodDaute, siempre según los datos preliminares obtenidos.

A continuación, se presenta la información específica obtenida para cada una de las comarcas de la isla de Tenerife.

Para la Comarca de Arona, se han obtenido datos de una residencia de mayores, la Residencia de Ancianos Evangélicos CEDAR, ubicada en Granadilla de Abona y que cuenta con 60 plazas de bajo y medio requerimiento.

En cuanto a la comarca de Acentejo, se han obtenido datos de tres residencias, dos de las cuales se encuentran en Tacoronte y una 
pertenece a Santa Úrsula. Los centros cuentan con un total de 190 plazas, de las cuales 175 están actualmente ocupadas. Los tres centros tienen plazas de bajo, medio y alto requerimiento.

Tabla 5.3. Plazas totales y ocupadas por hombres y mujeres de las residencias de mayores participantes en este estudio correspondientes a la Comarca de Acentejo

\begin{tabular}{lccccc}
\hline & $\begin{array}{c}\text { Plazas } \\
\text { Totales }\end{array}$ & $\begin{array}{c}\text { Plazas } \\
\text { Ocupadas }\end{array}$ & Hombres & Mujeres & No se sabe \\
\hline Parque residencial las Magnolias & 40 & 40 & - & - & 40 \\
\hline $\begin{array}{l}\text { Centro sociosanitario Santa Ursula } \\
\text { Residencia de mayores Geron }\end{array}$ & 64 & 59 & 10 & 49 & 0 \\
$\begin{array}{l}\text { Tacoronte } \\
\text { TOTAL }\end{array}$ & 86 & 76 & 26 & 50 & 0 \\
\hline
\end{tabular}

La residencia de mayores de Geron Tacoronte cuenta, entre sus servicios, con actividades de terapia con animales.

Respecto a la comarca de La Orotava, se ha obtenido respuesta de cuatro residencias de mayores, una de las cuales está actualmente cerrada (residencia de personas mayores Charlotte). De los otros tres centros, dos se encuentran en el Puerto de la Cruz y uno pertenece a la Orotava. Los centros cuentan con un total de 130 plazas, de las cuales 126 están actualmente ocupadas. Las plazas de Fundación Hospital de la Inmaculada Concepción y de la Residencia Geriátrica San Sebastián son de bajo requerimiento, mientras que la Residencia Privilegium San Fernando, ubicada en el Puerto de la Cruz, tiene plazas de bajo, medio y alto requerimiento.

Tabla 5.4. Plazas totales y ocupadas por hombres y mujeres de las residencias de mayores participantes en este estudio correspondientes a la Comarca de La Orotava

\begin{tabular}{lcccc}
\hline & $\begin{array}{c}\text { Plazas } \\
\text { Totales }\end{array}$ & $\begin{array}{c}\text { Plazas } \\
\text { Ocupadas }\end{array}$ & Hombres & Mujeres \\
\hline $\begin{array}{l}\text { Fundación Hospital de la Inmaculada } \\
\text { Concepción }\end{array}$ & 67 & 67 & 0 & 67 \\
\hline Residencia Privilegium San Fernando & 23 & 22 & 13 & 9 \\
\hline Residencia Geriatrica San Sebastián & 40 & 37 & 14 & 23 \\
\hline TOTAL & 130 & 126 & 27 & 99 \\
\hline
\end{tabular}

Para la comarca de Icod-Daute, se han obtenido datos de cinco residencias, dos de las cuales se encuentran en Icod de los Vinos, una en 
la Guancha, una en los Silos y una en San Juan de la Rambla. Como se muestra en la Tabla 5.5., los centros cuentan con un total de 323 plazas, de las cuales 295 están actualmente ocupadas. Hay 110 plazas ocupadas por hombres y 185 plazas ocupadas por mujeres.

En relación al tipo de plaza, el Centro Sociosanitario San Juan de la Rambla (municipio de San Juan de la Rambla) tiene plazas de bajo requerimiento; la Residencia Geriátrica Nuestra Señora de la Luz (municipio de Los Silos) y el Centro Sociosanitario San Juan de la Rambla (municipio San Juan de la Rambla) tienen plazas de medio requerimiento; y el Centro Sociosanitario de La Guancha (municipio de la Guancha), la Residencia Hospital Nuestra Señora de los Dolores (municipio de Icod de los Vinos), la Residencia Geriátrica Nuestra Señora de la Luz y el Centro Sociosanitario del Norte (municipio de Icod de los Vinos) tienen plazas de alto requerimiento.

Tabla 5.5. Plazas totales y ocupadas por hombres y mujeres de las residencias de mayores participantes en este estudio correspondientes a la Comarca lcod-Daute

\begin{tabular}{lcccc}
\hline & $\begin{array}{c}\text { Plazas } \\
\text { Totales }\end{array}$ & $\begin{array}{c}\text { Plazas } \\
\text { Ocupadas }\end{array}$ & Hombres & Mujeres \\
\hline Centro Sociosanitario de La Guancha & 75 & 75 & 32 & 43 \\
\hline Residencia Hospital Nuestra Sra de los Dolores & 28 & 28 & 0 & 28 \\
\hline Residencia Geriátrica Ntra Sra de la Luz & 32 & 26 & 13 & 13 \\
\hline Centro Sociosanitario del Norte & 150 & 128 & 51 & 77 \\
\hline Centro Sociosanitario San Juan de la Rambla & 38 & 38 & 14 & 24 \\
\hline TOTAL & 323 & 295 & 110 & 185 \\
\hline
\end{tabular}

Respecto a la comarca Metropolitana, del directorio inicial, se han obtenido datos de 12 centros, aunque uno se encuentra actualmente cerrado (residencia Granada Andalusi). En Santa Cruz se encuentran siete de las residencias, tres están establecidas en La Laguna y una en Candelaria. Las residencias cuentan con un total de 512 plazas, de las cuales 480 están actualmente ocupadas. Hay 157 plazas ocupadas por hombres y 323 plazas ocupadas por mujeres.

Con relación al tipo de plaza, dependiendo del caso pueden disponerse de plazas para diferentes perfiles. Seis centros tienen plazas de bajo requerimiento, siete centros tienen plazas de medio requerimiento $y$ cuatro centros tienen plazas de alto requerimiento. 
Tabla 5.6. Plazas totales y ocupadas por hombres y mujeres de las residencias de mayores participantes en este estudio correspondientes a la Comarca Metropolitana

\begin{tabular}{lcccc}
\hline & $\begin{array}{c}\text { Plazas } \\
\text { Totales }\end{array}$ & $\begin{array}{c}\text { Plazas } \\
\text { Ocupadas }\end{array}$ & Hombres & Mujeres \\
\hline Centro Gerontologico Amavir Tejina & 76 & 76 & 15 & 61 \\
\hline Residencia El Jardín del Abuelo & 23 & 20 & 6 & 14 \\
\hline Residencia Orden de los Hermanos de Belén & 30 & 14 & 14 & 0 \\
\hline Residencia Geriátrica Santa Ana & 15 & 15 & 3 & 12 \\
\hline Residencia Geriatrica Ofra & 136 & 130 & 78 & 52 \\
\hline Residencia de 3a Edad Acoran & 38 & 38 & 8 & 30 \\
\hline Residencia Centro de Mayores Toki Eder & 26 & 24 & 5 & 19 \\
\hline Residencia Ancianos Concha de Castro & 78 & 76 & 11 & 65 \\
\hline Residencia de 3a Edad Virgen de Begoña & 37 & 36 & 3 & 33 \\
\hline Residencia de 3a Edad Pancracio Vistabella & 28 & 26 & 6 & 20 \\
\hline Residencia y Centro de Día Los cristianos & 25 & 25 & 8 & 17 \\
\hline TOTAL & 512 & 480 & 157 & 323 \\
\hline
\end{tabular}

Para la comarca Valle de Güímar, se han obtenido datos de dos centros, uno de los cuales se encuentra en Arafo y el otro en Fasnia. Ambos suman un total de 184 plazas, de las cuales 182 están actualmente ocupadas.

Tabla 5.7. Plazas totales y ocupadas por hombres y mujeres de las residencias de mayores participantes en este estudio correspondientes a la Comarca Valle de Güímar

\begin{tabular}{lccccc}
\hline & $\begin{array}{c}\text { Plazas } \\
\text { Totales }\end{array}$ & $\begin{array}{c}\text { Plazas } \\
\text { Ocupadas }\end{array}$ & Hombres & Mujeres & No se sabe \\
\hline Residencia Sociosanitaria Ma Auxiliadora & 34 & 32 & 10 & 22 & 0 \\
\hline Residencias Sociosanitaria Fasnia & 75 & 75 & - & - & 75 \\
\hline Residencia Sociosanitaria Güímar & 75 & 75 & - & - & 75 \\
\hline TOTAL & 184 & 182 & 10 & 22 & 150 \\
\hline
\end{tabular}

Para finalizar, resaltar que, de las 27 residencias de mayores que han participado en el presente estudio, dos han informado que se encuentran actualmente cerradas. Entre las 25 restantes, la más pequeña dispone de 15 plazas (Residencia Geriátrica Santa Ana) y la mayor cuenta con 150 plazas (Centro Sociosanitario del Norte). Dentro de este rango, 15 residencias disponen de menos de 50 plazas y 10 residencias, de más de 50. Por su parte, en prácticamente todas las residencias es mayor el número de mujeres que ocupan plaza, en comparación con el de varones. Debe tenerse en cuenta que esta información debería complementarse con la información del resto de residencias situadas en la isla de Tenerife, que no han aportado datos durante el periodo de ejecución de este trabajo. 

6.Conclusiones y orientaciones

para el desarrollo de políticas públicas 

Este trabajo permite extraer una serie de conclusiones sobre la situación de las personas mayores en la isla de Tenerife. A continuación, pasan a describirse.

Respecto a la estructura de la población, Canarias es una de las comunidades autónomas con menor proporción de población mayor de 65 años, si bien se constata -en el caso de la isla de Tenerife- un progresivo envejecimiento de la estructura de su población en las últimas décadas. En esta última etapa de la vida se observa una feminización de la población, motivada por la mayor esperanza de vida que alcanzan las mujeres. Esta diferencia se acentúa entre la población que alcanza las edades más longevas.

Las Islas Canarias presentan una alta variabilidad respecto a sus tasas de envejecimiento y sobre-envejecimiento, observándose importantes contrastes entre las islas que presentan tasas superiores a la media nacional (El Hierro, La Gomera y La Palma) y las que presentan tasas inferiores (Fuerteventura y Lanzarote). Tenerife -de manera similar a Gran Canaria- presenta un valor intermedio respecto a esta comparativa interinsular, en su tasa de envejecimiento (16,2\%), la cual se sitúa casi tres puntos por debajo de la tasa nacional (19,3\%).

A nivel intrainsular, en Tenerife se observa también gran variabilidad respecto a las tasas de envejecimiento y sobre-envejecimiento que presentan sus municipios. De manera general, puede describirse un eje Norte - Sur respecto a los municipios con una estructura de la población más y menos envejecida, respectivamente. Este patrón presenta excepciones, como son los municipios de Fasnia y Vilaflor. Por su parte, los municipios del área metropolitana presentan valores intermedios en sus tasas de envejecimiento.

En cuanto a la tipología de los hogares, la mayoría de los hogares unipersonales de la población mayor están habitados por una mujer. En concreto, uno de cada doce hogares de las Islas Canarias corresponde a una mujer mayor que vive sola. Ello lleva a considerar que la soledad no deseada afecta en mayor medida a las mujeres que a los varones, así como el enfrentamiento a situaciones vitales altamente estresantes, como la pérdida de la pareja de vida. 
Por su parte, el nivel de estudios de las personas mayores de 65 años se distribuye de forma asimétrica, destacando las personas que cuentan con estudios primarios o menos y con estudios secundarios básicos. Sin embargo, se observa una tendencia que evoluciona hacia personas con mayores niveles de estudios, quienes posiblemente demandarán actividades socioeducativas y oportunidades de participación social de diferente calado.

Otro de los objetivos de este trabajo ha sido conocer características generales sobre la prestación de servicios sociales municipales dirigidos a personas mayores. Se ha conseguido recabar información de 24 de los 31 municipios de Tenerife.

En cuanto al servicio de teleasistencia, según el Imserso (2018) Canarias presenta uno de los índices de cobertura más bajos del territorio español. A partir de los resultados obtenidos en el presente trabajo, se observa que desde el ámbito municipal la gestión del servicio más frecuente es la externalización a la ONG Cruz Roja Española. Según los datos proporcionados por los municipios, el alcance del servicio es desigual entre las diferentes localidades, si bien son indicativos de índices de cobertura bajos, en comparación con los de otras comunidades autónomas. Es mayor la proporción de mujeres usuarias, en comparación con los varones.

Respecto al SAD, en este caso es más frecuente que se dé una gestión municipal, en algunos casos con apoyo complementario. Según los datos aportados por los municipios, el alcance del SAD es mayor que el observado para el servicio de teleasistencia, mostrando asimismo una mayor proporción de mujeres usuarias. No obstante, también en este caso los datos arrojan índices de cobertura orientativos que se sitúan, en términos generales, por debajo del índice nacional.

Debe tenerse en cuenta que tanto la teleasistencia como el SAD favorecen que se prolongue la permanencia de las personas mayores en su propio hogar, decisión que es la preferida en la mayoría de los casos.

El perfil profesional del SAD indica que se trata de una actividad marcadamente feminizada, tal y como sucede con el resto de las 
profesiones y actividades no remuneradas centradas en el cuidado de otras personas.

En cuanto a los centros de día / estancia diurna, son recursos con los que se cuenta en bajo número en la mayoría de los municipios participantes, con la excepción de Santa Cruz de Tenerife.

Por su parte, son Santa Cruz de Tenerife y La Laguna los municipios que concentran a la mayoría de las asociaciones de mayores, en consonancia con su mayor volumen de población. En la mayoría de los municipios, el tejido asociativo no se traduce en una formalización institucional, ya que solo el $20,8 \%$ de los municipios refiere contar con un Consejo Municipal de Mayores.

Por último, las viviendas para mayores son un recurso muy poco desarrollado. Se trata de un aspecto al que prestar atención, ya que ofrecen una alternativa habitacional más similar a la convivencia familiar que las residencias (por su número reducido de plazas) y que favorece la preservación de la autonomía de las personas usuarias.

Respecto a las actuaciones de carácter socioeducativo que se llevan a cabo desde el ámbito municipal. De los 24 municipios participantes en el estudio, seis no han indicado programas o proyectos de este tipo. De los 18 que sí disponen, la mayoría cuenta con menos de cinco. Las acciones descritas van dirigidas a las actividades de ocio; el uso de las TICs; la actividad física y promoción de la salud; la recuperación de capacidades y fomento de la autonomía; el acompañamiento; la participación social y apoyo al tejido asociativo; y el apoyo a la persona cuidadora. Se debe reseñar que, con toda probabilidad, hay acciones que se han llevado a cabo en años anteriores que durante este año 2020 se han visto afectadas o suprimidas con motivo de la pandemia de COVID-19.

Por último, se ha llevado a cabo una revisión de las residencias para mayores que se ubican en el territorio insular. Esta tarea ha resultado especialmente difícil de realizar en el tiempo de ejecución de este proyecto, dificultad que sin duda se ha visto agravada por la situación de pandemia que ha afectado de modo especial a las residencias de mayores. Sirvan por tanto los resultados obtenidos como datos 
preliminares, que deberán completarse, y que subrayan la importancia de contar con un directorio actualizado y publicado de residencias de mayores y del número de personas usuarias de este recurso. Estos resultados preliminares permiten establecer que existe variabilidad entre el tamaño de las residencias, con contrastes entre las 15 y las 150 plazas. La mayoría de las plazas residenciales están ocupadas y, prácticamente en todos los casos, en mayor medida por mujeres que por varones.

Para finalizar, se considera oportuno sugerir orientaciones que permitan llevar a cabo una Política Social dirigida a las personas mayores que promuevan un envejecimiento digno y satisfactorio, la participación y la inclusión social plena y favorezcan la promoción de la autonomía personal y la atención a la dependencia. Ello puede orientar las futuras acciones que se diseñen en materia de Política Social Gerontológica en la isla de Tenerife.

- Abandono del enfoque asistencialista e implementación del Enfoque de Derechos Humanos: es necesario afianzar la transición desde un paradigma asistencialista al Enfoque basado en los Derechos Humanos. Este enfoque supera la consideración de las personas como meros "beneficiarios" de programas sociales asistenciales, para que estas sean consideradas sujetos de derechos y de responsabilidades frente al Estado como titular de obligaciones. Desde la visión de "titular pleno", el Enfoque basado en Derechos Humanos se toma como marco de referencia para el análisis y el diseño de las Políticas Sociales considerando a la persona como centro de la intervención, y en este sentido se definen desde la igualdad y no son regresivas, sino progresivas, además de incorporar la noción de "responsabilidad". Esto supone abandonar la práctica "paternalista" y promover el papel activo de las personas mayores. Partir de modelos de intervención que acompañen en los procesos de empoderamiento de las personas mayores. Identificar, visibilizar y fomentar sus capacidades y competencias desde enfoques positivos y centrados en las potencialidades.

- Prevención y promoción desde el Modelo del Envejecimiento Activo: resulta primordial promover acciones preventivas que permitan disminuir los factores de riesgo y potenciar los factores de protección, 
las fortalezas y capacidades para potenciar el bienestar y la calidad de vida de las personas mayores. Se trata de adelantarse a las necesidades, promoviendo acciones protectoras y de prevención que potencien el envejecimiento activo, definido como "el proceso de optimizar las oportunidades de salud, participación y seguridad a fin de mejorar la calidad de vida a medida que las personas envejecen". En esta línea es fundamental promover el trabajo comunitario propiciando la participación de todas las personas y la creación de espacios intergeneracionales.

- Participación en el diseño de políticas públicas: es necesario considerar a las personas mayores las protagonistas en todas las acciones relacionadas con ellas. Generar los espacios y mecanismos adecuados para que las personas mayores puedan ejercer los derechos de participación, desde la planificación hasta la ejecución de las acciones.

- Modelo de atención centrado en la persona: las acciones deben partir del modelo de intervención centrado en la persona, atendiendo a todas sus dimensiones desde enfoques integrales. Esto supone trabajar desde el respeto a la dignidad de las personas mayores, el reconocimiento a su autodeterminación y, por tanto, su derecho a decidir cómo quieren continuar su proyecto de vida. En esta línea, es fundamental conocer y valorar la singularidad e individualidad de cada persona, única e irrepetible, para poder dar una respuesta acorde a sus necesidades. El trabajo desde esta premisa requiere apoyar los proyectos de vida de cada persona e incluir las preferencias y deseos de las personas mayores en todas las intervenciones y en cualquiera de los ámbitos.

- Coordinación y colaboración institucional: es necesario un esquema de trabajo coordinado y de colaboración entre todas las administraciones y entidades involucradas en el trabajo con personas mayores. Establecer canales de comunicación recíproca, procedimientos y actuaciones de colaboración y cooperación entre diferentes servicios (ej. servicios sociales y sanitarios) que faciliten el desarrollo de acciones que tienen como objetivo común mejorar la calidad de vida de las personas mayores. En este sentido, el modelo 
deseable es el trabajo en red, ya que apuesta por el trabajo integrado interprofesional e intersectorial.

- Innovación y rigurosidad: las acciones deben estar fundamentadas en el conocimiento científico actualizado. Se debe optar por utilizar acciones fundamentadas en los resultados de evaluación validados. Es recomendable optar por sistemas de evaluación e intervenciones que hayan demostrado ser buenas prácticas o prácticas basadas en la evidencia.

Por su parte, acorde con estas orientaciones se requieren acciones que promuevan, además de la participación y la inclusión, la sensibilización social. Para ello, se propone la promoción de una imagen positiva, diversa y realista de la vejez -habida cuenta de la heterogeneidad que caracteriza a este grupo poblacional-, que contribuya a un trato igualitario y digno de las personas mayores. También, fomentar la inclusión social de las personas mayores, para disminuir el aislamiento y la soledad no deseada; Promover la participación activa de las personas mayores en la vida sociocultural de su comunidad; y Favorecer las relaciones intergeneracionales, como vía de enriquecimiento recíproco entre las personas mayores y más jóvenes. Otra línea de trabajo puede orientarse a favorecer las redes protección y de cuidados en sus diversas formas: familiar, institucional, formal e informal. En este sentido, son necesarias acciones dirigidas a impulsar el envejecimiento en el hogar y/o en los contextos naturales y cercanos de las personas mayores; la promoción de la autonomía y el autocuidado, así como también la potenciación de los servicios que apoyan al cuidado y la mejora de la calidad de vida de las personas cuidadoras. Todo lo descrito requiere que los y las profesionales que trabajan "para" y "con" las personas mayores dispongan de una formación especializada en Política Social Gerontológica, en el enfoque basado en los derechos humanos, el envejecimiento activo y el modelo centrado en la persona. En cualquier caso, cualquier planificación de las actuaciones dirigidas a las personas mayores debe contar con la participación de la propia población implicada. De manera similar, es recomendable que la descripción que se ha realizado en este trabajo sobre las características sociodemográficas de las personas mayores, así como de los recursos sociales 
que se les prestan, se acompañe en un futuro de las valoraciones que realizan las propias personas mayores sobre cuáles son los problemas que les afectan y cómo desean conducir el resto de sus vidas. 


$$
\begin{array}{r}
\text { Anexo } 1 . \\
\text { Programas, } \\
\text { proyectos o } \\
\text { actividades } \\
\text { socioeducativas } \\
\text { dirigidas a } \\
\text { Personas } \\
\text { Mayores en los } \\
\text { ayuntamientos } \\
\text { de la isla de } \\
\text { Tenerife }
\end{array}
$$





\section{Arona}

Proyectos socioeducativos

Programa de acompañamiento a personas mayores en situación de soledad no voluntaria.

Fichas de los proyectos socioeducativos

Programa de acompañamiento a personas mayores en situación de soledad no voluntaria. (No rellena la ficha)

\section{Arafo}

Proyectos socioeducativos

Programa Movimiento y Salud.

Fichas de los proyectos socioeducativos

\section{Programa Movimiento y Salud}

\begin{tabular}{|l|l|}
\hline Año de inicio & \\
\hline Datos de contacto & Se incluyen en el directorio. \\
\hline Área / Concejalía responsable & \\
\hline Entidad responsable & Formas Nivaria \\
\hline Descripción & \\
\hline Número máximo de plazas ofertadas & Mujeres \\
\hline Mayoritariamente participan & \\
\hline Edad mínima para participar & \\
\hline Actividad accesible desde el punto de \\
vista de la movilidad \\
\hline $\begin{array}{l}\text { Coste de la actividad para las personas } \\
\text { beneficiarias }\end{array}$ \\
\hline Planificación temporal de la actividad \\
\hline Horario de la actividad \\
\hline Lugar en el que se realiza la actividad \\
\hline Desplazamiento de las personas \\
beneficiarias a la actividad
\end{tabular}




\section{Candelaria}

\section{Proyectos socioeducativos}

Sonrisas Mayores (Proyecto de acompañamiento a personas mayores de la Fundación Candelaria Solidaria).

CERI (Centro especial de recuperación integral).

Proyecto de Acompañamiento.

Mayores conectados.

Fichas de los proyectos socioeducativos

\section{Sonrisas Mayores (Proyecto de acompañamiento a personas mayores de la Fundación Candelaria Solidaria)}

\begin{tabular}{|c|c|}
\hline Año de inicio & 2020 \\
\hline Datos de contacto & Se incluyen en el directorio. \\
\hline \multicolumn{2}{|l|}{ Área / Concejalía responsable } \\
\hline Entidad responsable & Fundación Candelaria Solidaria. \\
\hline Descripción & $\begin{array}{l}\text { Sonrisas Mayores permite generar espacios } \\
\text { para la promoción de la autonomía y apoyo } \\
\text { social, destinados a las personas en proceso } \\
\text { de envejecimiento que presentan diferentes } \\
\text { discapacidades o necesidades de apoyo, } \\
\text { ofreciendo un programa de actuaciones de } \\
\text { prevención y mantenimiento de las } \\
\text { capacidades básicas de la vida diaria y la } \\
\text { vida en la comunidad. Actuaciones que se } \\
\text { desarrolla en el domicilio de las personas } \\
\text { beneficiarias. }\end{array}$ \\
\hline Número máximo de plazas ofertadas & 60 \\
\hline Mayoritariamente participan & Mujeres. \\
\hline \multicolumn{2}{|l|}{ Edad mínima para participar } \\
\hline $\begin{array}{l}\text { Actividad accesible desde el punto de } \\
\text { vista de la movilidad }\end{array}$ & Sí. \\
\hline $\begin{array}{l}\text { Coste de la actividad para las personas } \\
\text { beneficiarias }\end{array}$ & Gratuita. \\
\hline Planificación temporal de la actividad & Anual. \\
\hline
\end{tabular}


Horario de la actividad

Lugar en el que se realiza la actividad

Desplazamiento de las personas

beneficiarias a la actividad
Por la mañana.

Locales de asociaciones de vecinos, locales culturales, y domicilio.

Por cuenta propia y se ofrece un servicio de transporte.

\section{CERI (Centro especial de recuperación integral)}

\begin{tabular}{|c|c|}
\hline Año de inicio & 2007 \\
\hline Datos de contacto & Se incluyen en el directorio. \\
\hline Área / Concejalía responsable & $\begin{array}{l}\text { Servicios Sociales del Ayuntamiento de } \\
\text { Candelaria }\end{array}$ \\
\hline \multicolumn{2}{|l|}{ Entidad responsable } \\
\hline Descripción & $\begin{array}{c}\text { Intervenciones técnico-profesionales, } \\
\text { dirigidas al desarrollo de las capacidades } \\
\text { personales y a la integración de la persona } \\
\text { usuaria en su unidad convivencial y en su } \\
\text { mundo relacional. } \\
\text { Logopedia grupal e individualizada. } \\
\text { Animación terapéutica: actividades de } \\
\text { psicomotricidad, coordinación espacio - } \\
\text { temporal, habilidades cognitivas. } \\
\text { Psicólogo/a. }\end{array}$ \\
\hline \multicolumn{2}{|l|}{ Número máximo de plazas ofertadas } \\
\hline Mayoritariamente participan & Mujeres. \\
\hline \multicolumn{2}{|l|}{ Edad mínima para participar } \\
\hline $\begin{array}{l}\text { Actividad accesible desde el punto de } \\
\text { vista de la movilidad }\end{array}$ & Sí. \\
\hline $\begin{array}{l}\text { Coste de la actividad para las personas } \\
\text { beneficiarias }\end{array}$ & Gratuita. \\
\hline Planificación temporal de la actividad & Anual. \\
\hline Horario de la actividad & Por la mañana (9:30 a 13:00). \\
\hline Lugar en el que se realiza la actividad & Dependencias municipales. \\
\hline $\begin{array}{l}\text { Desplazamiento de las personas } \\
\text { beneficiarias a la actividad }\end{array}$ & $\begin{array}{c}\text { Por cuenta propia, se ofrece un servicio de } \\
\text { transporte. }\end{array}$ \\
\hline
\end{tabular}




\section{Proyecto de Acompañamiento}

\begin{tabular}{|c|c|}
\hline Año de inicio & 2019 \\
\hline Datos de contacto & Se incluyen en el directorio. \\
\hline \multicolumn{2}{|l|}{ Área / Concejalía responsable } \\
\hline Entidad responsable & Parroquia. \\
\hline Descripción & $\begin{array}{c}\text { Proyecto de acompañamiento a las } \\
\text { personas mayores, desarrollado en el } \\
\text { municipio de Candelaria, a través de } \\
\text { actividades en el domicilio realizadas por } \\
\text { voluntarios/as. } \\
\text { Se podrán beneficiar de dicho proyecto las } \\
\text { personas mayores que viven de manera } \\
\text { independiente o dependientes en sus } \\
\text { domicilios, evitando de este modo el } \\
\text { aislamiento social y aumentando la calidad } \\
\text { de vida de estas personas, buscando el } \\
\text { bienestar propio y de sus familias. }\end{array}$ \\
\hline \multicolumn{2}{|l|}{ Número máximo de plazas ofertadas } \\
\hline Mayoritariamente participan & Mixto. \\
\hline \multicolumn{2}{|l|}{ Edad mínima para participar } \\
\hline $\begin{array}{l}\text { Actividad accesible desde el punto de } \\
\text { vista de la movilidad }\end{array}$ & Sí. \\
\hline $\begin{array}{l}\text { Coste de la actividad para las personas } \\
\text { beneficiarias }\end{array}$ & Gratuita. \\
\hline Planificación temporal de la actividad & Anual. \\
\hline Horario de la actividad & Mañana y tarde. \\
\hline Lugar en el que se realiza la actividad & $\begin{array}{l}\text { Al aire libre y en el domicilio de las personas } \\
\text { participantes. }\end{array}$ \\
\hline $\begin{array}{l}\text { Desplazamiento de las personas } \\
\text { beneficiarias a la actividad }\end{array}$ & Por cuenta propia. \\
\hline
\end{tabular}




\section{Mayores conectados}

\begin{tabular}{|c|c|}
\hline Año de inicio & 2020 \\
\hline Datos de contacto & Se incluyen en el directorio. \\
\hline \multicolumn{2}{|l|}{ Área / Concejalía responsable } \\
\hline Entidad responsable & ONG Balanced World \\
\hline Descripción & $\begin{array}{l}\text { Debido a la situación actual provocada por } \\
\text { el virus SARS-COV-2, se está produciendo un } \\
\text { menoscabo significativo en la salud física y } \\
\text { psicológica de las personas en general, y de } \\
\text { las personas mayores de } 65 \text { años en } \\
\text { particular (especialmente las que están } \\
\text { solas). Por ello nace el proyecto } 59 \text { personas } \\
\text { mayores de } 65 \text { años que requieran } \\
\text { @asistencia y/o acompañamiento } \\
\text { psicológico, y deseen formación digital. }\end{array}$ \\
\hline Número máximo de plazas ofertadas & 59 \\
\hline \multicolumn{2}{|l|}{ Mayoritariamente participan } \\
\hline \multicolumn{2}{|l|}{ Edad mínima para participar } \\
\hline $\begin{array}{l}\text { Actividad accesible desde el punto de } \\
\text { vista de la movilidad }\end{array}$ & Sí. \\
\hline $\begin{array}{l}\text { Coste de la actividad para las personas } \\
\text { beneficiarias }\end{array}$ & Gratuita. \\
\hline Planificación temporal de la actividad & Cuatro meses. \\
\hline \multicolumn{2}{|l|}{ Horario de la actividad } \\
\hline Lugar en el que se realiza la actividad & Al aire libre y a domicilio. \\
\hline $\begin{array}{l}\text { Desplazamiento de las personas } \\
\text { beneficiarias a la actividad }\end{array}$ & Por cuenta propia. \\
\hline
\end{tabular}

\section{Proyectos socioeducativos}

Gimnasia de mantenimiento para personas mayores.

Los Mayores de El Rosario van a la playa.

Actividad fin de verano. 
Fichas de los proyectos socioeducativos

\section{Gimnasia de mantenimiento para personas mayores}

\begin{tabular}{|lc|}
\hline Año de inicio & 2006 \\
\hline Datos de contacto & Se incluyen en el directorio. \\
\hline Área / Concejalía responsable & Concejalía de Acción Social \\
\hline Entidad responsable & Iltre. Ayto. El Rosario \\
\hline $\begin{array}{l}\text { Descripción } \\
\text { Número máximo de plazas ofertadas } \\
\text { senderos. }\end{array}$ & 100 \\
\hline $\begin{array}{l}\text { Mayoritariamente participan } \\
\text { Edad mínima para participar }\end{array}$ & Mujeres. \\
\hline $\begin{array}{l}\text { Actividad accesible desde el punto de } \\
\text { vista de la movilidad }\end{array}$ & 50 \\
\hline $\begin{array}{l}\text { Coste de la actividad para las personas } \\
\text { beneficiarias }\end{array}$ & Gratis. \\
\hline $\begin{array}{l}\text { Planificación temporal de la actividad } \\
\text { Horario de la actividad }\end{array}$ & De octubre a junio. \\
\hline Lugar en el que se realiza la actividad \\
$\begin{array}{l}\text { Desplazamiento de las personas } \\
\text { beneficiarias a la actividad }\end{array}$ & Por la mañana. \\
\hline
\end{tabular}

\section{Los Mayores de El Rosario van a la playa}

\author{
Año de inicio \\ Datos de contacto \\ Área / Concejalía responsable \\ Entidad responsable \\ Descripción \\ Número máximo de plazas ofertadas \\ Mayoritariamente participan \\ Edad mínima para participar \\ Actividad accesible desde el punto de \\ vista de la movilidad \\ Coste de la actividad para las personas \\ beneficiarias \\ Planificación temporal de la actividad \\ Horario de la actividad \\ Lugar en el que se realiza la actividad \\ Desplazamiento de las personas \\ beneficiarias a la actividad
}

2006

Se incluyen en el directorio.

Concejalía de Acción Social Iltre. Ayto. El Rosario

Ejercicios físicos juegos, talleres, charlas y senderos. $150+20$

Mujeres.

Sí.

Gratis.

Trimestral.

Por la mañana, de 8:00 a 13:30 horas. Al aire libre, Playa de Las Teresitas y Playa de Radazul.

Se ofrece un servicio de transporte. 


\section{Actividad fin de verano}

\begin{tabular}{|l|c|}
\hline Año de inicio & 2010 \\
\hline Datos de contacto & Se incluyen en el directorio. \\
\hline $\begin{array}{l}\text { Área / Concejalía responsable } \\
\text { Entidad responsable }\end{array}$ & $\begin{array}{c}\text { Concejalía de Acción Social } \\
\text { Iltre. Ayto. El Rosario }\end{array}$ \\
\hline $\begin{array}{l}\text { Descripción } \\
\text { Visita cultural y de ocio a un municipio de las } \\
\text { islas Canarias. }\end{array}$ \\
\hline $\begin{array}{l}\text { Número máximo de plazas ofertadas } \\
\text { Mayoritariamente participan }\end{array}$ \\
\hline $\begin{array}{l}\text { Edad mínima para participar } \\
\text { Actividad accesible desde el punto de } \\
\text { vista de la movilidad }\end{array}$ \\
\hline $\begin{array}{l}\text { Coste de la actividad para las personas } \\
\text { beneficiarias }\end{array}$ \\
\hline $\begin{array}{l}\text { Planificación temporal de la actividad } \\
\text { Horario de la actividad }\end{array}$ \\
\hline $\begin{array}{l}\text { Lugar en el que se realiza la actividad } \\
\text { Desplazamiento de las personas } \\
\text { beneficiarias a la actividad }\end{array}$
\end{tabular}

\section{El Sauzal}

Proyectos socioeducativos

Talleres por los barrios.

Fichas de los proyectos socioeducativos

\section{Talleres por los barrios}

\begin{tabular}{|lc|}
\hline Año de inicio & 2019 \\
\hline Datos de contacto & Se incluyen en el directorio. \\
\hline Área / Concejalía responsable & Concejalía de Mayores. \\
\hline Entidad responsable & Generación 21 \\
\hline Descripción & Talleres de ocio y tiempo libre. \\
\hline Número máximo de plazas ofertadas & 50 \\
\hline Mayoritariamente participan & Mujeres. \\
\hline Edad mínima para participar & 55 \\
\hline $\begin{array}{l}\text { Actividad accesible desde el punto de } \\
\text { vista de la movilidad }\end{array}$ & Sí. \\
\hline $\begin{array}{l}\text { Coste de la actividad para las personas } \\
\text { beneficiarias } \\
\text { Planificación temporal de la actividad }\end{array}$ & Gratis. \\
\hline
\end{tabular}


Horario de la actividad

Lugar en el que se realiza la actividad

Desplazamiento de las personas

beneficiarias a la actividad
Por la tarde, de 17:00 a 20:00 horas. Locales de Asociaciones de Vecinos.

Por cuenta propia.

\section{El Tanque}

Proyectos socioeducativos

Manejo de las redes sociales.

Semana del mayor (no rellena ficha).

Fichas de los proyectos socioeducativos

\section{Manejo de las redes sociales}

\begin{tabular}{|c|c|}
\hline Año de inicio & 2020 \\
\hline Datos de contacto & Se incluyen en el directorio. \\
\hline Área / Concejalía responsable & Mayores \\
\hline Entidad responsable & $\begin{array}{l}\text { Fundación Ciber, voluntarios y } \\
\text { Ayuntamiento de El Tanque. }\end{array}$ \\
\hline Descripción & $\begin{array}{l}\text { Conocer el manejo de las redes } \\
\text { sociales. }\end{array}$ \\
\hline Número máximo de plazas oferładas & 6 \\
\hline Mayoritariamente participan & Hombres. \\
\hline Edad mínima para participar & 55 \\
\hline $\begin{array}{l}\text { Actividad accesible desde el punto de } \\
\text { vista de la movilidad }\end{array}$ & Sí. \\
\hline $\begin{array}{l}\text { Coste de la actividad para las personas } \\
\text { beneficiarias }\end{array}$ & Gratis. \\
\hline Planificación temporal de la actividad & Anual. \\
\hline Horario de la actividad & Por la tarde, de 16:00 a 17:30 horas. \\
\hline Lugar en el que se realiza la actividad & Dependencias municipales. \\
\hline $\begin{array}{l}\text { Desplazamiento de las personas } \\
\text { beneficiarias a la actividad }\end{array}$ & Por cuenta propia. \\
\hline
\end{tabular}

\section{Fasnia}

Proyectos socioeducativos

Envejecimiento activo.

Ocio saludable. 


\section{Envejecimiento activo}

\begin{tabular}{|c|c|}
\hline Año de inicio & 2011 \\
\hline Datos de contacto & Se incluyen en el directorio. \\
\hline Área / Concejalía responsable & Servicios Sociales y Mayores \\
\hline Entidad responsable & Ayuntamiento de Fasnia \\
\hline Descripción & $\begin{array}{l}\text { Este proyecto está integrado por dos } \\
\text { actividades: } \\
\text { - La desarrollada por un fisioterapeuta que } \\
\text { presta apoyo en el centro o en domicilios, } \\
\text { con el objeto de promover la mejora en la } \\
\text { calidad de vida por medio de la } \\
\text { estimulación física terapéutica. } \\
\text { - Actividad grupal dirigida a personas con } \\
\text { limitaciones en la movilidad que tengan } \\
\text { dificultades en participar en las actividades } \\
\text { de ocio para mayores, en la que se procura } \\
\text { trabajar la estimulación cognitiva y la física } \\
\text { en un espacio de encuentro. }\end{array}$ \\
\hline Número máximo de plazas oferładas & 24 \\
\hline Mayoritariamente participan & Mujeres. \\
\hline Edad mínima para participar & 60 \\
\hline $\begin{array}{l}\text { Actividad accesible desde el punto de } \\
\text { vista de la movilidad }\end{array}$ & Sí. \\
\hline $\begin{array}{l}\text { Coste de la actividad para las personas } \\
\text { beneficiarias }\end{array}$ & Gratuita. \\
\hline Planificación temporal de la actividad & Anual. \\
\hline Horario de la actividad & Por la mañana. \\
\hline Lugar en el que se realiza la actividad & Locales culturales y domicilios. \\
\hline $\begin{array}{l}\text { Desplazamiento de las personas } \\
\text { beneficiarias a la actividad }\end{array}$ & $\begin{array}{c}\text { Por cuenta propia y se ofrece servicio de } \\
\text { transporte. }\end{array}$ \\
\hline
\end{tabular}

\section{Ocio saludable}

Año de inicio

Datos de contacto

Área / Concejalía responsable

Entidad responsable

Descripción
2011

Se incluyen en el directorio.

Servicios Sociales y Mayores

Ayuntamiento de Fasnia

La actividad de ocio se desarrolla en tres pueblos del municipio para facilitar el

acceso de las personas mayores participantes. Se desarrolla una vez en la semana en cada uno de ellos y suelen prestarse actividades dirigidas al mantenimiento físico y manualidades. 
Número máximo de plazas ofertadas

Mayoritariamente participan

Edad mínima para participar

Actividad accesible desde el punto de

vista de la movilidad

Coste de la actividad para las personas

beneficiarias

Planificación temporal de la actividad

Horario de la actividad

Lugar en el que se realiza la actividad

Desplazamiento de las personas

beneficiarias a la actividad
Por otro lado, se realiza la actividad de piscina donde dos grupos de unas 12 personas son trasladadas a la piscina de Güímar una vez a la semana para realizan actividades y juegos en el agua.

30

Mujeres.

60

Sí.

Gratuita.

Anual.

Por la mañana.

Locales culturales y aire libre.

Por cuenta propia y se ofrece servicio de transporte.

\section{Garachico}

\section{Proyectos socioeducativos}

No tiene 0 no indica programas, proyectos 0 actividades socioeducativas dirigidas a personas mayores.

Fichas de los proyectos socioeducativos

No se rellenan las fichas para el apartado de proyectos socioeducativos.

\section{Guía de Isora}

\section{Proyectos socioeducativos}

Proyecto de acompañamiento a personas mayores en soledad.

Proyecto de apoyo al Área de mayores en materia de intervención psicológica y fisioterapia por situación de alerta sanitaria.

Programa de ocio y tiempo libre dirigido a mayores con actividades especializadas dirigidas a mayores de la escuela municipal de ocio y tiempo libre.

Programa de colaboración en materia de ocio y tiempo libre entre la Caixa y la Concejalía de mayores. 
Jornadas de celebración del Día del Mayor.

Actividades de verano en la playa y otras actividades de ocio.

Formación específica en materia de asociacionismo para mayores, informática y otros.

Fichas de los proyectos socioeducativos

No se rellenan las fichas para el apartado de proyectos socioeducativos.

\section{lcod de Los Vinos}

\section{Proyectos socioeducativos}

No tiene programas, proyectos o actividades socioeducativas dirigidas a personas mayores.

Fichas de los proyectos socioeducativos

No se rellenan las fichas para el apartado de proyectos socioeducativos.

\section{La Guancha}

Proyectos socioeducativos

Turismo social.

Respiro familiar.

Subvenciones para el folklore dirigidos a las asociaciones de mayores: La Guacha Casco, XXV de Noviembre y Renacer Costero.

Fichas de los proyectos socioeducativos

No se rellenan las fichas para el apartado de proyectos socioeducativos.

\section{La Matanza}

\section{Proyectos socioeducativos}

Responde que tienen más de 5 programas, proyectos 0 actividades socioeducativas dirigidas a personas mayores, pero no indican ninguna. 
Fichas de los proyectos socioeducativos

No se rellenan las fichas para el apartado de proyectos socioeducativos.

\section{La Orotava}

\section{Proyectos socioeducativos}

Salud y bienestar.

Programa de ocio.

Proyecto de mejora y actualización informática 3.0.

Promoción del voluntariado en personas mayores.

Programa cuidado de la persona cuidadora.

Fichas de los proyectos socioeducativos

\section{Salud y bienestar}

\begin{tabular}{|c|c|}
\hline Año de inicio & 2012 \\
\hline Datos de contacto & Se incluyen en el directorio. \\
\hline Área / Concejalía responsable & Protección y Promoción Social \\
\hline Entidad responsable & Ayuntamiento de La Orotava \\
\hline Descripción & $\begin{array}{c}\text { Planificación de actividades saludables que } \\
\text { mejoren la calidad de vida de las personas } \\
\text { mayores. }\end{array}$ \\
\hline Número máximo de plazas oferładas & $\begin{array}{c}\text { Variable (depende de la actividad a la que } \\
\text { se inscriban). }\end{array}$ \\
\hline Mayoritariamente participan & Mujeres. \\
\hline Edad mínima para participar & 55 \\
\hline $\begin{array}{l}\text { Actividad accesible desde el punto de } \\
\text { vista de la movilidad }\end{array}$ & Sí. \\
\hline $\begin{array}{l}\text { Coste de la actividad para las personas } \\
\text { beneficiarias }\end{array}$ & Gratis. \\
\hline Planificación temporal de la actividad & Anual. \\
\hline Horario de la actividad & Mañana y tarde de 9:00 a 19:00 horas. \\
\hline Lugar en el que se realiza la actividad & $\begin{array}{l}\text { Dependencias municipales, locales de las } \\
\text { Asociaciones de Mayores. }\end{array}$ \\
\hline $\begin{array}{l}\text { Desplazamiento de las personas } \\
\text { beneficiarias a la actividad }\end{array}$ & Por cuenta propia. \\
\hline
\end{tabular}




\section{Programa de ocio}

\begin{tabular}{|c|c|}
\hline Año de inicio & 2012 \\
\hline Datos de contacto & Se incluyen en el directorio. \\
\hline \multicolumn{2}{|l|}{ Área / Concejalía responsable } \\
\hline Entidad responsable & Ayuntamiento de La Orotava \\
\hline Descripción & $\begin{array}{c}\text { Programación de actividades que fomenten } \\
\text { las condiciones sociales de los mayores } \\
\text { usuarios/as, promocionando el ocio y su } \\
\text { disfrute. Por ejemplo, programación de } \\
\text { excursiones, salidas, actividades culturales, } \\
\text { etc. }\end{array}$ \\
\hline Número máximo de plazas ofertadas & $\begin{array}{c}\text { Variable (depende de la actividad } \\
\text { planificada). }\end{array}$ \\
\hline Mayoritariamente participan & Mujeres. \\
\hline \multicolumn{2}{|l|}{ Edad mínima para participar } \\
\hline $\begin{array}{l}\text { Actividad accesible desde el punto de } \\
\text { vista de la movilidad }\end{array}$ & Sí. \\
\hline $\begin{array}{l}\text { Coste de la actividad para las personas } \\
\text { beneficiarias }\end{array}$ & Gratis. \\
\hline Planificación temporal de la actividad & Anual. \\
\hline Horario de la actividad & Mañana y/o tarde de 9:00 a 19:30 horas. \\
\hline Lugar en el que se realiza la actividad & $\begin{array}{l}\text { Dependencias municipales, al aire libre, } \\
\text { Asociaciones de mayores del municipio. }\end{array}$ \\
\hline $\begin{array}{l}\text { Desplazamiento de las personas } \\
\text { beneficiarias a la actividad }\end{array}$ & Por cuenta propia. \\
\hline
\end{tabular}

\section{Proyecto de mejora y actualización informática 3.0}

\author{
Año de inicio \\ Datos de contacto \\ Área / Concejalía responsable \\ Entidad responsable \\ Descripción \\ Número máximo de plazas ofertadas \\ Mayoritariamente participan \\ Edad mínima para participar \\ Actividad accesible desde el punto de \\ vista de la movilidad \\ Coste de la actividad para las personas \\ beneficiarias \\ Planificación temporal de la actividad \\ Horario de la actividad
}

\begin{tabular}{c}
2012 \\
\hline Se incluyen en el directorio. \\
Ayuntamiento de La Orotava \\
Reducir la brecha tecnológica de las \\
personas mayores. Actividades relacionadas \\
con la actualización informática y mejora en \\
el manejo de redes sociales. \\
Variable (depende de la actividad \\
programada). \\
Mujeres. \\
Sí. \\
Gratis. \\
Anual. \\
\hline Por la mañana de 9:00 a 13:00 horas.
\end{tabular}


Lugar en el que se realiza la actividad

Desplazamiento de las personas

beneficiarias a la actividad
Dependencias municipales.

Por cuenta propia.

\section{Promoción del voluntariado en personas mayores}

\section{Año de inicio \\ Datos de contacto \\ Área / Concejalía responsable \\ Entidad responsable}

Descripción

Número máximo de plazas ofertadas

Mayoritariamente participan

Edad mínima para participar

Actividad accesible desde el punto de

vista de la movilidad

Coste de la actividad para las personas

beneficiarias

Planificación temporal de la actividad

Horario de la actividad

Lugar en el que se realiza la actividad

Desplazamiento de las personas

beneficiarias a la actividad
2012

Se incluyen en el directorio.

Ayuntamiento de La Orotava y AMAVITE En colaboración con la Asociación de Mayores Voluntarios de Tenerife, se fomenta la participación de personas mayores en acciones y proyectos de voluntariado, tales como acompañamiento social, club de lectura en centros residenciales, etc.

Variable (depende de la actividad programada). Mujeres.

Sí.

Gratis.

Anual.

Mañana y tarde de 9:00 a 19:30 horas.

Dependencias municipales, al aire libre, en el domicilio de la persona usuaria, en los diferentes centros residenciales, etc.

Por cuenta propia, se pagan traslados.

\section{Programa cuidado de la persona cuidadora}

Año de inicio

Datos de contacto

Área / Concejalía responsable

Entidad responsable

Descripción

Número máximo de plazas ofertadas

Mayoritariamente participan

Edad mínima para participar
2012- 2014

Se incluyen en el directorio.

Ayuntamiento de La Orotava y ACUFADE y

Servicio Canario de Salud.

Proyecto destinado a personas cuidadoras, que busca conectar nuevas redes sociales

que les permitan mejorar su calidad de vida. Aparte de formación específica para

cuidadoras, se busca motivarlas y reforzarlas en diferentes recursos con sus labores de cuidado.

Mujeres. 
Actividad accesible desde el punto de

vista de la movilidad

Coste de la actividad para las personas

beneficiarias

Planificación temporal de la actividad

Horario de la actividad

Lugar en el que se realiza la actividad

Desplazamiento de las personas

beneficiarias a la actividad
Sí.

Gratis.

Anual.

Por la tarde. Último jueves de cada mes de

17 a 19 horas, más actividades online.

Dependencias municipales, al aire libre.

Por cuenta propia, se pagan traslados.

\section{La Victoria de Acentejo}

Proyectos socioeducativos

Apoyo a la unidad convivencial con mayores.

Fichas de los proyectos socioeducativos

\section{Apoyo a la unidad convivencial con mayores}

\begin{tabular}{|c|c|}
\hline Año de inicio & 2018 \\
\hline Datos de contacto & Se incluyen en el directorio. \\
\hline Área / Concejalía responsable & \\
\hline Entidad responsable & Ayuntamiento de La Victoria de Acentejo. \\
\hline Descripción & $\begin{array}{l}\text { Apoyo psicológico y de fisioterapia a } \\
\text { mayores y sus cuidadoras en domicilio. }\end{array}$ \\
\hline Número máximo de plazas ofertadas & llimitado. \\
\hline Mayoritariamente participan & Mixto. \\
\hline Edad mínima para participar & \\
\hline $\begin{array}{l}\text { Actividad accesible desde el punto de } \\
\text { vista de la movilidad }\end{array}$ & Sí. \\
\hline $\begin{array}{l}\text { Coste de la actividad para las personas } \\
\text { beneficiarias }\end{array}$ & Gratis. \\
\hline Planificación temporal de la actividad & Mensual. \\
\hline Horario de la actividad & Mañana y tarde. \\
\hline Lugar en el que se realiza la actividad & En los domicilios de los mayores. \\
\hline $\begin{array}{l}\text { Desplazamiento de las personas } \\
\text { beneficiarias a la actividad }\end{array}$ & El personal va al domicilio de los mayores. \\
\hline
\end{tabular}

\section{Los Realejos}

Proyectos socioeducativos

Proyecto Mayores en soledad. 
Fichas de los proyectos socioeducativos

Proyecto Mayores en soledad (no se rellena la ficha).

\section{Los Silos}

Proyectos socioeducativos

No tiene $\bigcirc$ no indica programas, proyectos $\bigcirc$ actividades socioeducativas dirigidas a personas mayores.

Fichas de los proyectos socioeducativos

No se rellenan las fichas para el apartado de proyectos socioeducativos.

\section{San Cristóbal de La Laguna}

Programas, proyectos y/o actividades socioeducativas

Programa de dinamización de mayores. 


\section{Programa de dinamización de mayores}

\begin{tabular}{|c|c|}
\hline Año de inicio & 2001 \\
\hline Datos de contacto & Se incluyen en el directorio. \\
\hline Área / Concejalía responsable & Bienestar Social \\
\hline Entidad responsable & Bienestar Social \\
\hline Descripción & $\begin{array}{l}\text { Asesoramiento, gestión y coordinación de } \\
\text { actividades para las asociaciones de } \\
\text { mayores del municipio. Es permanente, sin } \\
\text { personal propio. Coordina diversos proyectos } \\
\text { dirigidos a un "envejecimiento activo y/o } \\
\text { saludable": talleres formativos (adaptados en } \\
\text { varios formatos a causa de la pandemia } \\
\text { actual), ocio y tiempo libre (suspendido } \\
\text { temporalmente), aula de cultura, } \\
\text { senderismo, programación de otras } \\
\text { actividades a lo largo del año, Encuentro } \\
\text { Anual de Mayores, etc. }\end{array}$ \\
\hline Número máximo de plazas ofertadas & No hay plazas limitadas \\
\hline Mayoritariamente participan & Mujeres \\
\hline Edad mínima para participar & 60 aunque no hay sesgo de entrada. \\
\hline $\begin{array}{l}\text { Actividad accesible desde el punto de } \\
\text { vista de la movilidad }\end{array}$ & No. \\
\hline $\begin{array}{l}\text { Coste de la actividad para las personas } \\
\text { beneficiarias }\end{array}$ & $\begin{array}{c}\text { Son gratuitas las organizadas por el } \\
\text { Ayuntamiento. }\end{array}$ \\
\hline Planificación temporal de la actividad & Anual. \\
\hline Horario de la actividad & $\begin{array}{l}\text { Por lo general en horario de tarde. } \\
\text { 16:00 a 19:00h. }\end{array}$ \\
\hline Lugar en el que se realiza la actividad & $\begin{array}{l}\text { Locales de asociaciones de vecinos, al aire } \\
\text { libre. }\end{array}$ \\
\hline $\begin{array}{l}\text { Desplazamiento de las personas } \\
\text { beneficiarias a la actividad }\end{array}$ & $\begin{array}{c}\text { Por cuenta propia, se ofrece un servicio de } \\
\text { transporte y depende del tipo de actividad } \\
\text { organizada. }\end{array}$ \\
\hline
\end{tabular}

\section{San Juan de La Rambla}

\section{Proyectos socioeducativos}

No tiene programas, proyectos o actividades socioeducativas dirigidas a personas mayores.

\section{Fichas de los proyectos socioeducativos}

No se rellenan las fichas para el apartado de proyectos socioeducativos. 


\section{Santa Cruz de Tenerife}

\section{Proyectos socioeducativos}

Personas mayores en situación de vulnerabilidad.

Envejecimiento activo y saludable.

Rompiendo Barreras.

Proyecto de bienestar integral.

Dinamización de las asociaciones de mayores para un ocio y tiempo libre saludable y positivo y potenciación de las redes comunitarias.

Cooperación social subvenciones entidades.

Fichas de los proyectos socioeducativos

\section{Personas mayores en situación de vulnerabilidad}

\begin{tabular}{|c|c|}
\hline Año de inicio & 2016 \\
\hline Datos de contacto & Se incluyen en el directorio. \\
\hline Área / Concejalía responsable & Acción Social. \\
\hline Entidad responsable & $\begin{array}{l}\text { Instituto Municipal de Atención Social } \\
\text { (IMAS). }\end{array}$ \\
\hline Descripción & $\begin{array}{c}\text { Prevención, detección e intervención con } \\
\text { personas mayores en situación de } \\
\text { vulnerabilidad. }\end{array}$ \\
\hline Número máximo de plazas ofertadas & $\begin{array}{c}\text { Se atienden todas las comunicaciones de } \\
\text { posibles personas en situación de } \\
\text { vulnerabilidad. }\end{array}$ \\
\hline Mayoritariamente participan & \\
\hline Edad mínima para participar & 60 \\
\hline $\begin{array}{l}\text { Actividad accesible desde el punto de } \\
\text { vista de la movilidad } \\
\text { Coste de la actividad para las personas } \\
\text { beneficiarias }\end{array}$ & \\
\hline Planificación temporal de la actividad & Continua. \\
\hline Horario de la actividad & Por la mañana, 7 a 15 h. \\
\hline Lugar en el que se realiza la actividad & $\begin{array}{l}\text { Dependencias municipales, domicilio de las } \\
\text { personas y entorno inmediato de la } \\
\text { persona. }\end{array}$ \\
\hline
\end{tabular}




\section{Envejecimiento activo y saludable}

\begin{tabular}{|c|c|}
\hline Año de inicio & 1992 \\
\hline Datos de contacto & Se incluyen en el directorio. \\
\hline Área / Concejalía responsable & Acción Social. \\
\hline Entidad responsable & Instituto Municipal de Atención Social (IMAS) \\
\hline Descripción & $\begin{array}{c}\text { Actividades para la promoción de la } \\
\text { autonomía personal. }\end{array}$ \\
\hline Número máximo de plazas ofertadas & Abierto. \\
\hline Mayoritariamente participan & Mujeres. \\
\hline \multicolumn{2}{|l|}{ Edad mínima para participar } \\
\hline $\begin{array}{l}\text { Actividad accesible desde el punto de } \\
\text { vista de la movilidad }\end{array}$ & Sí. \\
\hline $\begin{array}{l}\text { Coste de la actividad para las personas } \\
\text { beneficiarias }\end{array}$ & Gratuito. \\
\hline Planificación temporal de la actividad & $\begin{array}{c}\text { Permanente, a través de contrato mayor y } \\
\text { menor. }\end{array}$ \\
\hline Horario de la actividad & Mañana y tarde, 9 a 20 h. \\
\hline Lugar en el que se realiza la actividad & $\begin{array}{c}\text { Dependencias municipales, locales de } \\
\text { asociaciones de vecinos, locales culturales, } \\
\text { al aire libre y espacios públicos de todo tipo: } \\
\text { parques, culturales, patrimonio. }\end{array}$ \\
\hline $\begin{array}{l}\text { Desplazamiento de las personas } \\
\text { beneficiarias a la actividad }\end{array}$ & $\begin{array}{l}\text { Por cuenta propia, Se ofrece un servicio de } \\
\text { transporte, para actividades concretas. }\end{array}$ \\
\hline
\end{tabular}

\section{Rompiendo Barreras}

\begin{tabular}{l|c}
\hline Año de inicio & 2020 \\
\hline Datos de contacto & $\begin{array}{c}\text { Se incluyen en el directorio. } \\
\text { Acción Social. }\end{array}$ \\
\hline Área / Concejalía responsable & $\begin{array}{c}\text { Municipal de Atención Social } \\
\text { (IMAS) }\end{array}$ \\
\hline Entidad responsable & $\begin{array}{c}\text { Intervención en domicilio y entorno en } \\
\text { personas en situación de soledad y } \\
\text { aislamiento. }\end{array}$ \\
\hline Descripción & \begin{tabular}{c} 
Mujeres. \\
\hline Número máximo de plazas ofertadas
\end{tabular} \\
\hline Mayoritariamente participan & \begin{tabular}{c} 
Sí. \\
\hline Edad mínima para participar \\
Actividad accesible desde el punto de \\
vista de la movilidad \\
Coste de la actividad para las personas \\
beneficiarias
\end{tabular} \\
\hline $\begin{array}{l}\text { Planificación temporal de la actividad } \\
\text { Horario de la actividad }\end{array}$ & \begin{tabular}{c} 
Gensual. \\
\hline Lugar en el que se realiza la actividad
\end{tabular} \\
\hline $\begin{array}{l}\text { Desplazamiento de las personas } \\
\text { beneficiarias a la actividad }\end{array}$ & $\begin{array}{c}\text { Por cuenta propia, se desplaza el personal } \\
\text { técnico al domicilio y al entorno. }\end{array}$ \\
\hline
\end{tabular}




\section{Proyecto de bienestar integral}

\begin{tabular}{|c|c|}
\hline Año de inicio & 2019 \\
\hline Datos de contacto & Se incluyen en el directorio. \\
\hline Área / Concejalía responsable & Acción Social. \\
\hline Entidad responsable & $\begin{array}{l}\text { Instituto Municipal de Atención Social } \\
\text { (IMAS). }\end{array}$ \\
\hline Descripción & Promoción de la autonomía. \\
\hline Número máximo de plazas ofertadas & 200 \\
\hline Mayoritariamente participan & Mujeres. \\
\hline \multicolumn{2}{|l|}{ Edad mínima para participar } \\
\hline $\begin{array}{l}\text { Actividad accesible desde el punto de } \\
\text { vista de la movilidad }\end{array}$ & Sí. \\
\hline $\begin{array}{l}\text { Coste de la actividad para las personas } \\
\text { beneficiarias }\end{array}$ & Gratuito. \\
\hline Planificación temporal de la actividad & Mensual. \\
\hline Horario de la actividad & Mañana y tarde, 9 a 20 h. \\
\hline Lugar en el que se realiza la actividad & $\begin{array}{c}\text { Dependencias municipales, locales de } \\
\text { asociaciones de vecinos, locales culturales, } \\
\text { al aire libre, espacios públicos de toda } \\
\text { índole. }\end{array}$ \\
\hline $\begin{array}{l}\text { Desplazamiento de las personas } \\
\text { beneficiarias a la actividad }\end{array}$ & Por cuenta propia. \\
\hline
\end{tabular}




\section{Dinamización de las asociaciones de mayores para un ocio y}

tiempo libre saludable y positivo y potenciación de las redes comunitarias

\begin{tabular}{|c|c|}
\hline Año de inicio & 2020 \\
\hline Datos de contacto & Se incluyen en el directorio. \\
\hline Área / Concejalía responsable & Acción Social. \\
\hline Entidad responsable & $\begin{array}{l}\text { Instituto Municipal de Atención Social } \\
\text { (IMAS). }\end{array}$ \\
\hline Descripción & $\begin{array}{l}\text { Informe Diagnóstico del impacto del Covid- } \\
19 \text { en las asociaciones de mayores del } \\
\text { municipio y potenciar las actividades } \\
\text { saludables, redes comunitarias, brecha } \\
\text { digital, detección de vulnerabilidad. }\end{array}$ \\
\hline Número máximo de plazas oferładas & 45 asociaciones de mayores. \\
\hline Mayoritariamente participan & Mujeres. \\
\hline \multicolumn{2}{|l|}{ Edad mínima para participar } \\
\hline $\begin{array}{l}\text { Actividad accesible desde el punto de } \\
\text { vista de la movilidad }\end{array}$ & Sí. \\
\hline $\begin{array}{l}\text { Coste de la actividad para las personas } \\
\text { beneficiarias }\end{array}$ & Gratuito. \\
\hline Planificación temporal de la actividad & Mensual. \\
\hline Horario de la actividad & Mañana y tarde, 9 a 20 h. \\
\hline Lugar en el que se realiza la actividad & $\begin{array}{l}\text { Dependencias municipales, locales de } \\
\text { asociaciones de vecinos, locales culturales, } \\
\text { al aire libre, espacios públicos de toda } \\
\text { índole (actualmente aire libre). }\end{array}$ \\
\hline $\begin{array}{l}\text { Desplazamiento de las personas } \\
\text { beneficiarias a la actividad }\end{array}$ & Por cuenta propia. \\
\hline
\end{tabular}




\section{Cooperación social subvenciones entidades}

\begin{tabular}{|c|c|}
\hline Año de inicio & \\
\hline Datos de contacto & Se incluyen en el directorio. \\
\hline Área / Concejalía responsable & $\begin{array}{l}\text { Instituto Municipal de Atención Social } \\
\text { (IMAS). }\end{array}$ \\
\hline Entidad responsable & $\begin{array}{l}\text { Instituto Municipal de Atención Social } \\
\text { (IMAS). }\end{array}$ \\
\hline Descripción & $\begin{array}{c}\text { Subvenciones a entidades que ejecuten } \\
\text { proyectos en el municipio, entre estos para } \\
\text { personas mayores. }\end{array}$ \\
\hline Número máximo de plazas ofertadas & Establecido según bases que regulan. \\
\hline Mayoritariamente participan & \\
\hline Edad mínima para participar & \\
\hline $\begin{array}{l}\text { Actividad accesible desde el punto de } \\
\text { vista de la movilidad }\end{array}$ & \\
\hline $\begin{array}{l}\text { Coste de la actividad para las personas } \\
\text { beneficiarias }\end{array}$ & \\
\hline Planificación temporal de la actividad & \\
\hline Horario de la actividad & \\
\hline Lugar en el que se realiza la actividad & $\begin{array}{l}\text { Dependencias municipales y en las } \\
\text { entidades de los proyectos subvencionados } \\
\text { para hacer el seguimiento. }\end{array}$ \\
\hline $\begin{array}{l}\text { Desplazamiento de las personas } \\
\text { beneficiarias a la actividad }\end{array}$ & Por cuenta propia. \\
\hline
\end{tabular}

\section{Proyectos socioeducativos}

Programa de envejecimiento activo (animación sociocultural con mayores: canto, acompañamiento en domicilio, alfabetización, etc).

Programa de estimulación cognitiva. (No se rellena ficha).

Actividades deportivas varias: verano en la playa, piscina municipal, etc). (No se rellena ficha).

Apoyo al club de mayores. (No se rellena ficha). 


\section{Programa de envejecimiento activo (animación sociocultural con mayores: canto, acompañamiento en domicilio, alfabetización, etc)}

\begin{tabular}{|c|c|}
\hline Año de inicio & 2019 \\
\hline Datos de contacto & Se incluyen en el directorio \\
\hline Área / Concejalía responsable & $\begin{array}{c}\text { Deportes, Ocio y Tiempo Libre y Nuevas } \\
\text { Tecnologías }\end{array}$ \\
\hline Entidad responsable & Ilustre Ayuntamiento de Santa Úrsula \\
\hline Descripción & $\begin{array}{c}\text { Actividades de ocio y tiempo libre dirigidas a } \\
\text { la población adulta ( } 3^{\circ} \text { edad) del municipio } \\
\text { de Santa Úrsula. Los talleres son de nuevas } \\
\text { tecnologías, escuelita, estimulación } \\
\text { cognitiva, taller de lanas, parranda, } \\
\text { informática, gimnasia, ruta al aire libre, } \\
\text { manualidades y tejido y costura. }\end{array}$ \\
\hline Número máximo de plazas ofertadas & 10 personas por grupo, aproximadamente. \\
\hline \multicolumn{2}{|l|}{ Mayoritariamente participan } \\
\hline Edad mínima para participar & 60 años. \\
\hline $\begin{array}{l}\text { Actividad accesible desde el punto de } \\
\text { vista de la movilidad }\end{array}$ & Sí. \\
\hline $\begin{array}{l}\text { Coste de la actividad para las personas } \\
\text { beneficiarias }\end{array}$ & Gratuitas. \\
\hline Planificación temporal de la actividad & Actividades durante todo el año. \\
\hline Horario de la actividad & Mañana y tarde. \\
\hline Lugar en el que se realiza la actividad & $\begin{array}{c}\text { Centros de la Tercera Edad El Ciprés y La } \\
\text { Acequia, Centro Social El Tinglado, Pabellón } \\
\text { Fernando Lu }\end{array}$ \\
\hline $\begin{array}{l}\text { Desplazamiento de las personas } \\
\text { beneficiarias a la actividad }\end{array}$ & $\begin{array}{c}\text { Por cuenta propia, menos a la actividad de } \\
\text { la piscina que van con transporte facilitado } \\
\text { por el Ayuntamiento. }\end{array}$ \\
\hline
\end{tabular}

Proyectos socioeducativos

Mantenimiento físico para mayores. 
Fichas de los proyectos socioeducativos

\section{Mantenimiento físico para mayores}

\begin{tabular}{|c|c|}
\hline Año de inicio & \\
\hline Datos de contacto & Se incluyen en el directorio. \\
\hline Área / Concejalía responsable & Mayores \\
\hline Entidad responsable & Ayuntamiento de Santiago del Teide \\
\hline Descripción & $\begin{array}{l}\text { Se trata de una actividad de mantenimiento } \\
\text { físico adecuado a los mayores del municipio. }\end{array}$ \\
\hline Número máximo de plazas ofertadas & 3 grupos de 10 personas. \\
\hline Mayoritariamente participan & Mujeres. \\
\hline Edad mínima para participar & 50 \\
\hline $\begin{array}{l}\text { Actividad accesible desde el punto de } \\
\text { vista de la movilidad }\end{array}$ & Sí. \\
\hline $\begin{array}{l}\text { Coste de la actividad para las personas } \\
\text { beneficiarias }\end{array}$ & Gratuita. \\
\hline Planificación temporal de la actividad & \\
\hline Horario de la actividad & \\
\hline Lugar en el que se realiza la actividad & $\begin{array}{c}\text { Dependencias municipales, locales de } \\
\text { asociaciones de vecinos, locales culturales y } \\
\text { al aire libre. }\end{array}$ \\
\hline $\begin{array}{l}\text { Desplazamiento de las personas } \\
\text { beneficiarias a la actividad }\end{array}$ & Por cuenta propia \\
\hline
\end{tabular}

\section{Tacoronte}

Proyectos socioeducativos

No tiene $\bigcirc$ no indica programas, proyectos $\bigcirc$ actividades socioeducativas dirigidas a personas mayores.

Fichas de los proyectos socioeducativos

No se rellenan las fichas para el apartado de proyectos socioeducativos. 


\section{Tegueste}

Proyectos socioeducativos

Programa de Acompañamiento en la Soledad (temporal por subvención).

Fichas de los proyectos socioeducativos

No se rellenan las fichas para el apartado de proyectos socioeducativos.

\section{Vilaflor de Chasna}

\section{Proyectos socioeducativos}

Planificación y programación de la Concejalía de la Tercera Edad: Viajes culturales, fomento de la participación social, manualidades, informática para mayores, ejercicio en la playa, etc.

Fichas de los proyectos socioeducativos

No se rellenan las fichas para el apartado de proyectos socioeducativos. 

Anexo 2. Ficha sobre Servicios Sociales y Proyectos socioeducativos en los municipios de Tenerife 

Un equipo interdisciplinario de profesorado e investigadores de la Universidad de La Laguna pertenecientes al Centro de Estudios Universitarios de Desigualdad Social y Gobernanza, estamos llevando a cabo un estudio por encargo del Cabildo Insular de Tenerife, con el objeto de realizar un diagnóstico sobre la situación de las personas mayores en la isla de Tenerife.

La colaboración que le solicitamos consiste en la cumplimentación de los datos que especifican en esta ficha.

Es posible que haya datos que no pueda proporcionar o no estén disponibles. En ese caso, deje la casilla en blanco y continúe con las cuestiones que pueda responder. Cualquier información que nos proporcione resultará muy valiosa.

Se entiende que la persona que responde da su consentimiento informado para la utilización de estos datos en el citado estudio.

Si tiene cualquier consulta, no dude en dirigirla al equipo a través del correo electrónico grodrigs@ull.edu.es

Agradecemos de antemano su colaboración. 



\section{EQUIPOS MUNICIPALES}

Datos de contacto del/a profesional de referencia de la Unidad de Mayores / área de Servicios Sociales dedicada al trabajo con personas mayores;

- Nombre:

- Correo electrónico:

- Teléfono:

Autorizo a que los datos aquí consignados sean compartidos con el Instituto de Atención Social y Sociosanitaria (Cabildo Insular de Tenerife), a efectos de crear un directorio de profesionales de referencia en el trabajo con personas mayores desde el ámbito municipal (Sí / NO).

\section{EQUIPOS MUNICIPALES}

¿Cuenta el Ayuntamiento con un área específica dedicada a la intervención con personas mayores?

En su caso, composición del equipo técnico de la Unidad de Mayores / área específica

PLANES / PROGRAMAS MUNICIPALES DIRIGIDOS A PERSONAS MAYORES

Planes / Programas municipales dirigidos a personas mayores de los últimos 10 años: (Indicar el nombre y temporalidad)

SERVICIO DE AYUDA A DOMICILIO

EI SAD municipal está gestionado por

\begin{tabular}{|c|c|c|}
\hline El ayuntamiento & Una empresa privada (especificar) & Una ONG (especificar) \\
\hline
\end{tabular}

Número de usuarios/as 
Número de personas usuarias mayores de 65 años:

$\mathrm{N}^{\circ}$ de usuarios varones:

$\mathrm{N}^{\circ}$ de usuarias mujeres:

Número de trabajadoras/es en el servicio:

$\mathrm{N}^{0}$ auxiliares mujeres: ...... $\quad \mathrm{N}^{\circ}$ auxiliares varones: ......

Otros profesionales que constituyen el SAD (especificar):

\section{SERVICIO DE TELEASISTENCIA}

El servicio de teleasistencia municipal está gestionado por:

\begin{tabular}{l|l} 
El ayuntamiento & Una empresa privada (especificar)
\end{tabular}

Una ONG (especificar)

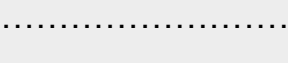

\section{Número de usuarios/as}

Número de personas usuarias mayores de 65 años:

$\mathrm{N}^{\circ}$ de usuarios varones:

$\mathrm{N}^{\circ}$ de usuarias mujeres:

VIVIENDAS TUTELADAS PARA PERSONAS MAYORES

\begin{tabular}{|c|c|c|c|c|}
\hline $\begin{array}{l}\text { ¿Existen viv } \\
\text { municipio? }\end{array}$ & ladas pa & ayores en el & Sí & NO \\
\hline En caso afirn & & & & \\
\hline ¿Con cuánta & cuenta el & & & \\
\hline Titularidad: & Pública & Privada & ON & \\
\hline
\end{tabular}

\section{CENTROS DE DÍA / ESTANCIA DIURNA}

\begin{tabular}{|l|l|}
\hline № de centros de día / estancia diurna en el municipio \\
\hline Nombre & Titularidad (pública, privada, ONG) \\
\hline & \\
\hline & \\
\hline & \\
\hline & \\
\hline & \\
\hline
\end{tabular}

\section{ASOCIACIONES DE MAYORES Y HOGARES / CLUBS DE LA TERCERA EDAD}

¿Con cuántas asociaciones de mayores cuenta el municipio?

¿Con cuántos hogares / clubs de la tercera edad cuenta el municipio?

¿Existe Consejo de Mayores Municipal?

Sí

\section{OBSERVACIONES}

Puede utilizar este espacio para añadir cualquier información que considere oportuna: 


\section{PROYECTOS SOCIOEDUCATIVOS}

Cumplimente la información de los programas/proyectos/actividades socioeducativas dirigidas a personas mayores implementados desde su municipio. Es IMPORTANTE cumplimentar un formulario (una página) por cada programa/proyecto/actividad. Cumplimente solo las páginas que necesite. Si tiene más de 5 proyectos, señale la siguiente casilla:

\begin{tabular}{|l|c|c|}
\hline $\begin{array}{l}\text { El municipio tiene más de } 5 \text { proyectos } \\
\text { socioeducativos }\end{array}$ & Sí No \\
\hline
\end{tabular}

\section{Nombre del programa / proyecto / actividad:}

Año de inicio:

Nombre, apellidos y rol de la persona responsable:

Correo electrónico de la persona responsable:

Teléfono de la persona responsable: ..

Área / Concejalía de la que depende el proyecto:

Entidad o institución que lo ejecuta:

\section{Breve descripción de la actividad}

\section{Participantes}

Número máximo de plazas ofertadas:

\begin{tabular}{l|l|l|l} 
La mayor parte de quienes participan son: & Mujeres & Hombres & Mixto
\end{tabular}

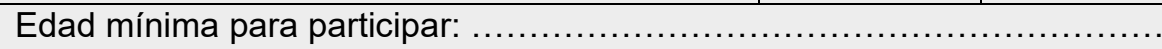

\begin{tabular}{|l|c|c|c|}
\hline Actividad accesible desde el punto de vista de la movilidad & Sí & No & No sabe
\end{tabular}

Coste de la actividad para las personas beneficiarias

(especificar si existe algún tipo de ayuda para la inscripción)

\begin{tabular}{|c|c|c|c|}
\hline \multicolumn{4}{|c|}{ Planificación temporal / espacios } \\
\hline Anual & Trimestral & \begin{tabular}{l|l} 
Mensual & \\
\end{tabular} & 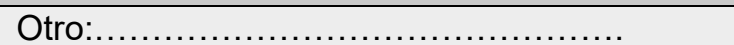 \\
\hline Horario: & Mañana & Tarde & 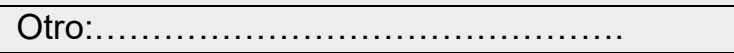 \\
\hline \multicolumn{4}{|c|}{ ¿Podría especificar la franja horaria? } \\
\hline \multirow{4}{*}{\multicolumn{2}{|c|}{$\begin{array}{l}\text { Lugar en que se realiza } \\
\text { la actividad (marcar la } \\
\text { que corresponda) }\end{array}$}} & \multicolumn{2}{|c|}{ Dependencias municipales } \\
\hline & & \multicolumn{2}{|c|}{ Locales de asociaciones de vecinos } \\
\hline & & \multicolumn{2}{|c|}{ Locales culturales } \\
\hline & & \multicolumn{2}{|c|}{ Al aire libre } \\
\hline
\end{tabular}




\begin{tabular}{|c|c|c|}
\hline & Otro: & \\
\hline \multirow{3}{*}{\multicolumn{2}{|c|}{$\begin{array}{l}\text { ¿Cómo se desplazan las personas } \\
\text { usuarias? } \\
\text { (se puede marcar más de una opción) }\end{array}$}} & Por cuenta propia \\
\hline & & Se ofrece servicio de transporte \\
\hline & & $\begin{array}{l}\text { Otro: } \\
\ldots \ldots \ldots \ldots \ldots \ldots \ldots \ldots \ldots \ldots \ldots \ldots \ldots \ldots \ldots \ldots \ldots \ldots \ldots \ldots\end{array}$ \\
\hline
\end{tabular}

